Predicting Metal-Support Interactions in Oxide-Supported Single-Atom Catalysts

by

\title{
Kaiyang Tan
}

B.S. Material Chemistry, University of Science and Technology of China, 2017

\author{
Submitted to the Graduate Faculty of \\ Swanson School of Engineering in partial fulfillment \\ of the requirements for the degree of \\ Master of Science
}

University of Pittsburgh

2019 


\section{UNIVERSITY OF PITTSBURGH}

\section{SWANSON SCHOOL OF ENGINEERING}

This thesis was presented

by

\section{Kaiyang Tan}

It was defended on

July 10, 2019

and approved by

Goetz Veser, Ph.D., Professor

Department of Chemical and Petroleum Engineering

J Karl Johnson, Ph.D., W.K. Whiteford Professor Department of Chemical and Petroleum Engineering

Thesis Advisor: Giannis Mpourmpakis, Assistant Professor

Department of Chemical and Petroleum Engineering 
Copyright (C) by Kaiyang Tan

2019 


\title{
Predicting Metal-Support Interactions in Oxide-Supported Single-Atom Catalysts
}

\author{
Kaiyang Tan, M.S.
}

University of Pittsburgh, 2019

Single-Atom Catalysts (SACs), containing under-coordinated single metal atoms bound on the surface of supports, have recently emerged as promising heterogeneous catalysts due to their intrinsic catalytic properties and efficient utilization (high dispersion) of noble metal atoms. Strong Metal-Support Interactions (MSIs) present in these catalysts can dictate the physicochemical properties, activity, and stability of SACs, which are significantly different from the conventional supported nanoscale metal catalysts. Although SACs exhibit unique catalytic behavior, their stability under catalytic operation is questioned due to the tendency of metals to sinter (aggregation). An optimal MSI can avoid metal aggregation and tune the stability and catalytic activity of SACs. Herein, we investigate MSIs of a series of transition metal atoms $(\mathrm{Au}, \mathrm{Cu}, \mathrm{Ag}$, $\mathrm{Pt}, \mathrm{Pd}, \mathrm{Ni}, \mathrm{Rh}$, and Ir) supported on low-index surface facets of three oxides $\left(\gamma-\mathrm{Al}_{2} \mathrm{O}_{3}, \mathrm{MgO}\right.$, and $\mathrm{MgAl}_{2} \mathrm{O}_{4}$ ) that are commonly used as supports in catalysis. By investigating the adsorption of the metals at different binding sites across the oxide surfaces, we identify the best descriptors of MSI to be the gas-phase metal-oxygen binding energy and the oxide support's band gap. Moreover, utilizing the results of Density-Functional Theory (DFT) calculations and genetic programming, we develop a predictive model for the strength of MSI (which we quantify as adsorption energy) using simple properties of the SAC and the support. Finally, we introduce some guidelines to hypothesize the synthetic accessibility of a series of SACs based on thermodynamic arguments. Our computational work can guide experimentation by identifying combinations of metals and oxides that can potentially lead to highly stable (and catalytically durable) SACs. 


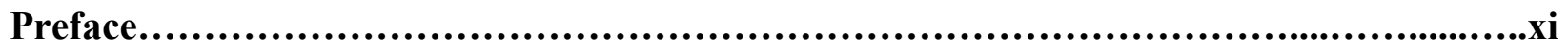

1.0 Introduction..........................................................................

1.1 Single Atom Catalyst............................................................

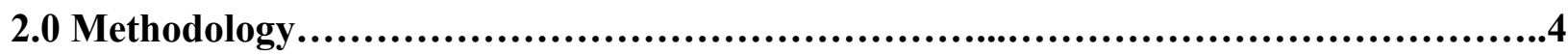

2.1 Density Functional Theory ..................................................5

2.2 Genetic Programming..........................................................

3.0 Results and Discussion............................................................9

3.1 The Selection of Metals, Supports, Surface Facets, and Sites......................10

3.2 Preferred Adsorption Sites of Metals on Supports............................13

3.3 Adsorption Trend of Metals on Supports......................................22

3.4 Descriptors of Metal Adsorption Energy $. . . \ldots \ldots \ldots \ldots \ldots \ldots \ldots \ldots \ldots \ldots \ldots \ldots \ldots \ldots \ldots \ldots . . . .24$

3.5 Predictive Model of Metals Adsorption Energy $. . \ldots \ldots \ldots \ldots \ldots \ldots \ldots \ldots \ldots \ldots \ldots \ldots \ldots . . . .27$

3.6 Hypothesize the Synthetic Accessibility of Single-Atom Catalysts.................31

4.0 Conclusions..............................................................................34

Appendix A.......................................................................................35

Appendix B...................................................................................50

Appendix C...................................................................................57

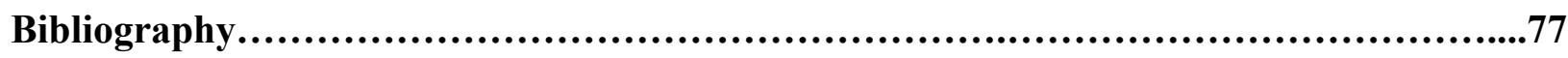




\section{List of Tables}

Table S1 Cell configurations, layers, and lattice constants used in optimizing the surface facets...57

Table S2 Valence electron configurations of supported metals.............................57

Table S3a Physical properties of supported metal from literature...........................58

Table S3b Physical properties of supported metal from literature (continued)..................59

Table S3c The metal-oxygen binding energy of supported metal calculated by CP2K program

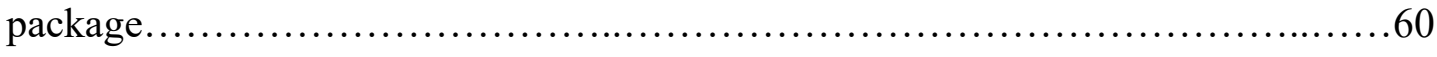

Table S3d Physical properties of supported metal calculated by CP2K program package.........61

Table S3e Ionization potential of oxide support calculated by CP2K program package..........62

Table S3f Physical properties of oxide support calculated by CP2K program package...........63

Table S4 The information of most preferred sites of supported metals on different surface facets

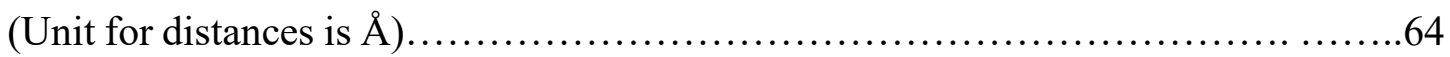

Table S5 The standard of counting supported metal coordination numbers....................68

Table S6 Bootstrapping results for model construction................................. 70 


\section{List of Figures}

Figure 1 Structures of (a) $\gamma-\mathrm{Al}_{2} \mathrm{O}_{3}$ bulk, (b) $\gamma-\mathrm{Al}_{2} \mathrm{O}_{3}$ (100) surface plane, (c) $\mathrm{MgO}$ bulk, (d) $\mathrm{MgO}$ (100) surface plane, (e) $\mathrm{MgAl}_{2} \mathrm{O}_{4}$ bulk, and (f) $\mathrm{MgAl}_{2} \mathrm{O}_{4}$ (100) surface plane. The surface cleaving plane is highlighted in blue. Orange atoms represent $\mathrm{Mg}$, grey atoms represent

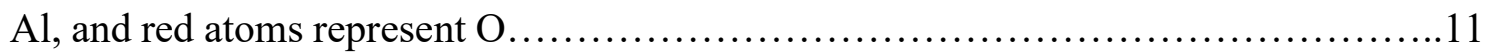

Figure 2 Chosen sites on the lowest energy termination of (a) $\gamma-\mathrm{Al}_{2} \mathrm{O}_{3}(100)$, (b) $\gamma-\mathrm{Al}_{2} \mathrm{O}_{3}(110)$, (c) $\gamma-\mathrm{Al}_{2} \mathrm{O}_{3}$ (111), (d) $\mathrm{MgO}$ (100), (e) $\mathrm{MgO}$ (110), (f) $\mathrm{MgAl}_{2} \mathrm{O}_{4}$ (100), and (g) $\mathrm{MgAl}_{2} \mathrm{O}_{4}$ (110). Sites are indicated with capital letters. Only top layers are shown by ball-and-stick, the atoms in the subsurface are shown by a wireframe. Green atoms represent $\mathrm{Mg}$, pink

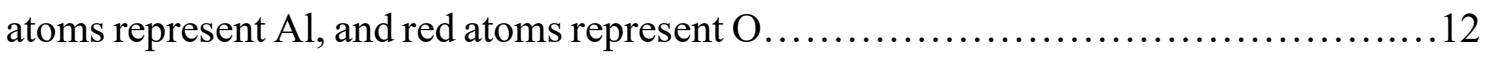

Figure $3 \mathrm{Pd}$ adsorption on $\gamma-\mathrm{Al}_{2} \mathrm{O}_{3}$ (100) in (a) top, (b) side view and $\mathrm{Cu}$ adsorption on $\gamma-\mathrm{Al}_{2} \mathrm{O}_{3}$ (100) in (c) top view. The copper atom represents $\mathrm{Cu}$, blue atoms represent $\mathrm{Pt}$, pink atoms

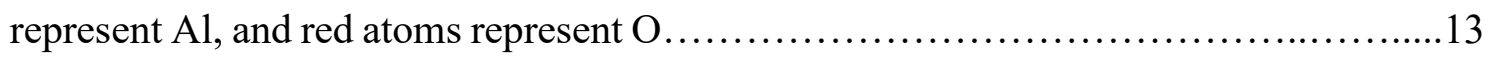

Figure $4 \mathrm{Au}$ adsorption on $\gamma-\mathrm{Al}_{2} \mathrm{O}_{3}$ (110) (a) top view, (b) side view; Pt adsorption on $\gamma-\mathrm{Al}_{2} \mathrm{O}_{3}$ (110) (c) top view, (d) side view. Surface restructuring is observed by comparing side views of the $\gamma-\mathrm{Al}_{2} \mathrm{O}_{3}$ (110) support surface when interacting with (e) $\mathrm{Au}$ and (f) Pt. Yellow atoms represent $\mathrm{Au}$, blue atoms represent $\mathrm{Pt}$, pink atoms represent $\mathrm{Al}$, and red

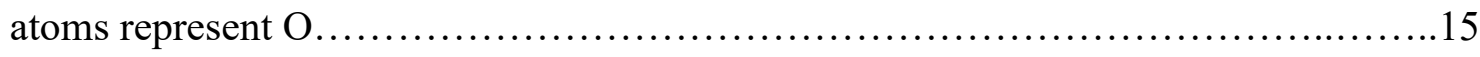

Figure $5 \mathrm{Ag}$ adsorption on $\gamma-\mathrm{Al}_{2} \mathrm{O}_{3}$ (111) in (a) top view, (b) side view; Pt adsorption on $\gamma-\mathrm{Al}_{2} \mathrm{O}_{3}$ (111) in (c) top view, (d) side view. Grey atoms represent $\mathrm{Ag}$, blue atoms represent $\mathrm{Pt}$,

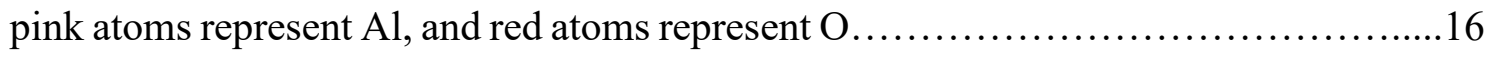


Figure $6 \mathrm{Cu}$ adsorption on $\mathrm{MgO}$ (100) from (a) top view, (b) side view; $\mathrm{Rh}$ adsorption on $\mathrm{MgO}$ (100) from the respective (c) top view, (d) side view. Copper atoms represent $\mathrm{Cu}$, blue atoms represent $\mathrm{Rh}$, green atoms represent $\mathrm{Mg}$, and red atoms represent $\mathrm{O} \ldots \ldots \ldots \ldots \ldots .17$

Figure $7 \mathrm{Rh}$ adsorption on $\mathrm{MgO}$ (110) in (a) top view, (b) side view; Pt adsorption on $\mathrm{MgO}$ (110) in (c) top view, (d) side view. Light blue atoms represent $\mathrm{Rh}$, dark atoms represent $\mathrm{Pt}$,

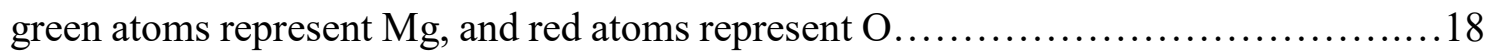

Figure $8 \mathrm{Pt}$ adsorption on $\mathrm{MgAl}_{2} \mathrm{O}_{4}$ (100) (a) top view, (b) side view; $\mathrm{Rh}$ adsorption on $\mathrm{MgAl}_{2} \mathrm{O}_{4}$ (100) (c) top view, (d) side view. Dark blue atoms represent Pt, light blue atoms represent $\mathrm{Rh}$, green atoms represent $\mathrm{Mg}$, pink atoms represent $\mathrm{Al}$, and red atoms represent $\mathrm{O}$......19

Figure $9 \mathrm{Ag}$ adsorption on $\mathrm{MgAl}_{2} \mathrm{O}_{4}$ (110) in (a) top view, (b) side view; Ir adsorption on $\mathrm{MgAl}_{2} \mathrm{O}_{4}$ (110) in (c) top view, (d) side view. Grey atoms represent Ag, blue atoms represent Ir, green atoms represent $\mathrm{Mg}$, pink atoms represent $\mathrm{Al}$, and red atoms represent $\mathrm{O} . \ldots \ldots \ldots .20$

Figure 10 (a) Initial placement of $\mathrm{Ni}$ on $\mathrm{MgO}$ (100), (b) Ni adsorption on $\mathrm{MgO}$ (100) after optimization. Light blue atoms represent $\mathrm{Ni}$, green atoms represent $\mathrm{Mg}$, and red atoms

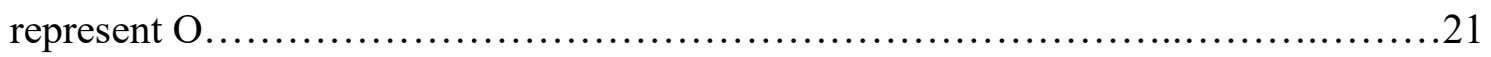

Figure 11 The DFT-calculated metal adsorption energy for most preferred sites of different transition metals adsorbed on different supports; the structures of Pt adsorption are attached for an insight in the structures. Blue atoms represent Pt, green atoms represent

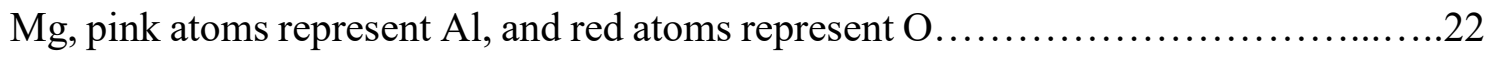

Figure 12 Relationships between DFT-calculated metal adsorption energy on each surface facet and metal-oxygen binding energy of the supported SAC .24

Figure 13 Relationship between DFT metal adsorption energy and band gap of the oxide

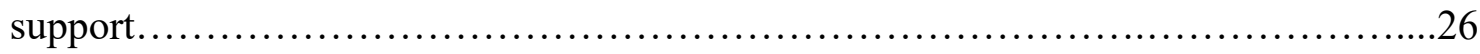


Figure 14 DFT adsorption energy versus predictive adsorption energy calculated by Equation 3-

Figure 15 DFT adsorption energy vs hypothetical cohesive energy of supported metal on (a) $\gamma$ -

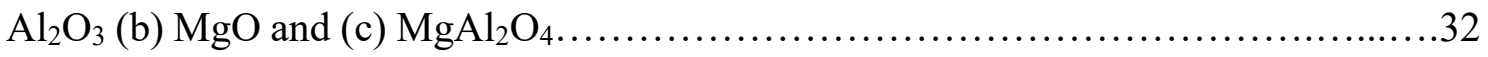

Figure S1 An equation generated randomly by symbolic regression......................50

Figure S2 Structures of surface facets which are not the most stable ones: (a) $\gamma-\mathrm{Al}_{2} \mathrm{O}_{3}(110)$, (b) $\gamma-\mathrm{Al}_{2} \mathrm{O}_{3}$ (111), (c) $\mathrm{MgO}$ (110), and (d) $\mathrm{MgAl}_{2} \mathrm{O}_{4}$ (110). The surface cleaving plane is highlighted in green and brown. Orange atoms represent $\mathrm{Mg}$, grey atoms represent $\mathrm{Al}$,

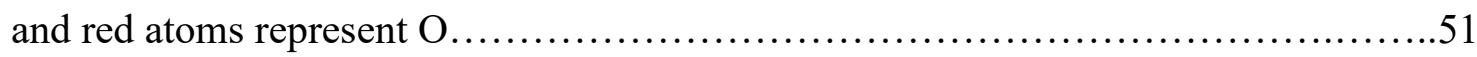

Figure $\mathrm{S} 3 \mathrm{Ag}$ adsorption on $\gamma-\mathrm{Al}_{2} \mathrm{O}_{3}(110)$ in (a) top view, (b) side view; Pd adsorption on $\gamma-\mathrm{Al}_{2} \mathrm{O}_{3}$ (110) in (a) top view, (b) side view. Grey atoms represent Ag, blue atoms represent $\mathrm{Pd}$,

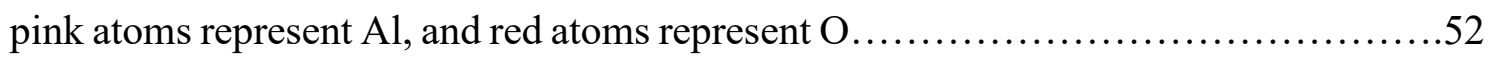

Figure S4 $\mathrm{Au}$ adsorption on $\mathrm{MgAl}_{2} \mathrm{O}_{4}$ (100) in (a) top view, (b) side view; $\mathrm{Cu}$ adsorption on $\mathrm{MgAl}_{2} \mathrm{O}_{4}$ (100) in (c) top view, (d) side view. Yellow atoms represent $\mathrm{Au}$, copper atoms represent $\mathrm{Cu}$, green atoms represent $\mathrm{Mg}$, pink atoms represent $\mathrm{Al}$, and red atoms represent

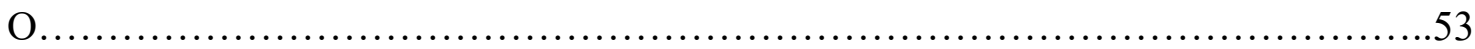

Figure S5 RMSE versus complexity of equations generated in Eureqa by training data of (a) dataset

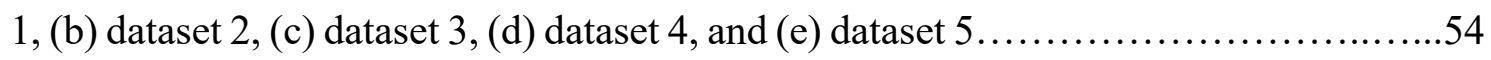

Figure S6 Pareto Front plotted by using the lowest RMSE error in each dataset for a particular complexity .55

Figure S7 Correlation Matrix of physical properties indicated by Eureqa. Along the diagonal are histograms of the selected descriptors. Correlation coefficients between the different descriptors are plotted in the upper right triangle, with a font chosen to convey their 
magnitude (e.g. the best correlations are the largest, near-zero correlations are written with a tiny font). Plots of the two descriptors versus one another are in the lower left triangle. As an example, the correlation coefficient between MOB and MOE is -0.94 , and their plot can be found on the leftmost column, three squares up from the

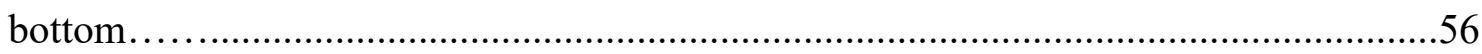




\section{Preface}

First, I would like to thank my thesis advisor, Dr. Giannis Mpourmpakis. His strict and warm-hearted guidance educated me a lot. In the past two years I enjoyed a busy but beneficial life in his lab, where I learnt new tools and methods every day. Second, I would like to thank Dr. Mudit. He helped me a lot in literature search and paper writing. I am also grateful to the students in the lab. They are all experienced researchers and never refused to help me when I was confused. I also want to thank the University of Pittsburgh and the Department of Chemical Engineering for providing me valuable research opportunities. Last but not least, I would like to thank my parents because of their physical and mental support. I hope my research in this thesis can help other scientists in the future. 


\subsection{Introduction}

Single-Atom Catalysts (SACs) are a new frontier to increase the utilization of metal atoms in catalysis: the catalytic metal is dispersed on the support atomically, making all metal atoms accessible for catalysis ${ }^{1-6}$. Due to the under-coordination of the metal, quantum size effects, and strong Metal-Support Interactions $(\mathrm{MSIs})^{3-4}$, SACs also exhibit high catalytic activity and selectivity in a wide range of chemical transformations $\mathrm{s}^{3,5}$.

Because of the strong cohesive energy and high surface energy of single metal atoms, the active metals of SACs have the thermodynamic tendency to sinter, which raises obvious problems regarding the stability of SACs under realistic catalytic conditions ${ }^{7-9}$. Sintering of SACs reduces

their catalytic activity ${ }^{10-12}$ by reducing the surface area and increasing the average coordination of the metal atoms ${ }^{13}$. Strong MSIs can mitigate sintering by anchoring metals to the support, stabilizing the SACs and preserving their high surface area. For instance, in the case of $\mathrm{Pt}_{1} / \mathrm{FeO}_{\mathrm{x}}$, despite the high surface free energies of single Pt atoms, the Pt atoms are stabilized on the support via the formation of Pt-O-Fe metal-support bonds ${ }^{14}$. It has also been shown that the MSIs can dictate the performance of SACs, making it feasible to tune their catalytic activity, selectivity, and stability during catalytic operation ${ }^{15-17}$.

Recent years a number of research efforts have focused on characterizing MSIs through both experiment (such as utilizing aberration-corrected environmental TEM chambers to dynamically study MSIs ${ }^{18}$ ) and computation (using Density-Functional Theory (DFT) and statistical learning to generate predictive $\operatorname{model} \mathrm{s}^{19}$ ). Despite this attention, a fundamental understanding of the primary interactions in SACs is still lacking. To understand MSIs, one needs to identify simple 
descriptors for the strength of MSI (quantified in this work as the metal adsorption energy of SACs), ideally based on fundamental physical properties of the supported metals and the supports. Several outstanding works have demonstrated linear relationships between metal adsorption energy and metal-support pair properties (for SACs or other supported metal nanoparticles) such as surface energy of the metal, metal oxidation enthalpy ${ }^{20}$, heat of metal oxide formation ${ }^{21}$, and support reducibility ${ }^{22}$. These findings suggest that MSIs are influenced by the properties of both the metal and the support. Recently, O'Connor et a ${ }^{19}$ applied statistical leaning methods to build predictive models of MISs by including various metal-support properties and investigated a large set of descriptors and predictive models for adsorption energy.

\subsection{Single Atom Catalyst}

Catalysts play an important role in various chemical and biological transformations through controlling the rates of both desired and undesired reactions ${ }^{1,23-24}$. Among different homogeneous and heterogeneous catalysts, due to their ability to change oxidation states and form complexes, Transition Metal Nanoparticles (TMNPs) play a dominant role in catalysis ${ }^{2-3}, 25$. Since catalysis occurs at the surface of TMNP-based catalysts, only the surface metal atoms can be utilized as active catalytic sites. As a result, the subsurface atoms of TMNPs are essentially wasted and introduce an extra economic cost to industrial processes ${ }^{1-2}$. In order to maximize the ratio of exposed metal atoms, an obvious solution is to make the TMNP as small as possible. Efforts to reduce TMNP size have led to the development of SACs.

Recently, a series of noble metal SACs were synthesized and characterized on a variety of supports $^{26-35}$. For instance, $\mathrm{Pd}_{1} / \mathrm{MgO}(100)$ synthesized by high frequency laser evaporation shows 
a unique size effect: the Pd cluster size governs the reacting temperature and mechanism of the catalyzed cyclotrimerization of acetylene to benzene ${ }^{36}$. $\mathrm{Pt}_{1} /$ Graphene has been successfully synthesized by atomic layer deposition and exhibits a high activity for methanol oxidation with superior tolerance for $\mathrm{CO}$. This catalyst has excellent performance due to low-coordination and the presence of unsaturated $5 \mathrm{~d}$ orbitals of the single $\mathrm{Pt}$ atom $^{37} . \mathrm{Rh} / \mathrm{ZnO}$ nanowires have been fabricated via the facile adsorption method. When catalyzing the hydroformylation of olefins, these nanowires exhibit levels of activity orders of magnitude higher than typical heterogeneous catalysts $^{38}$. A well-known SAC is $\operatorname{Ir}_{1} / \mathrm{FeO}_{x}$, whose water-gas shift activity is an order of magnitude higher than its TMNP ${ }^{14}$. Overall, SACs show great promise in catalyzing a variety of reactions ${ }^{14}$, ${ }^{27,36}$, even though this new frontier in catalysis has yet to be commercially-exploited ${ }^{1}$. 


\subsection{Methodology}

DFT calculations were performed by using the $\mathrm{CP} 2 \mathrm{~K}^{46}$ package. The Perdew-Burke-Ernzerhof (PBE) exchange-correlation functional ${ }^{47}$ was used in combination with Grimme's D3 dispersion-

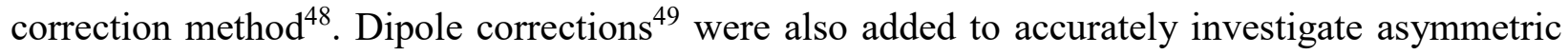
slab systems. TZVP basis sets ${ }^{50}$ were used for O; DZVP basis sets ${ }^{50}$ were used for $\mathrm{Al}, \mathrm{Mg}, \mathrm{Au}$, $\mathrm{Cu}, \mathrm{Ag}, \mathrm{Pt}, \mathrm{Pd}, \mathrm{Ni}, \mathrm{Rh}$, and Ir. Additionally, we use the pseudopotentials of Goedecker, Teter, and Hutter $^{51-53}$ with a kinetic energy cutoff $400 \mathrm{Ry}$. We use a $1 \times 1 \times 1$ "supercell" for $\gamma-\mathrm{Al}_{2} \mathrm{O}_{3}$ and $\mathrm{MgAl}_{2} \mathrm{O}_{4}$ due to their already-large unit cell. We use a $2 \times 2 \times 2$ supercell for the bulk optimization of $\mathrm{MgO}$. Following optimization of the bulk, we cleave the supercells to construct slabs. We use a $2 \times 1 \mathrm{slab}$ with 2 layers of repeating supercell for $\gamma-\mathrm{Al}_{2} \mathrm{O}_{3}$, a $1 \times 1$ slab with 1 layer of repeating supercell for $\mathrm{MgO}$, and a $2 \times 1$ slab with 1 layer of repeating supercell for $\mathrm{MgAl}_{2} \mathrm{O}_{4}$. The two bottom atomic layers remaining fixed in their cell positions. Systems were relaxed with a forceconvergence criterion of $0.0004 \mathrm{E}_{\mathrm{h}} / \mathrm{bohr}$, and an SCF convergence criterion of $10^{-8} \mathrm{au}$. Metal adsorption energy is calculated by Equation 2-1, where $E_{\text {ads }}$ is the metal atom adsorption energy, $\mathrm{E}_{\mathrm{M} \text {-support }}$ is the total energy of the metal-support system, $\mathrm{E}_{\text {support }}$ is the energy of the support, and $\mathrm{E}_{\mathrm{M}}$ is the gas phase energy of the single metal atom.

$$
E_{\text {ads }}=E_{M-s u p p o r t}-E_{\text {support }}-E_{M}
$$


The metal-oxygen binding energy of supported metal is calculated by $\mathrm{CP} 2 \mathrm{~K}$ program package $^{46}$ and all metals are considered as +2 oxidation state ${ }^{54}$. To calculate the metal-oxygen binding energy ( $\left.\mathrm{E}_{\mathrm{M}-\mathrm{O}}\right)$ accurately (listed in Table S3c), we calculate the energy of a gas phase metal binding with a single oxygen atom $\left(\mathrm{E}_{\mathrm{M}+\mathrm{O}}\right)$. We investigate several different spin-states (listed in Table S3c) and choose the spin-state minimizing the energy of the metal-oxygen complex in order to investigate the energies accurately. $E_{O}$ is gas phase energy of an oxygen atom. The metaloxygen binding energy is calculated by Equation 2-2.

$$
\mathrm{E}_{\mathrm{M}-\mathrm{O}}=\mathrm{E}_{\mathrm{M}+\mathrm{O}}-\mathrm{E}_{\mathrm{M}}-\mathrm{E}_{\mathrm{O}}
$$

All gas phase energies of atoms are calculated in a $10 * 10 * 10 \AA^{3}$ cube.

\subsection{Density Functional Theory}

To study the atomistic interactions of the many-body electronic structure by ab initio methods, we need to solve the Schrodinger's equation ${ }^{39}$. However, this is very expensive in computation since the wavefunction of many-body systems depends on the number of electrons of every individual particles. Density Functional Theory (DFT) is an approach to calculate the ground state properties of a many-electron system ${ }^{40}$ in condensed matter physics and chemistry ${ }^{41}$ using the functional of electron density. This approach provides a balance between the system size and computational cost during the calculation of electronic structure. Yet according to Hohenberg- 
Kohn $(\mathrm{H}-\mathrm{K})$ theorem ${ }^{42}$, the energies of interacting electrons remain unknown, which produces limitations to original DFT calculations. In Kohn-Sham (KS) DFT ${ }^{43}$, the energies of interacting electrons are regarded as electrons moving into a static external potential by fictitious orbitals without interacting with other particles. The sum of densities of occupied orbitals represents the overall ground-state density of the system.

$$
(r)=\sum\left|\varphi_{i}(r)\right|^{2}
$$

In equation $1-1, \varphi_{i}(r)$ is Kohn-Sham (K-S) orbital. The ground-state energy $(E[\rho])$ in DFT is

$$
E[\rho]=T_{s}[\rho]+\int \operatorname{Vext}_{\operatorname{ext}}(r) \rho(r) d r+E_{H}[\rho]+E_{X C}[\rho]
$$

In equation 1-2, $T_{s}[\rho]$ is the K-S kinetic energy represents the sum of the kinetic energies of noninteracting electrons, $\mathrm{V}_{\text {ext }}$ is the external potential representing the interaction between an electron and the nuclei, $E_{H}$ is the potential representing the interaction between an electron with electron density determined by other electrons, and $E_{X C}$ represents the exchange-correlation energy. In 
short, $E_{X C}$ is comprised of the energy released when electrons with same spin exchange their positions and the energy gained when an atom moving under the influence of other electrons.

$E_{X C}$ is the only part in K-S equation that requires effective approximations due to being mathematically undefined. The first approximation used in K-S DFT calculation is Local-Density Approximation (LDA) assuming the exchange correlation energy is same regardless of the position in the system. Generalized Gradient Approximation (GGA) is an approximation which considers both local electron density and its gradient ${ }^{44}$, and that makes GGA more reliable than LDA. Perdew-Burke-Ernzerhof(PBE) functional is a commonly used GGA functional which we used in this research, which can calculate the properties of metal compounds accurately ${ }^{45}$. We implement the K-S DFT calculations by using the CP2K package that performs atomistic simulation of solid state, liquid, molecular, and biological systems.

\subsection{Genetic Programming}

Fundamentally, symbolic regression is the creation of equations by combining functions, operators, and variables. For convenience in generating and modifying equations algorithmically, they are typically represented as trees (see Figure S1 for an example of a function represented as a tree). Unfortunately, because it is not restricted to linear combinations of descriptors (which would be linear regression), symbolic regression poses an NP (as in Non-Polynomial time) - hard optimization problem ${ }^{55}$. Oftentimes, a genetic algorithm is used as the optimization algorithm in the case of symbolic regression. This combination of symbolic regression and genetic algorithm is actually a type of genetic programming ${ }^{56}$. In genetic programming, a population of programs (in

our case, a tree representation of a function) are randomly generated, and evaluated with a training 
set to measure its fitness. Programs will be selected for future generation base on their fitness. When the next generation is reached, the programs are either kept the same or modified using methods such as reproduction, crossover, or mutation to form a new population. Over time, the programs tend stochastically toward the best fitness ${ }^{57}$.

In this study we use the implementation of genetic programming given by Eureqa ${ }^{58}$. In addition to its genetic programming capabilities, Eureqa tries to assess the complexity of each model generated, by supplying a complexity value to each operator (for example, the natural logarithm may receive a value of 3 , whereas the addition operator may receive a value of 1 ) and reporting the sum total of an equation's complexity values. For example, $\ln (x)$ would have a lower complexity score than $\ln \left(x^{2}\right)$, due to the presence of an additional operation (taking the square of $x$ ) in the latter. At each complexity level, it reports the best-fitting equation it has found. 


\subsection{Results and Discussion}

In this part, we first select the suitable metals, supports, surface facets, and sites to investigate the MSIs of metals on supports. We choose them to screen the physical properties of metal-support pairs and understand the origins of SAC stabilization. After adding single metal atoms on the sites of support facets we select, we calculate the corresponding adsorption energies of metals on supports by DFT calculations, and observe the final structures after optimization.

Next we plot the adsorption trend of metals on supports to retrieve the relationship between adsorption energy and the metal-support pairs. We determine two descriptors of adsorption energy, which are metal-oxygen binding energy in gas phase and band gap of the oxide support. Then we

utilize the DFT calculation results as training set for genetic programming. We develop a predictive model that can predict the adsorption energy of metals on supports.

Finally, we apply the Square-Root Bond (SRB) cutting model ${ }^{59-60}$ to introduce a hypothetical cohesive energy of metal nanoparticles. We plot the hypothetical cohesive energy versus the DFT calculated metal adsorption energy. Based on this plot, we introduce a guiding principle to hypothesize the synthetic accessibility of SACs based on the balance between metal adsorption on support and cohesion of metal nanoparticles. 


\subsection{The Selection of Metals, Supports, Surface Facets, and Sites}

In this work, we studied the MSIs of single metal atoms spanning different columns and rows in the periodic table $\left(\mathrm{Au}, \mathrm{Cu}, \mathrm{Ag}, \mathrm{Pt}, \mathrm{Pd}, \mathrm{Ni}, \mathrm{Rh}\right.$, Ir) on $\gamma-\mathrm{Al}_{2} \mathrm{O}_{3}, \mathrm{MgO}$, and $\mathrm{MgAl}_{2} \mathrm{O}_{4}$, which are both thermally stable and commonly used as supports in catalysis ${ }^{61-63}$. In these oxides, the surface Lewis acid-base properties for under-coordinated site pairs enable charge transfer when metal atoms adsorb on the surface ${ }^{64-67}$. Because of their ubiquity as supports, a series of SACs have already been synthesized on them, including $\mathrm{Pt}_{1} / \gamma-\mathrm{Al}_{2} \mathrm{O}_{3}{ }^{68}, \mathrm{Rh}_{1} / \gamma-\mathrm{Al}_{2} \mathrm{O}_{3}{ }^{25,}{ }^{69}, \mathrm{Au}_{1} / \mathrm{MgO}^{70}$, $\mathrm{Pd}_{1} / \mathrm{MgO}^{36}$, and $\mathrm{Ir}_{1} / \mathrm{MgAl}_{2} \mathrm{O}_{4}{ }^{71}$.

Different surface facets of metal oxides exhibit different surface coordination, so we investigate some low-index surface facets: $\gamma-\mathrm{Al}_{2} \mathrm{O}_{3}(100), \gamma-\mathrm{Al}_{2} \mathrm{O}_{3}(110), \gamma-\mathrm{Al}_{2} \mathrm{O}_{3}(111), \mathrm{MgO}$ (100), $\mathrm{MgO}$ (110), $\mathrm{MgAl}_{2} \mathrm{O}_{4}(100)$, and $\mathrm{MgAl}_{2} \mathrm{O}_{4}$ (110). Depending on the offset of the termination plane from the origin of the unit cell, each crystallographic facet can be terminated with different atoms. Therefore, we screen multiple surface terminations for each facet and report the most thermodynamically-stable surfaces since they likely represent a significant portion of the exposed surface area. The $\mathrm{MgO}$ (111) and $\mathrm{MgAl}_{2} \mathrm{O}_{4}$ (111) surfaces exhibit high net dipole due to their asymmetric nature, which results in high energy regardless of termination. In addition, they undergo severe restructuring (indicative of unstable surfaces), so we do not include them in this study. The optimized bulk structures and the most stable facets of the rest of the considered oxide supports are shown in Figure 1. The other facets are shown in Figure S2. 

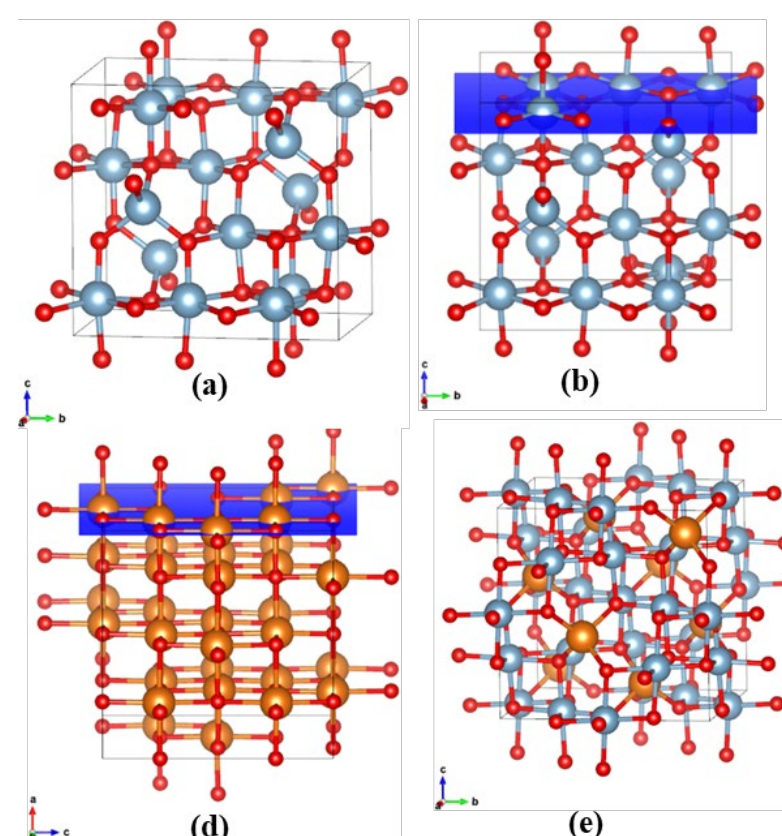

(d) (b)

$\stackrel{i}{\rightarrow 0}$

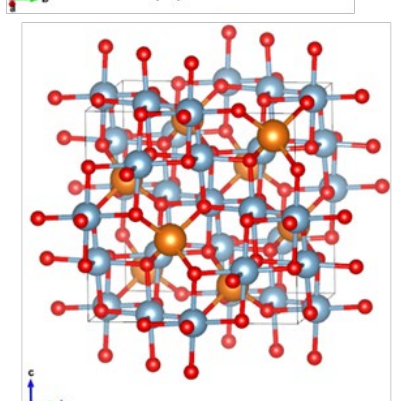

(e)

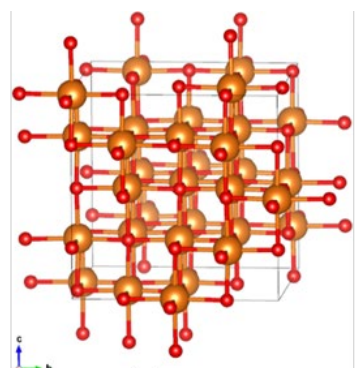

(c)

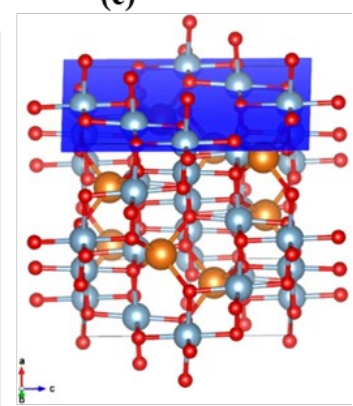

(f)

Figure 1 Structures of (a) $\gamma-\mathrm{Al}_{2} \mathrm{O}_{3}$ bulk, (b) $\gamma-\mathrm{Al}_{2} \mathrm{O}_{3}$ (100) surface plane, (c) $\mathrm{MgO}$ bulk, (d) $\mathrm{MgO}$ (100) surface plane, (e) $\mathrm{MgAl}_{2} \mathrm{O}_{4}$ bulk, and (f) $\mathrm{MgAl}_{2} \mathrm{O}_{4}$ (100) surface plane. The surface cleaving plane is highlighted in blue. Orange atoms represent $\mathrm{Mg}$, grey atoms represent $\mathrm{Al}$, and red atoms represent $\mathrm{O}$.

Following optimization of the different surfaces, we placed single metal atoms on different sites. Depending on the surface heterogeneity of the oxide surface, several metal adsorption sites may be possible. The initial guess for the metal adsorption site is selected to maximize the interaction of metal atom with neighboring surface oxygen atoms, because many of the metal atoms we select are oxophilic in nature. We investigate 4 adsorption sites each on $\gamma$ $\mathrm{Al}_{2} \mathrm{O}_{3}(100)$ and (111) (Figure 2a, 2c), 5 sites on $\gamma-\mathrm{Al}_{2} \mathrm{O}_{3}$ (110) (Figure 2b), 1 site each on $\mathrm{MgO}$ (100) and (110) (Figure 2d, 2e), 3 sites on $\mathrm{MgAl}_{2} \mathrm{O}_{4}$ (100) (Figure 2f), and 2 sites on $\mathrm{MgAl}_{2} \mathrm{O}_{4}$ (110) (Figure 2g). Overall, this allows us to include a large variety of adsorption sites in our dataset. 


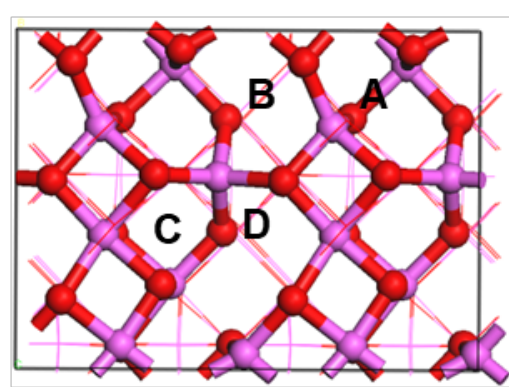

(a)

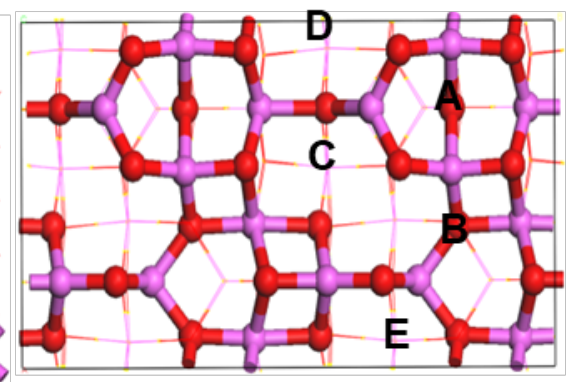

(b)

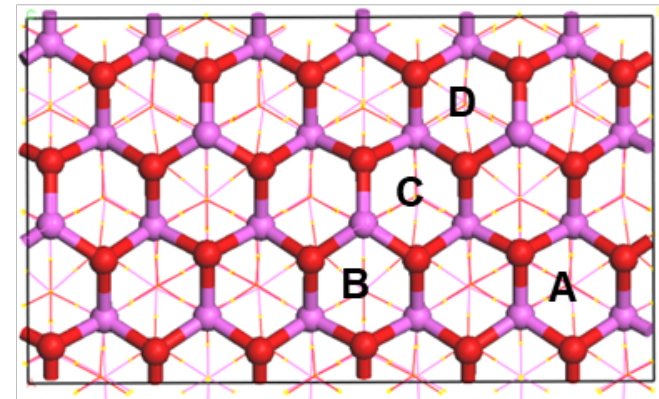

(c)

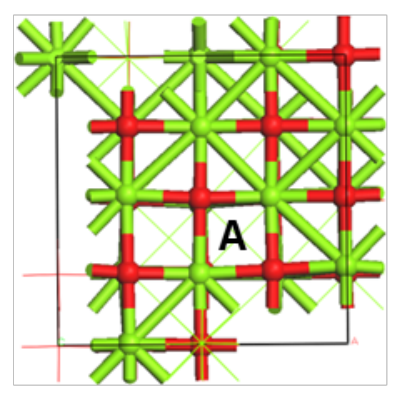

(d)

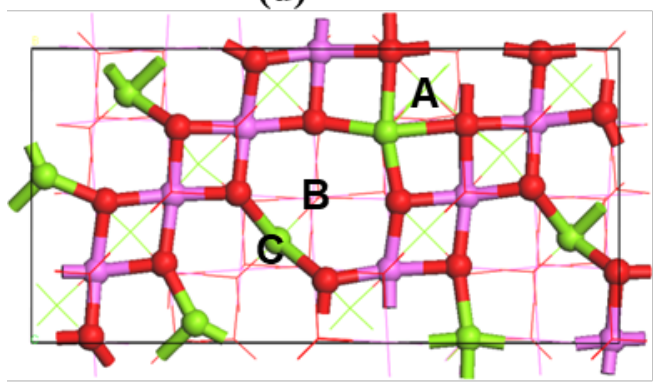

(f)

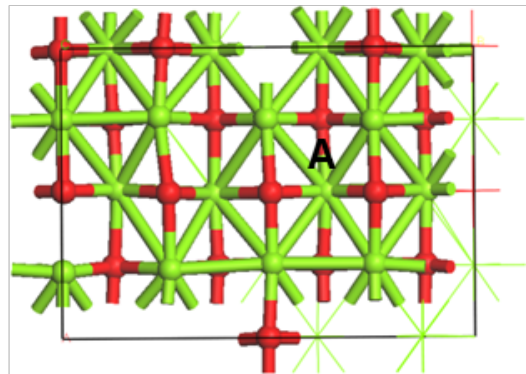

(e)

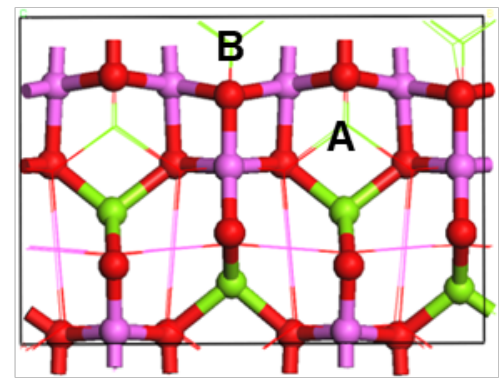

(g)

Figure 2 Chosen sites on the lowest energy termination of (a) $\gamma-\mathrm{Al}_{2} \mathrm{O}_{3}(100)$, (b) $\gamma-\mathrm{Al}_{2} \mathrm{O}_{3}$ (110), (c) $\gamma-\mathrm{Al}_{2} \mathrm{O}_{3}(111)$, (d) $\mathrm{MgO}$ (100), (e) $\mathrm{MgO}$ (110), (f) $\mathrm{MgAl}_{2} \mathrm{O}_{4}$ (100), and (g) $\mathrm{MgAl}_{2} \mathrm{O}_{4}$ (110). Sites are indicated with capital letters. Only top layers are shown by ball-and-stick, the atoms in the subsurface are shown by a wireframe. Green atoms represent $\mathrm{Mg}$, pink atoms represent $\mathrm{Al}$, and red atoms represent $\mathrm{O}$. 


\subsection{Preferred Adsorption Sites of Metals on Supports}

On $\gamma-\mathrm{Al}_{2} \mathrm{O}_{3}(100)$, the preferred adsorption configuration for all metal atoms except $\mathrm{Cu}$ is a hollow site between two oxygens (Figure 3a, 3b), while $\mathrm{Cu}$ is in a hollow site between two different oxygens (Figure 3c). The metal atoms coordinate with both $\mathrm{Al}$ and $\mathrm{O}$ atoms. The DFT-calculated adsorption energies are as follows: $\operatorname{Pt}\left(E_{a d s}=-4.62 \mathrm{eV}\right)<\operatorname{Ir}\left(E_{a d s}=-4.56 \mathrm{eV}\right)<\operatorname{Rh}\left(E_{a d s}=-3.57\right.$ $\mathrm{eV})<\mathrm{Ni}\left(\mathrm{E}_{\mathrm{ads}}=-3.55 \mathrm{eV}\right)<\mathrm{Pd}\left(\mathrm{E}_{\mathrm{ads}}=-2.59 \mathrm{eV}\right)<\mathrm{Cu}\left(\mathrm{E}_{\mathrm{ads}}=-1.64 \mathrm{eV}\right)<\mathrm{Au}\left(\mathrm{E}_{\mathrm{ads}}=-0.97 \mathrm{eV}\right)<$ $\mathrm{Ag}\left(\mathrm{E}_{\mathrm{ads}}=-0.79 \mathrm{eV}\right)$. By convention, more negative adsorption energies are stronger. Additional details regarding the geometry of the binding sites can be found in Table S4.

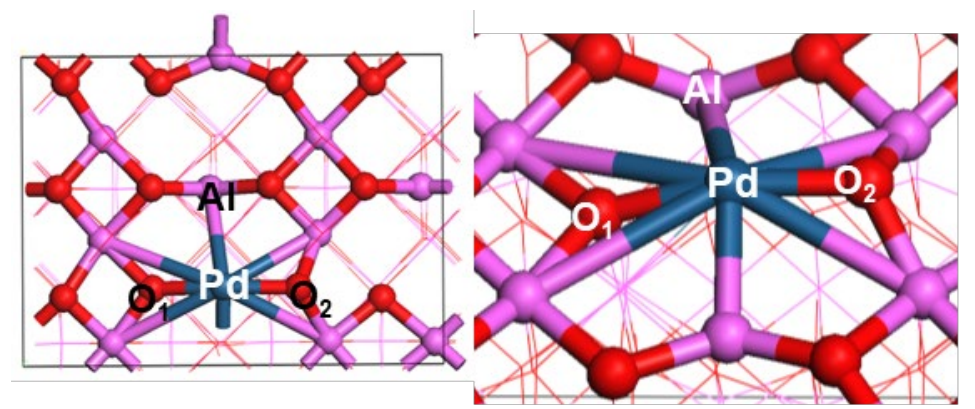

(a)

(b)

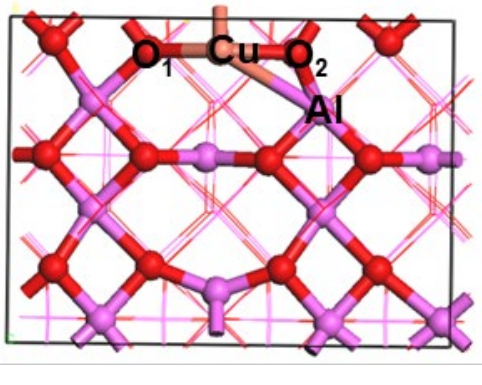

(c)

Figure $3 \mathrm{Pd}$ adsorption on $\gamma-\mathrm{Al}_{2} \mathrm{O}_{3}(100)$ in (a) top, (b) side view and $\mathrm{Cu}$ adsorption on $\gamma$ - $\mathrm{Al}_{2} \mathrm{O}_{3}(100)$ in (c) top view. The copper atom represents $\mathrm{Cu}$, blue atoms represent $\mathrm{Pt}$, pink atoms represent $\mathrm{Al}$, and red atoms represent $O$.

On $\gamma-\mathrm{Al}_{2} \mathrm{O}_{3}(110)$ the strongest adsorption site for $\mathrm{Au}$ is a hollow site between $\mathrm{Al}$ and $\mathrm{O}$ atoms (Figure 4a, 4b), Cu binds in the same configuration. Ag prefers adsorption in a hollow site between a different pair of $\mathrm{Al}$ and $\mathrm{O}$ atoms (Figure S3a, S3b). Pd adsorbs to a hollow site which 
is close to the adsorption site of $\mathrm{Au}$ and $\mathrm{Cu}$ (Figure S3c, S3d). Pt prefers a different hollow site (Figure 4c, 4d), while Ni, Rh, and Ir bind in an identical configuration. The DFT-calculated metal adsorption energies follow $\operatorname{Ir}\left(E_{\text {ads }}=-3.87 \mathrm{eV}\right)<\operatorname{Pt}\left(E_{\text {ads }}=-3.71 \mathrm{eV}\right)<\mathrm{Ni}\left(\mathrm{E}_{\mathrm{ads}}=-3.14 \mathrm{eV}\right)<\mathrm{Rh}$ $\left(\mathrm{E}_{\mathrm{ads}}=-2.69 \mathrm{eV}\right)<\mathrm{Pd}\left(\mathrm{E}_{\mathrm{ads}}=-2.20 \mathrm{eV}\right)<\mathrm{Cu}\left(\mathrm{E}_{\mathrm{ads}}=-1.64 \mathrm{eV}\right)<\mathrm{Au}\left(\mathrm{E}_{\mathrm{ads}}=-1.49 \mathrm{eV}\right)<\mathrm{Ag}\left(\mathrm{E}_{\mathrm{ads}}\right.$ $=-1.18 \mathrm{eV})$. We note that the strong adsorptions $(\mathrm{Pt}, \mathrm{Ni}, \mathrm{Rh}$, and $\mathrm{Ir})$ cause surface restructuring on the surface facet (Figure 4e, 4f). 


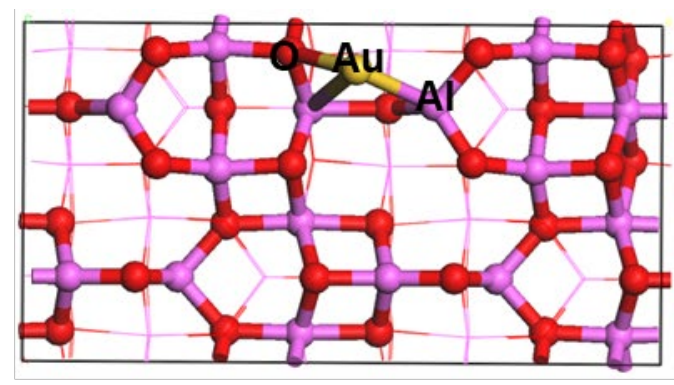

(a)

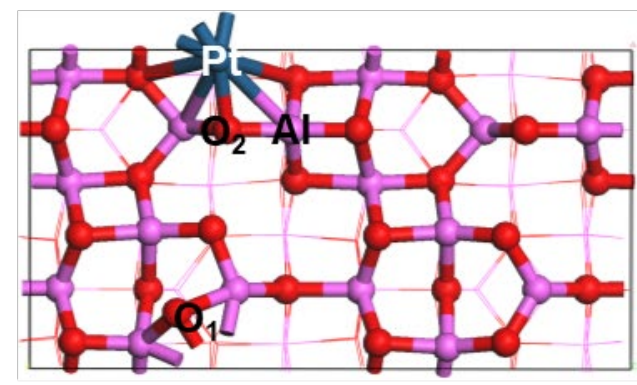

(c)

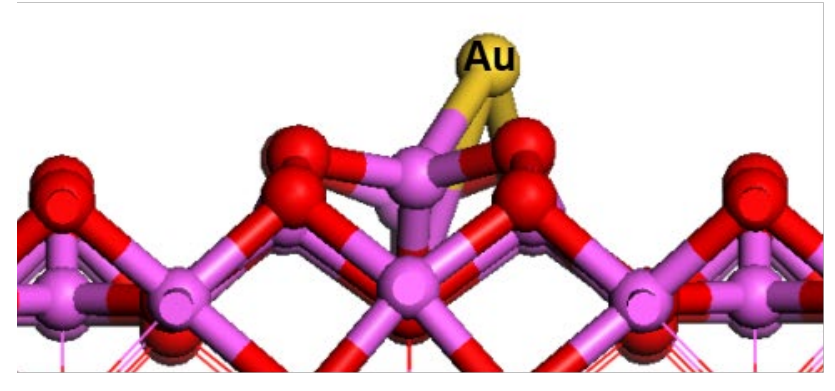

(e)

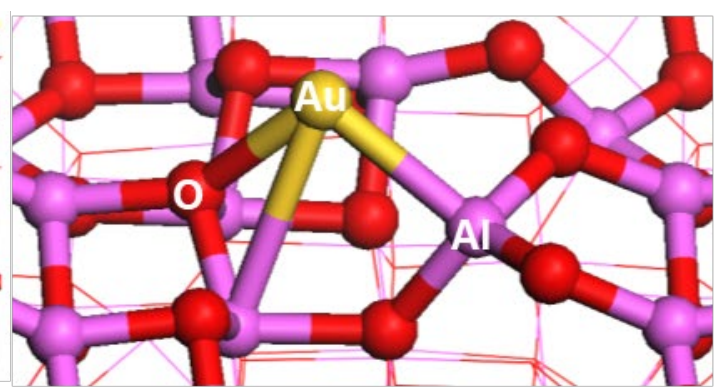

(b)

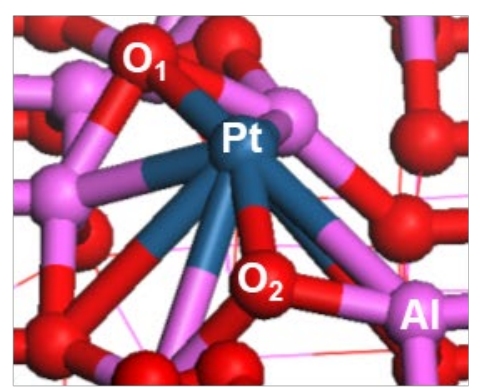

(d)

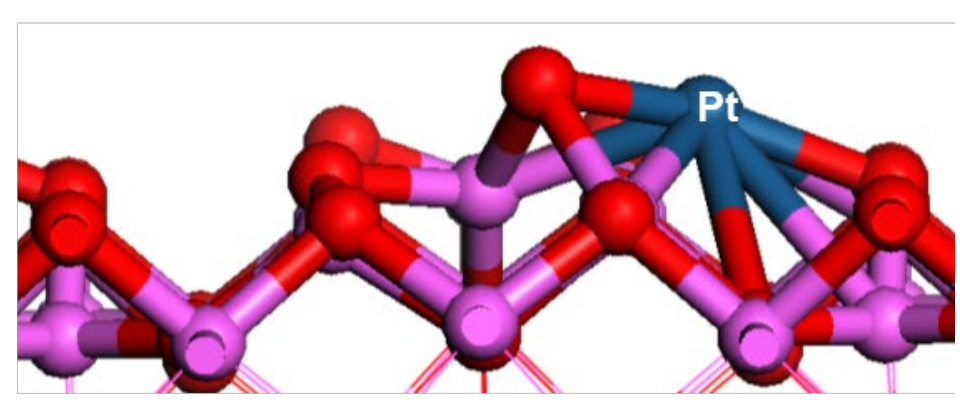

(f)

Figure 4 Au adsorption on $\gamma-\mathrm{Al}_{2} \mathrm{O}_{3}$ (110) (a) top view, (b) side view; Pt adsorption on $\gamma$ - $\mathrm{Al}_{2} \mathrm{O}_{3}$ (110) (c) top view, (d) side view. Surface restructuring is observed by comparing side views of the $\gamma-\mathrm{Al}_{2} \mathrm{O}_{3}(110)$ support surface when interacting with (e) Au and (f) Pt. Yellow atoms represent Au, blue atoms represent Pt, pink atoms represent $A l$, and red atoms represent $O$.

On $\gamma-\mathrm{Al}_{2} \mathrm{O}_{3}$ (111), metals bind on the hollow site (Figure 5c, 5d). The DFT-calculated metal adsorption energies are $\operatorname{Ir}\left(E_{\text {ads }}=-8.25 \mathrm{eV}\right)<\mathrm{Ni}\left(\mathrm{E}_{\mathrm{ads}}=-8.04 \mathrm{eV}\right)<\mathrm{Rh}\left(\mathrm{E}_{\mathrm{ads}}=-7.36 \mathrm{eV}\right)<\mathrm{Pt}\left(\mathrm{E}_{\mathrm{ads}}\right.$ $=-6.35 \mathrm{eV})<\mathrm{Cu}\left(\mathrm{E}_{\mathrm{ads}}=-5.96 \mathrm{eV}\right)<\mathrm{Pd}\left(\mathrm{E}_{\mathrm{ads}}=-5.13 \mathrm{eV}\right)<\mathrm{Ag}\left(\mathrm{E}_{\mathrm{ads}}=-4.54 \mathrm{eV}\right)<\mathrm{Au}\left(\mathrm{E}_{\mathrm{ads}}=-\right.$ 
$3.75 \mathrm{eV}$ ). For the relatively weak-binding metals $\mathrm{Ag}$, they bind in a different hollow site from the stronger-binding metals $\mathrm{Pt}$ (Figure 5a, 5b). The binding configuration for $\mathrm{Au}$ is same as $\mathrm{Ag}$. $\mathrm{Cu}$, $\mathrm{Pd}, \mathrm{Ni}, \mathrm{Rh}$, and Ir bind in the identical configuration.

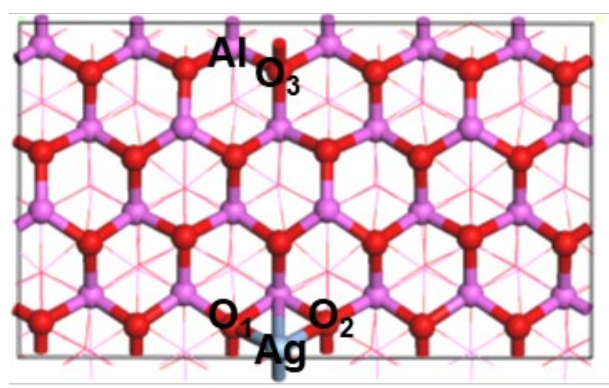

(a)

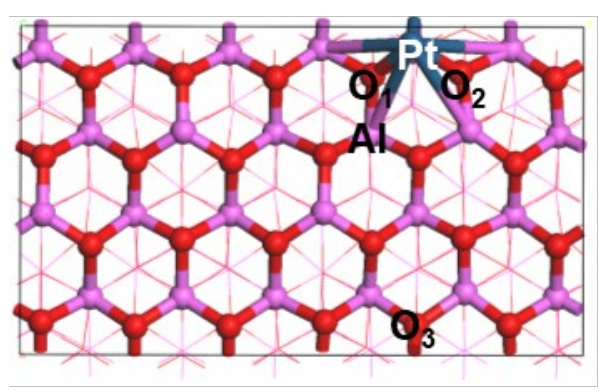

(c)

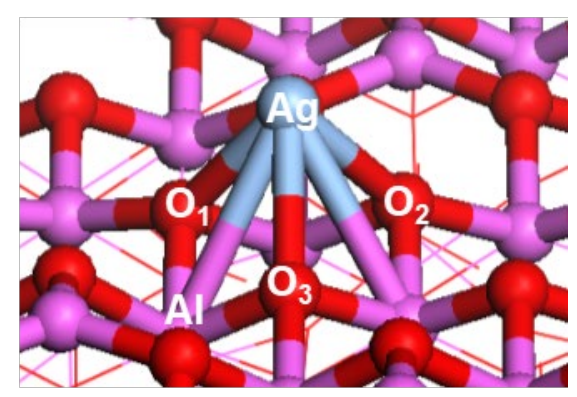

(b)

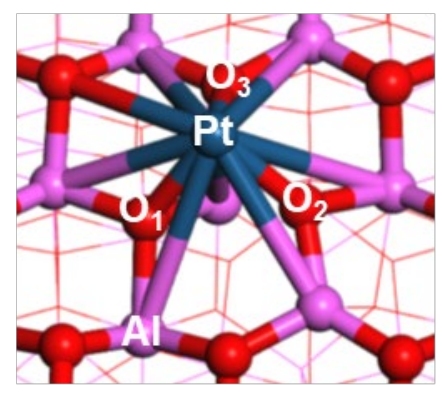

(d)

Figure $5 \mathrm{Ag}$ adsorption on $\gamma-\mathrm{Al}_{2} \mathrm{O}_{3}$ (111) in (a) top view, (b) side view; Pt adsorption on $\gamma-\mathrm{Al}_{2} \mathrm{O}_{3}$ (111) in (c) top view, (d) side view. Grey atoms represent $\mathrm{Ag}$, blue atoms represent $\mathrm{Pt}$, pink atoms represent $\mathrm{Al}$, and red atoms represent 0 .

The slab model of $\mathrm{MgO}(100)$ yields a highly symmetric support structure. We note that metals adsorb directly above an oxygen atom and coordinate with several neighboring $\mathrm{Mg}$ atoms (Figure 6a, 6b). Rh prefers to bind in a hollow site (Figure 6c, 6d), and Ir binds in the same configuration. The DFT-calculated adsorption energies are: $\mathrm{Pt}\left(\mathrm{E}_{\mathrm{ads}}=-3.07 \mathrm{eV}\right)<\operatorname{Ir}\left(\mathrm{E}_{\mathrm{ads}}=-2.56\right.$ 
$\mathrm{eV})<\mathrm{Rh}\left(\mathrm{E}_{\mathrm{ads}}=-2.03 \mathrm{eV}\right)<\mathrm{Ni}\left(\mathrm{E}_{\mathrm{ads}}=-1.98 \mathrm{eV}\right)<\mathrm{Pd}\left(\mathrm{E}_{\mathrm{ads}}=-1.68 \mathrm{eV}\right)<\mathrm{Au}\left(\mathrm{E}_{\mathrm{ads}}=-1.08 \mathrm{eV}\right)<$

$\mathrm{Cu}\left(\mathrm{E}_{\mathrm{ads}}=-0.98 \mathrm{eV}\right)<\mathrm{Ag}\left(\mathrm{E}_{\mathrm{ads}}=-0.68 \mathrm{eV}\right)$.

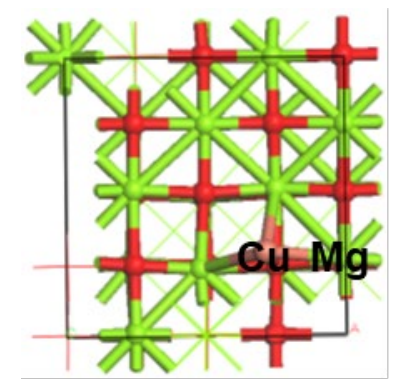

(a)

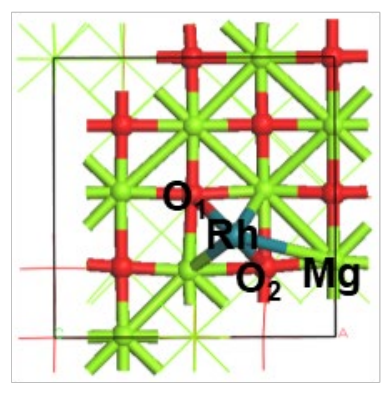

(c)

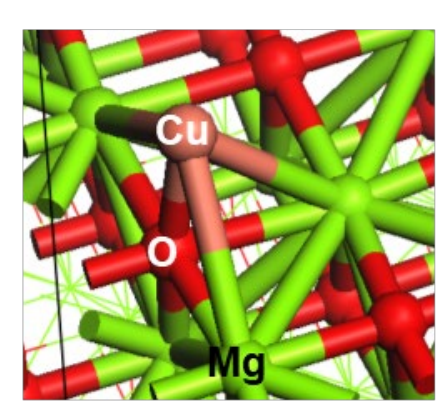

(b)

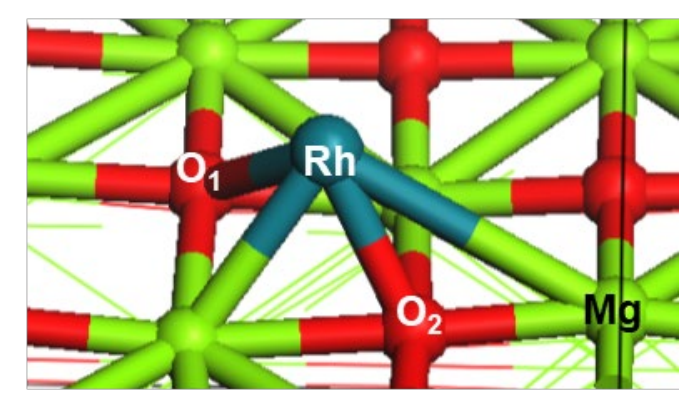

(d)

Figure $6 \mathrm{Cu}$ adsorption on MgO (100) from (a) top view, (b) side view; Rh adsorption on MgO (100) from the respective (c) top view, (d) side view. Copper atoms represent $\mathrm{Cu}$, blue atoms represent $\mathrm{Rh}$, green atoms represent $\mathrm{Mg}$, and red atoms represent $\mathrm{O}$.

On the other stable surface facet of $\mathrm{MgO}$, the (110), most metals strongly bind in a hollow site between two oxygen atoms and coordinate with several nearby Mg atoms (Figure 7a, 7b). The most-favorable binding site for Pt is slightly different, instead preferring a site directly above an 
oxygen and coordinates nearby $\mathrm{O}$ and $\mathrm{Mg}$ atoms (Figure 7c, 7d). The DFT-calculated metal adsorption energy is as follows: $\operatorname{Ir}\left(E_{\text {ads }}=-4.73 \mathrm{eV}\right)<\operatorname{Pt}\left(E_{\text {ads }}=-4.48 \mathrm{eV}\right)<\mathrm{Ni}\left(\mathrm{E}_{\mathrm{ads}}=-3.84 \mathrm{eV}\right)$ $<\mathrm{Rh}\left(\mathrm{E}_{\mathrm{ads}}=-3.78 \mathrm{eV}\right)<\mathrm{Cu}\left(\mathrm{E}_{\mathrm{ads}}=-2.57 \mathrm{eV}\right)<\mathrm{Pd}\left(\mathrm{E}_{\mathrm{ads}}=-2.54 \mathrm{eV}\right)<\mathrm{Au}\left(\mathrm{E}_{\mathrm{ads}}=-2.10 \mathrm{eV}\right)<\mathrm{Ag}$ $\left(E_{\text {ads }}=-2.08 \mathrm{eV}\right)$.

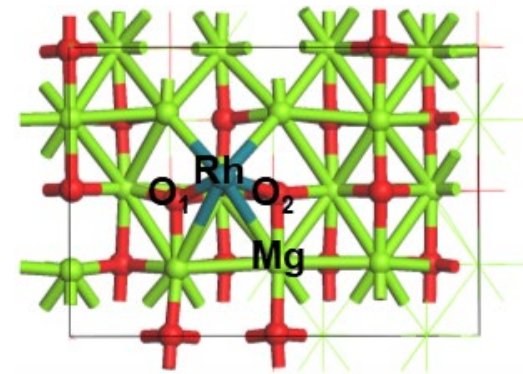

(a)

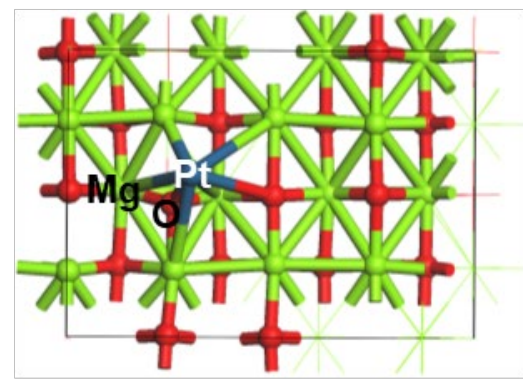

(c)

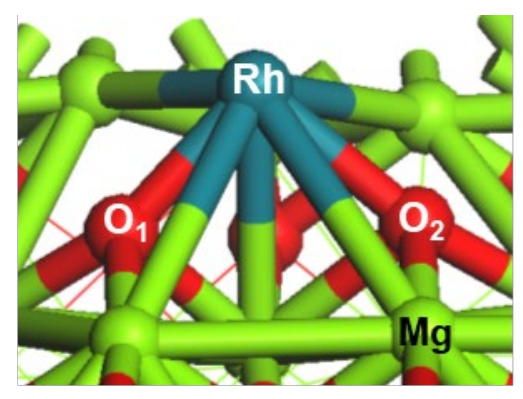

(b)

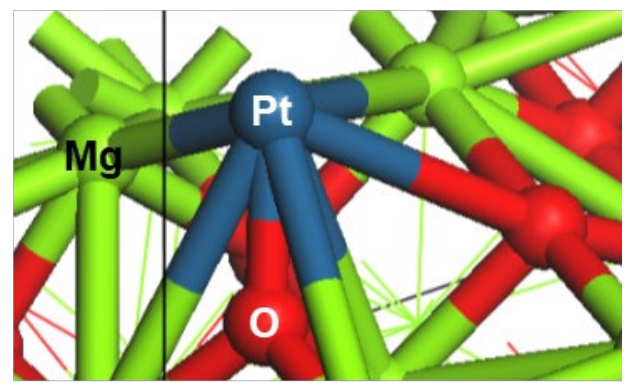

(d)

Figure 7 Rh adsorption on MgO (110) in (a) top view, (b) side view; Pt adsorption on MgO (110) in (c) top view, (d) side view. Light blue atoms represent $\mathrm{Rh}$, dark atoms represent $\mathrm{Pt}$, green atoms represent $\mathrm{Mg}$, and red atoms represent $\mathrm{O}$.

Due to the lower symmetry of $\mathrm{MgAl}_{2} \mathrm{O}_{4}(100)$, the observed adsorption behavior of different metals varies. Au and $\mathrm{Cu}$ bridge the same two nearby $\mathrm{Mg}$ atoms (Figure S4), the binding configuration of $\mathrm{Ag}$ is the same as $\mathrm{Au}$. Pt adsorption in a hollow site while coordinating with neighboring $\mathrm{Mg}, \mathrm{Al}$, and $\mathrm{O}$ atoms (Figure $8 \mathrm{a}, 8 \mathrm{~b}$ ), $\mathrm{Pd}$ and $\mathrm{Ni}$ bind on the identical configuration. 
$\mathrm{Rh}$ is in a different hollow site between two oxygens and coordinating with nearby $\mathrm{Mg}, \mathrm{Al}$ atoms (Figure 8c, 8d), while the binding configuration of Ir is the same as Rh. The DFT-calculated metal adsorption energies are: $\operatorname{Pt}\left(E_{\text {ads }}=-3.89 \mathrm{eV}\right)<\operatorname{Ir}\left(E_{\text {ads }}=-3.61 \mathrm{eV}\right)<\mathrm{Ni}\left(E_{\text {ads }}=-2.94 \mathrm{eV}\right)<\operatorname{Rh}\left(E_{\text {ads }}\right.$ $=-2.76 \mathrm{eV})<\mathrm{Au}\left(\mathrm{E}_{\mathrm{ads}}=-2.38 \mathrm{eV}\right)<\mathrm{Cu}\left(\mathrm{E}_{\mathrm{ads}}=-1.81 \mathrm{eV}\right)<\mathrm{Pd}\left(\mathrm{E}_{\mathrm{ads}}=-1.81 \mathrm{eV}\right)<\mathrm{Ag}\left(\mathrm{E}_{\text {ads }}=-\right.$ $1.21 \mathrm{eV})$.

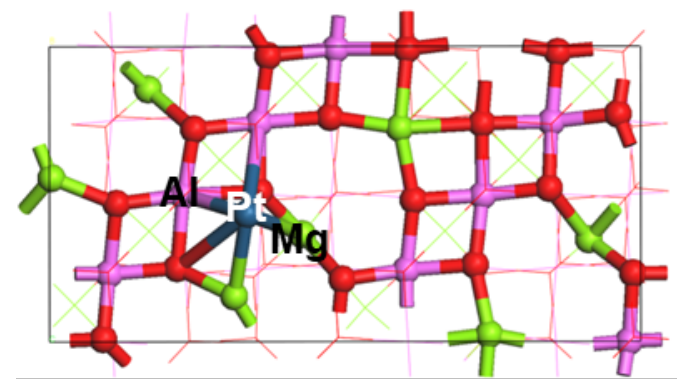

(a)

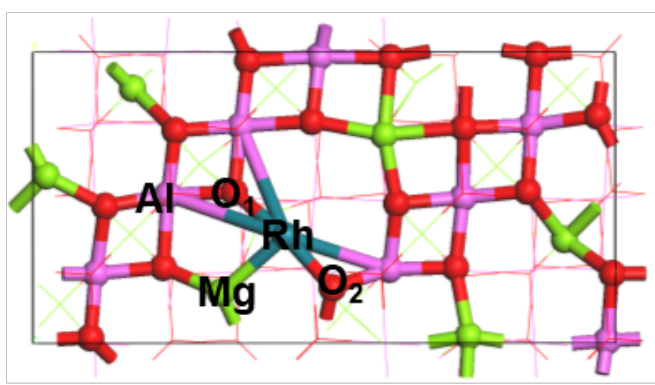

(c)

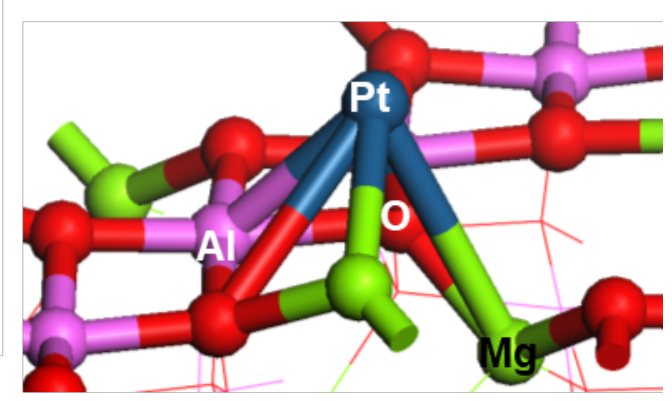

(b)

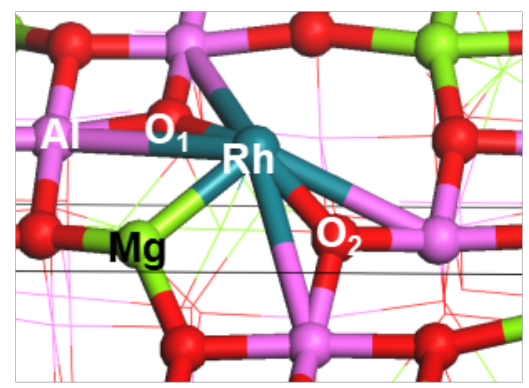

(d)

Figure 8 Pt adsorption on $\mathrm{MgAl}_{2} \mathrm{O}_{4}$ (100) (a) top view, (b) side view; Rh adsorption on $\mathrm{MgAl}_{2} \mathrm{O}_{4}(100)$ (c) top view, (d) side view. Dark blue atoms represent $\mathrm{Pt}$, light blue atoms represent $\mathrm{Rh}$, green atoms represent $\mathrm{Mg}$, pink atoms represent $\mathrm{Al}$, and red atoms represent $\mathrm{O}$. 
On $\mathrm{MgAl}_{2} \mathrm{O}_{4}$ (110), the strongest adsorption site for all metals are similar, which is a hollow site between two nearby oxygens on the surface (Figure 9). DFT-calculated metal adsorption energies are as follows: Ir $($ Eads $=-7.34 \mathrm{eV})<\mathrm{Ni}\left(\mathrm{E}_{\mathrm{ads}}=-6.18 \mathrm{eV}\right)<\mathrm{Pt}\left(\mathrm{E}_{\mathrm{ads}}=-5.77\right.$ $\mathrm{eV})<\mathrm{Rh}\left(\mathrm{E}_{\mathrm{ads}}=-5.50 \mathrm{eV}\right)<\mathrm{Cu}\left(\mathrm{E}_{\mathrm{ads}}=-4.78 \mathrm{eV}\right)<\mathrm{Pd}\left(\mathrm{E}_{\mathrm{ads}}=-3.74 \mathrm{eV}\right)<\mathrm{Ag}\left(\mathrm{E}_{\mathrm{ads}}=-3.25 \mathrm{eV}\right)<$ $\mathrm{Au}\left(\mathrm{E}_{\mathrm{ads}}=-3.24 \mathrm{eV}\right)$. Although their binding sites are similar, due to initially high surface energy of $\mathrm{MgAl}_{2} \mathrm{O}_{4}$ (110), the strong Ir adsorption resulted in a significant surface restructuring (Figure 9c, 9d).

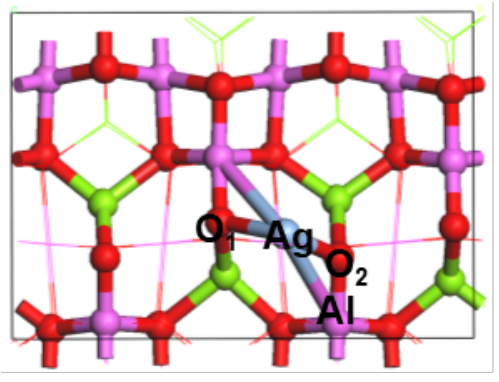

(a)

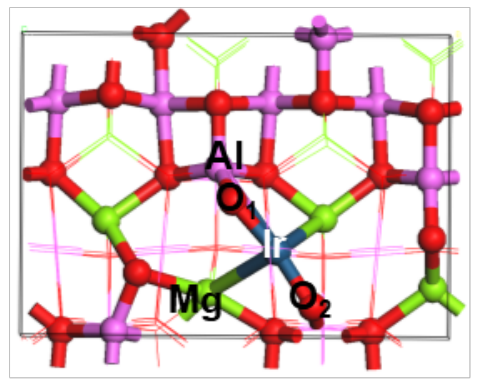

(c)

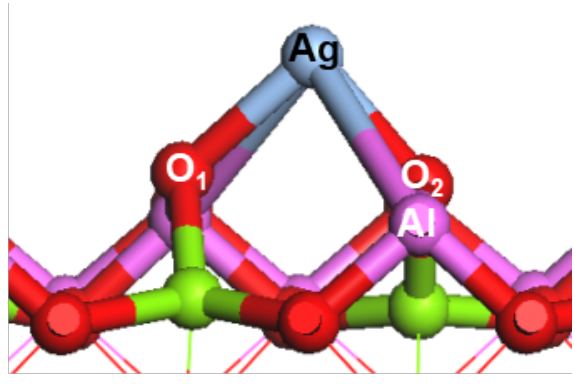

(b)

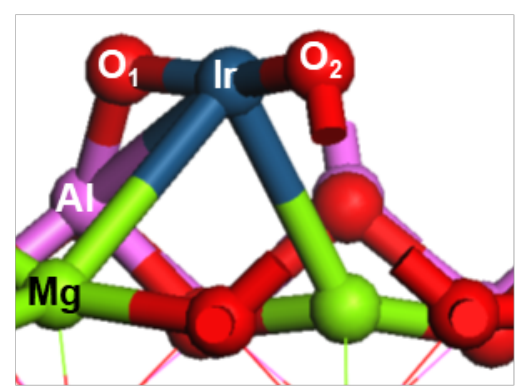

(d)

Figure $9 \mathrm{Ag}$ adsorption on $\mathrm{MgAl}_{2} \mathrm{O}_{4}$ (110) in (a) top view, (b) side view; $\mathrm{Ir}$ adsorption on $\mathrm{MgAl}_{2} \mathrm{O}_{4}(110)$ in (c) top view, (d) side view. Grey atoms represent $\mathrm{Ag}$, blue atoms represent $\mathrm{Ir}$, green atoms represent $\mathrm{Mg}$, pink atoms represent $\mathrm{Al}$, and red atoms represent $\mathrm{O}$. 
Overall, we note that (i) metals are closer to oxygens after optimization. In the case of $\mathrm{Ni}$ adsorption on $\mathrm{MgO}(100)$, the initial placement of $\mathrm{Ni}$ is in a hollow site coordinate with nearby two Mg and 2 oxygens with average Ni-O distance $2.042 \AA$ (Figure 10a). During DFT calculation, Ni atom moves toward the on-top site of an oxygen with final Ni-O distance $1.805 \AA$ (Figure 10b). This suggests that the metal-oxygen binding is crucial for metal adsorption; (ii) strong MSIs $\left(\mathrm{Pt} / \mathrm{Ni} / \mathrm{Rh} / \mathrm{Ir}\right.$ on $\gamma-\mathrm{Al}_{2} \mathrm{O}_{3}(110)$ and $\mathrm{Ir}$ on $\left.\mathrm{MgAl}_{2} \mathrm{O}_{4}(110)\right)$ induce surface restructuring in order to accommodate guest metals appropriately on the surface. During restructuring oxygen atoms which are initially close to the surface (Figure 9b) move away from the surface towards the supported metal (Figure 9d).

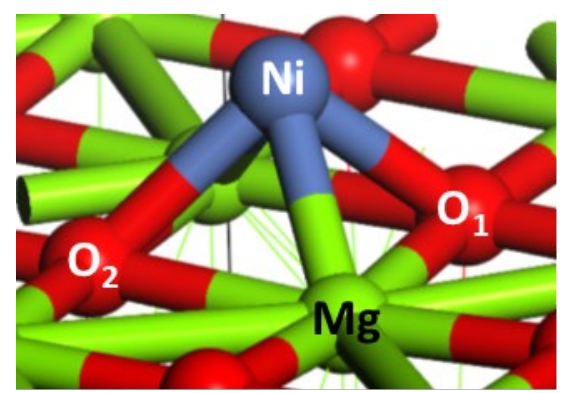

(a)

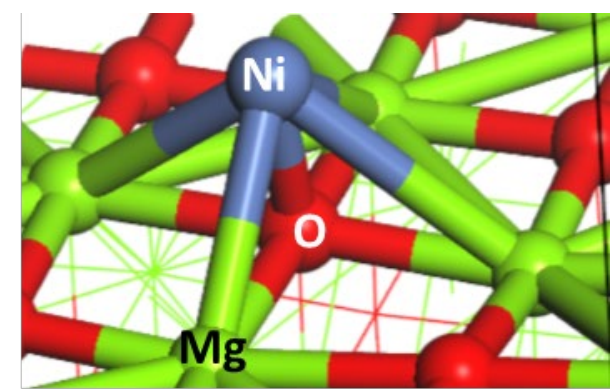

(b)

Figure 10 (a) Initial placement of Ni on MgO (100), (b) Ni adsorption on MgO (100) after optimization. Light blue atoms represent $\mathrm{Ni}$, green atoms represent $\mathrm{Mg}$, and red atoms represent $\mathrm{O}$. 


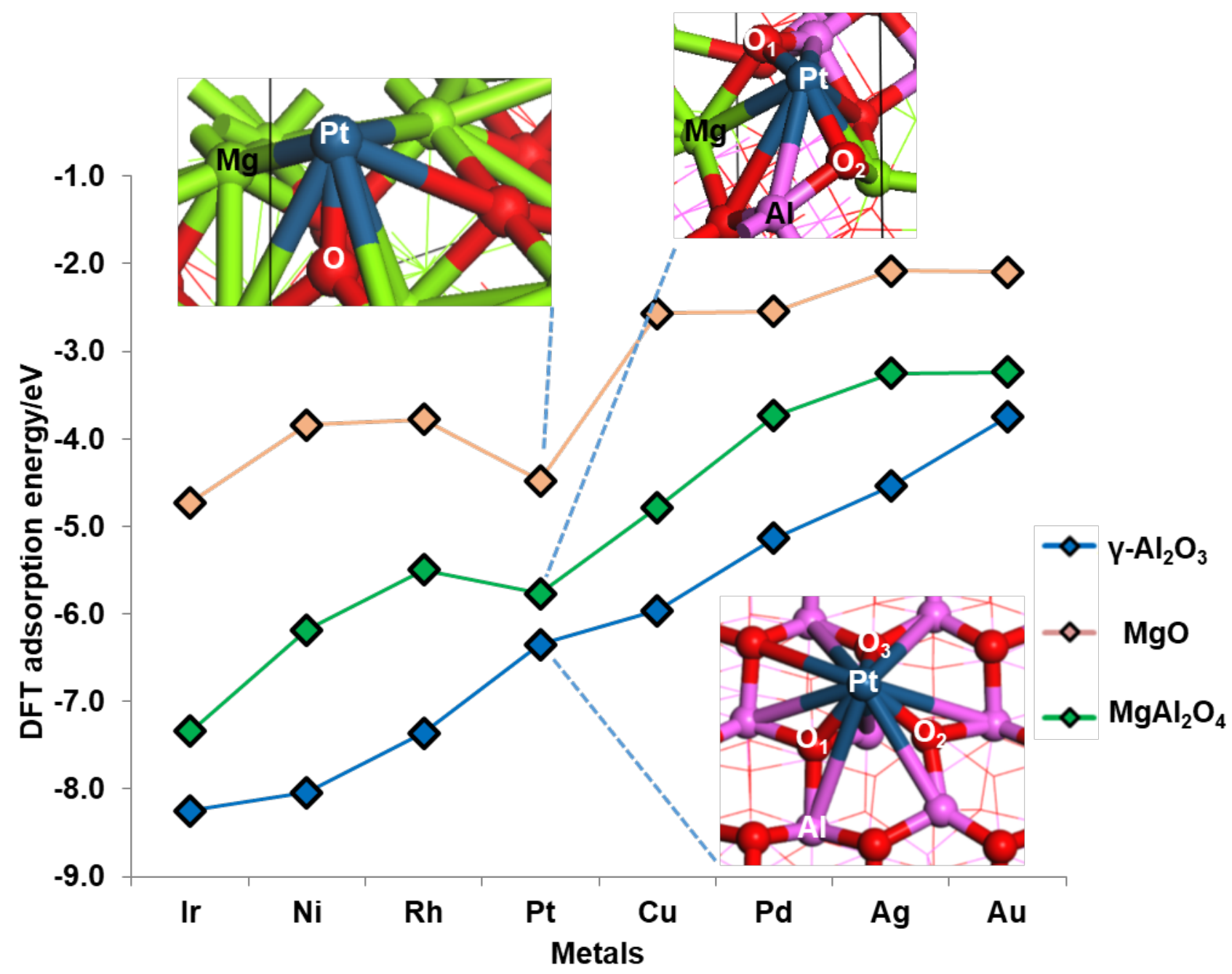

Figure 11 The DFT-calculated metal adsorption energy for most preferred sites of different transition metals adsorbed on different supports; the structures of Pt adsorption are attached for an insight in the structures. Blue atoms represent $\mathrm{Pt}$, green atoms represent $\mathrm{Mg}$, pink atoms represent $\mathrm{Al}$, and red atoms represent $\mathrm{O}$.

In Figure 11, we plot the adsorption energy of metals in their most preferred sites on different oxide supports in order to compare their adsorption behavior. We observe for every metal, 
the metal adsorption is strongest on $\gamma-\mathrm{Al}_{2} \mathrm{O}_{3}$ and weakest on $\mathrm{MgO}$. The metal adsorption on $\mathrm{MgAl}_{2} \mathrm{O}_{4}$ is between $\gamma-\mathrm{Al}_{2} \mathrm{O}_{3}$ and $\mathrm{MgO}$ while the chemical formula of $\mathrm{MgAl}_{2} \mathrm{O}_{4}$ is the combination of $\mathrm{Al}_{2} \mathrm{O}_{3}$ and $\mathrm{MgO}$. Because of the similarity in adsorption energy trends for every metal, this suggests that if a metal strongly adsorbs to $\gamma-\mathrm{Al}_{2} \mathrm{O}_{3}$, it would also adsorb on $\mathrm{MgO}$ and $\mathrm{MgAl}_{2} \mathrm{O}_{4}$ with a stronger interaction compared to the other metals, Ir always binds strongest among the metals we choose for instance. These highlighting the role of both the metal and support in governing the overall MSIs. 


\subsection{Descriptors of Metal Adsorption Energy}

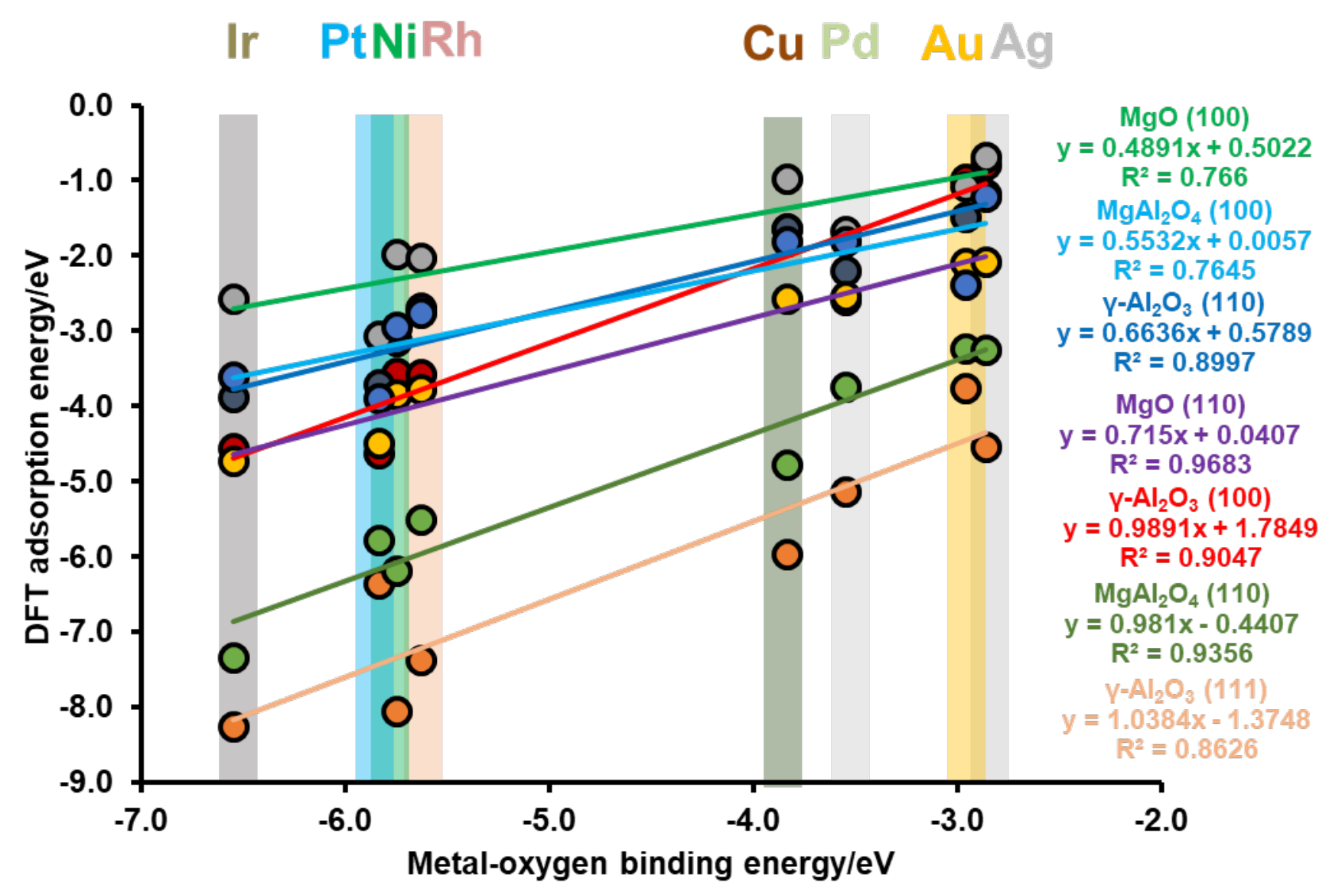

Figure 12 Relationships between DFT-calculated metal adsorption energy on each surface facet and metaloxygen binding energy of the supported SAC.

To solidify our conclusions regarding the relationship between the metal-oxygen binding and the MSI, in Figure 12 we plot the adsorption energy of the most preferred site for each metal on several different surface facets versus the metal-oxygen binding energy $\left(\mathrm{E}_{\mathrm{M}-\mathrm{O}}\right)$. $\mathrm{E}_{\mathrm{M}-\mathrm{O}}$ refers to the calculated binding energy of a single metal atom with a single oxygen atom in the gas phase 
(Table S3c). We observe a linear relationship between the metal's adsorption energy on its preferred site of the support and the corresponding $\mathrm{E}_{\mathrm{M}-\mathrm{O}}$ : the stronger the $\mathrm{E}_{\mathrm{M}-\mathrm{O}}$ in the gas phase, the stronger the adsorption energy to the support. On all the considered facets of $\gamma-\mathrm{Al}_{2} \mathrm{O}_{3}$, the relationship between metal adsorption energy and $\mathrm{E}_{\mathrm{M}-\mathrm{O}}$ is strong. One of the reasons for this relationship is that except for the relatively weaker-binding cases of $\mathrm{Au} / \mathrm{Cu} / \mathrm{Ag}$ on $\gamma-\mathrm{Al}_{2} \mathrm{O}_{3}$ (110) (Figure 4a, 4b and Figure S3a, S3b), all preferred sites for metals on $\gamma-\mathrm{Al}_{2} \mathrm{O}_{3}$ are found to coordinate with a number of oxygen atoms. As a result, the metal-oxygen interaction becomes a major factor for adsorption on $\gamma-\mathrm{Al}_{2} \mathrm{O}_{3}$, which $\mathrm{E}_{\mathrm{M}-\mathrm{O}}$ characterizes. The correlation between metal adsorption energy and $\mathrm{E}_{\mathrm{M}-\mathrm{O}}$ on $\mathrm{MgO}(100)$ is weaker due to most metals only coordinating with one oxygen (Figure 6a, 6b). On MgO (110) every metal participates in strong bonds with two oxygens (Figure S7) and as a result $\mathrm{E}_{\mathrm{M}-\mathrm{O}}$ works well as a descriptor. On $\mathrm{MgAl}_{2} \mathrm{O}_{4}(100), \mathrm{Au}, \mathrm{Cu}$, and Ag do not form any bond with oxygen on the support (Figure S4) and the correlation between metal adsorption energy and $\mathrm{E}_{\mathrm{M}-\mathrm{O}}$ is low. On $\mathrm{MgAl}_{2} \mathrm{O}_{4}(110)$, the correlation is excellent due to a higher metal-oxygen coordination compares with $\mathrm{MgAl}_{2} \mathrm{O}_{4}$ (100) (Figure 9). To summarize, EM-O is correlated with MSIs on oxide supports and is useful as a descriptor for metal adsorption energy when the metal is expected to bind with oxygen atoms.

We now search for a descriptor based on the properties of support, because it is also an important aspect of the adsorption interaction (see our discussion of Figure 11). However, this is not straightforward because the supports display complex structures which occasionally reconstruct during metal adsorption. After screening several support properties (surface energy, band gap, ionization potential, and fermi energy), we identified the support band gap correlates best with metal adsorption energy. We plot the adsorption energy of metal atoms on the most preferred site versus the band gap of the support in Figure 13. We note that the smaller the band 
gap the stronger the adsorption. This makes sense, because adsorption of metals on supports involves charge transfer ${ }^{19}$. A support with a low band gap can more-easily transfer electron density to form bonds with the adsorbed metal atom, enhancing the adsorption interaction ${ }^{72}$.

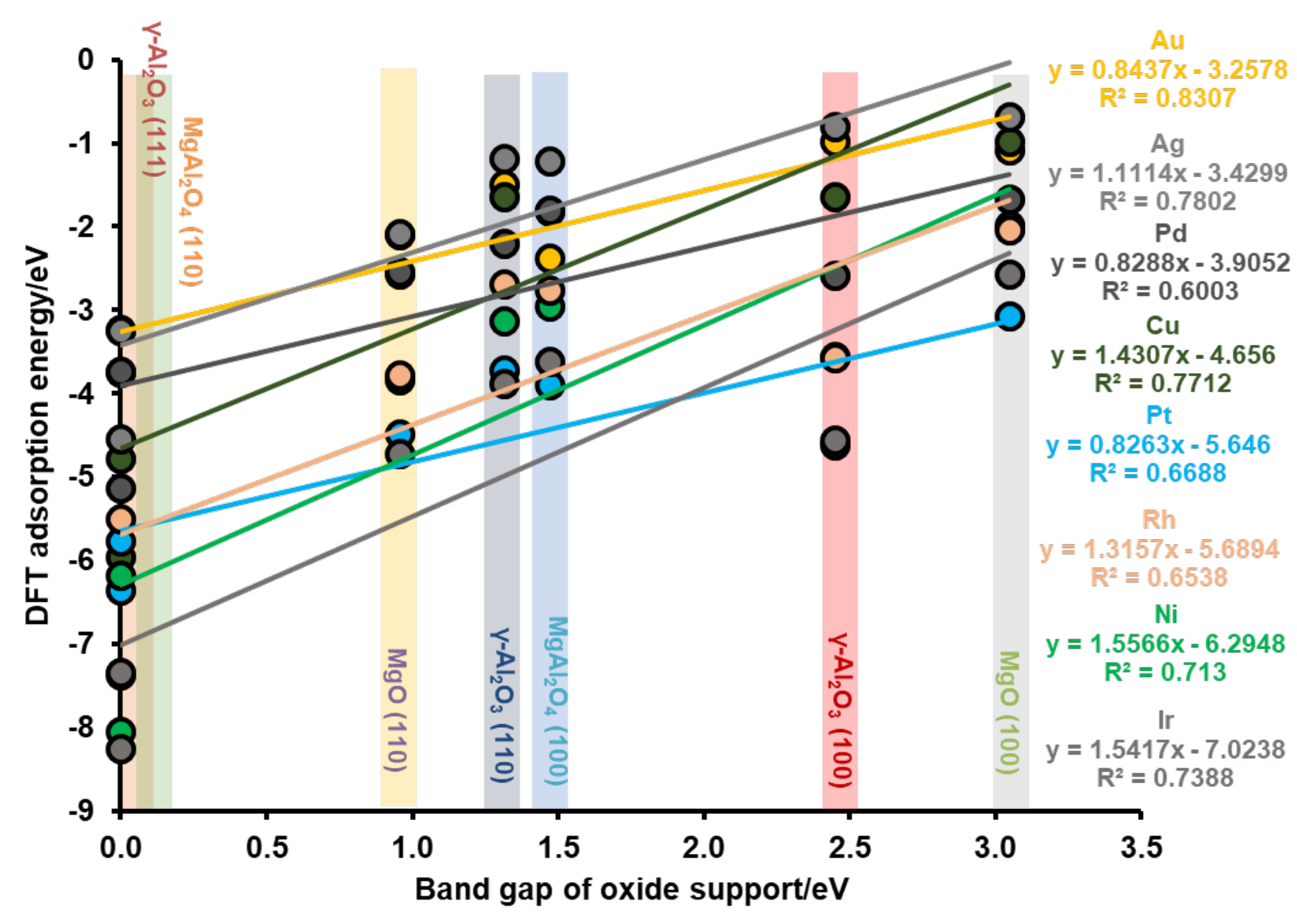

Figure 13 Relationship between DFT metal adsorption energy and band gap of the oxide support. 


\subsection{Predictive Model of Metal Adsorption Energy}

The adsorption of metal atoms on the oxide supports involves complex MSIs. As a result, we suspect that additional nonlinear factors may play a role on describing adsorption. To explore possibly nonlinear factors related to the MSI, we employ symbolic regression via genetic programming as implemented in Eureqa ${ }^{58}$.

The training set consists of our DFT-calculated adsorption energies, along with several possible physical descriptors which are obtained from literature and our own calculations. We calculate the following descriptors using DFT: gas-phase metal-oxygen binding energy ( $\left.\mathrm{E}_{\mathrm{M}-\mathrm{O}}\right)$, ionization potential of the support, band gap of the support, Fermi energy of the oxide support, gas-phase HOMO-LUMO gap of the metal, gas-phase Fermi energy of metal, and surface energy of the support (more details are given in Table S3c, S3d, S3e, S3f). In addition to the DFTcalculated parameters, we also investigate coordination numbers (using the Van der Waals radii reported in Table S5). We also use a "hypothetical cohesive energy" ( $\left.\mathrm{CE}_{\text {hyp }}\right)$ described in the SRB cutting model to predict metal nanoparticle energetics in SACs ${ }^{59-60}$. This is given in Equation 3-1, where $\mathrm{CE}_{\text {bulk }}$ is the experimental cohesive energy for metals in the bulk, $\mathrm{CN}$ is the total coordination between the supported metal atom and support; $\mathrm{CN}_{\text {bulk }}$ is the metal atom's coordination number in its own bulk. Because we only investigate FCC metals, $\mathrm{CN}_{\text {bulk }}$ is always 12. We assume the metal cohesive energy on the support is the cohesive energy of metal on its own metal slab while the coordination number is the same as the metal adsorption on the support. 


$$
C E_{\text {hyp }}=C E_{\text {bulk }} \sqrt{\frac{C N}{C N_{\text {bulk }}}}
$$

We take the following physical properties for the metal from literature: experimental bulk cohesive energy ${ }^{73}$, experimental ionization potential ${ }^{74}$, experimental electron affinity ${ }^{74}$, oxidation enthalpy $^{19}$, Van del Waal radius $^{75-76}$, electron configuration $^{74}$, Martynov-Batsanov electronegativity ${ }^{19}$, covalent radius of a triple bond ${ }^{77}$, heat of vaporization ${ }^{78}$, and electrical resistivity at $273 \mathrm{~K}^{74}$ (Table S3a, S3b).

In order to combat overfitting, we take 5 subsamples of the dataset, consisting of only $75 \%$ of the total dataset, and use each as separate training sets. Genetic programming is inherently a stochastic process, so we run it multiple times to have confidence on our results. For each training set we run Eureqa 5 times ( 25 searches total), halting each search after 2 million generations. The complexity is assessed on the equation generated by the genetic algorithm. We plot in Figure S6 the Pareto Front ${ }^{56}$ (the set of equations for each complexity which minimize the error ) of equations generated by Eureqa, using the RMSE reported by Eureqa.

The equations generated by Eureqa don't necessarily have their coefficients optimized, as they are generated with a genetic algorithm. To further reduce the error of the beset equations found by Eureqa, we optimize their coefficients using the Simplex method of Nelder and Mead ${ }^{79}$ as implemented in the optim function in R. To ensure accurate estimates of RMSE, we utilize bootstrapping (i.e. sampling with replacement from the dataset). We take a bootstrap sample, then optimize the coefficients. The RMSE is then recorded and another round of sampling and 
optimization is performed. We repeat this process of bootstrap sampling and optimization 10,000 times for each function. The results of this method are provided in Table S6. Finally, we use the whole (un-bootstrapped) dataset and optimize its coefficients to generate Equation 3-2. Equation 3-2 is the best equation in terms of bootstrapped RMSE, equaling $0.69 \mathrm{eV}$. Eads is metal adsorption energy, $\mathrm{E}_{\mathrm{M}-\mathrm{O}}$ represents the gas-phase metal-oxygen binding energy of supported metal, $\mathrm{IP}_{\mathrm{s}}$ represents the ionization potential of the oxide support, and $\mathrm{BG}_{\mathrm{s}}$ represents the band gap of the oxide support.

$$
E_{\text {ads }}=0.523 * E_{M-O}+\frac{0.413 * E_{M-O}-1.243 * I P_{s}-4.147}{4.740 * B G_{s}+1.165}+0.859
$$

The correlation between DFT adsorption energy in our data set and hypothetical adsorption energy calculated using Equation 3-2 is show in Figure 14. 


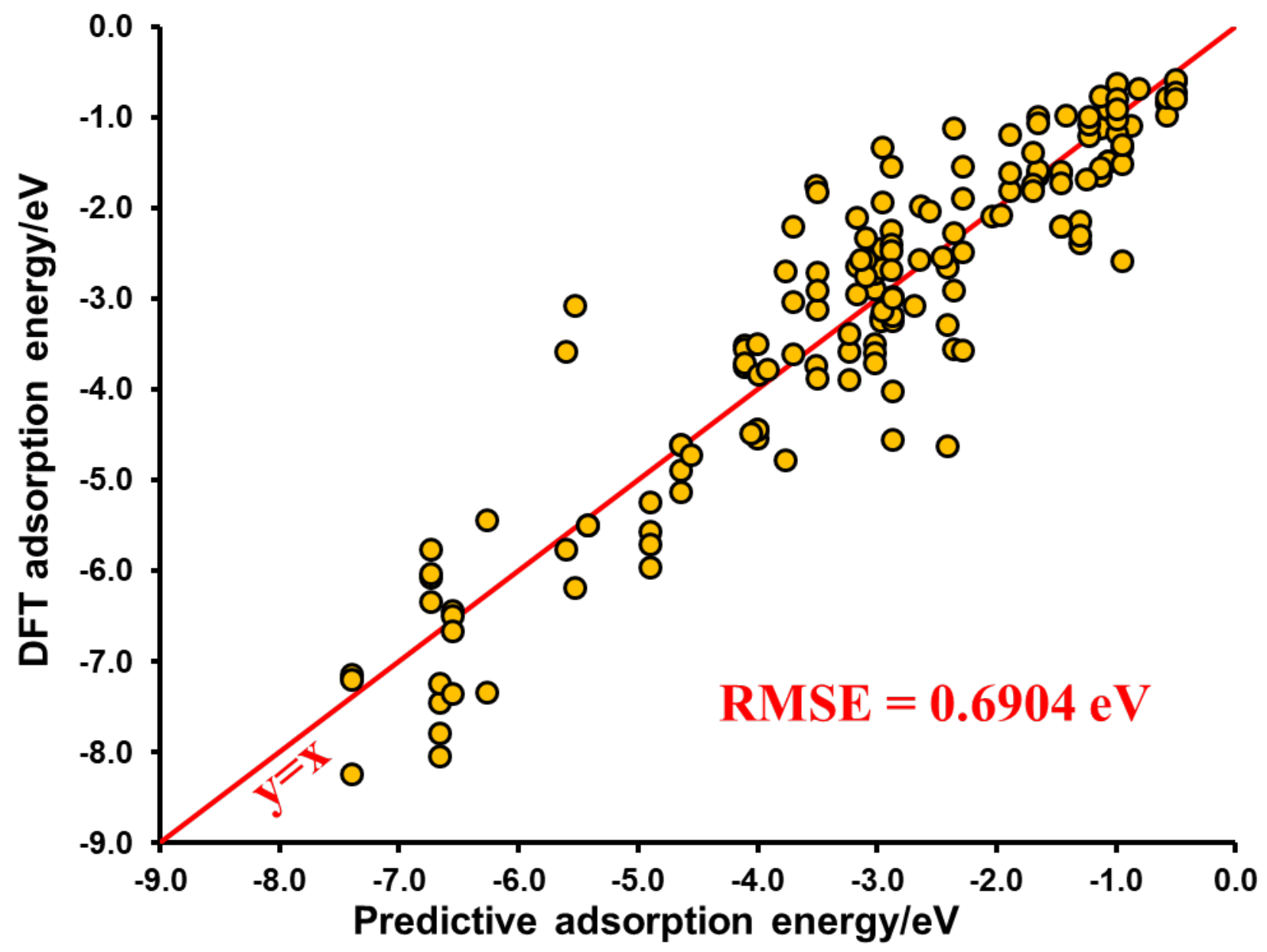

Figure 14 DFT adsorption energy versus predictive adsorption energy calculated by Equation 3-2.

Overall, this equation supports what we elucidated from our calculations. We have already shown the band gap of the oxide support $\left(\mathrm{BG}_{\mathrm{s}}\right)$ and metal oxygen binding energy $\left(\mathrm{E}_{\mathrm{M}-\mathrm{O}}\right)$ strongly correlate with the metal adsorption energy. Furthermore, the inclusion of the ionization potential of the support $\left(\mathrm{IP}_{\mathrm{s}}\right)$ supports our conclusion of charge transfer playing an important role in metal adsorption on support. Examining models recently reported by $\mathrm{O}^{\prime} \mathrm{Connor}$ et $\mathrm{al}^{19}$, we find several similar descriptors: the oxide formation enthalpy of the metal (which is similar to our $\mathrm{E}_{\mathrm{M}-\mathrm{O}}$ ), ratio of the LUMO of the support and metal (we use the support band gap, which is the LUMO - 
HOMO), and electron affinity of the metal (we use ionization potential of the support) in particular stand out. Our bootstrapped RMSE equals 0.69 , which indicates our model is better-suited to a coarse-grained approach to screen a large pool of potential metal-surface pairs before applying a more expensive technique such as DFT.

\subsection{Hypothesize the Synthetic Accessibility of Single-Atom Catalysts}

Stabilizing single metal atoms with a support is a necessity for the creation of stable (i.e. sintering-resistant) SACs. This manifests as a competition between the bulk cohesive energy of the metal atoms (which enhances sintering) and their binding energy with the support (which enhances atomic dispersion). From a thermodynamics perspective, if the strength of the MSI is stronger than the (pure) metal cohesive energy (in the same coordination environment), the single metal atom will energetically prefer adsorption to the support, stabilizing the SAC to resist sintering. We use the SRB model (Equation 3-1) to estimate the hypothetical cohesive energy $\left(E_{\text {hyp }}\right)$ of the metal atom. 
(a)

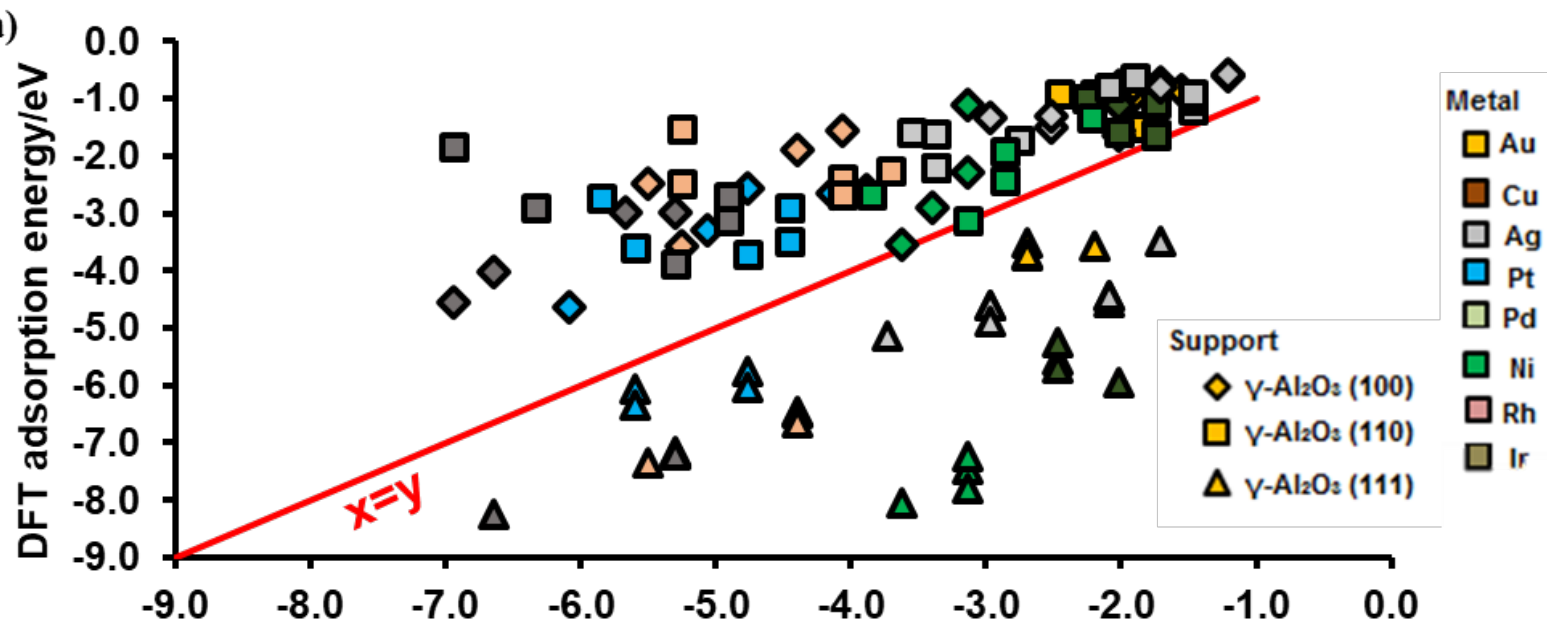

(b)

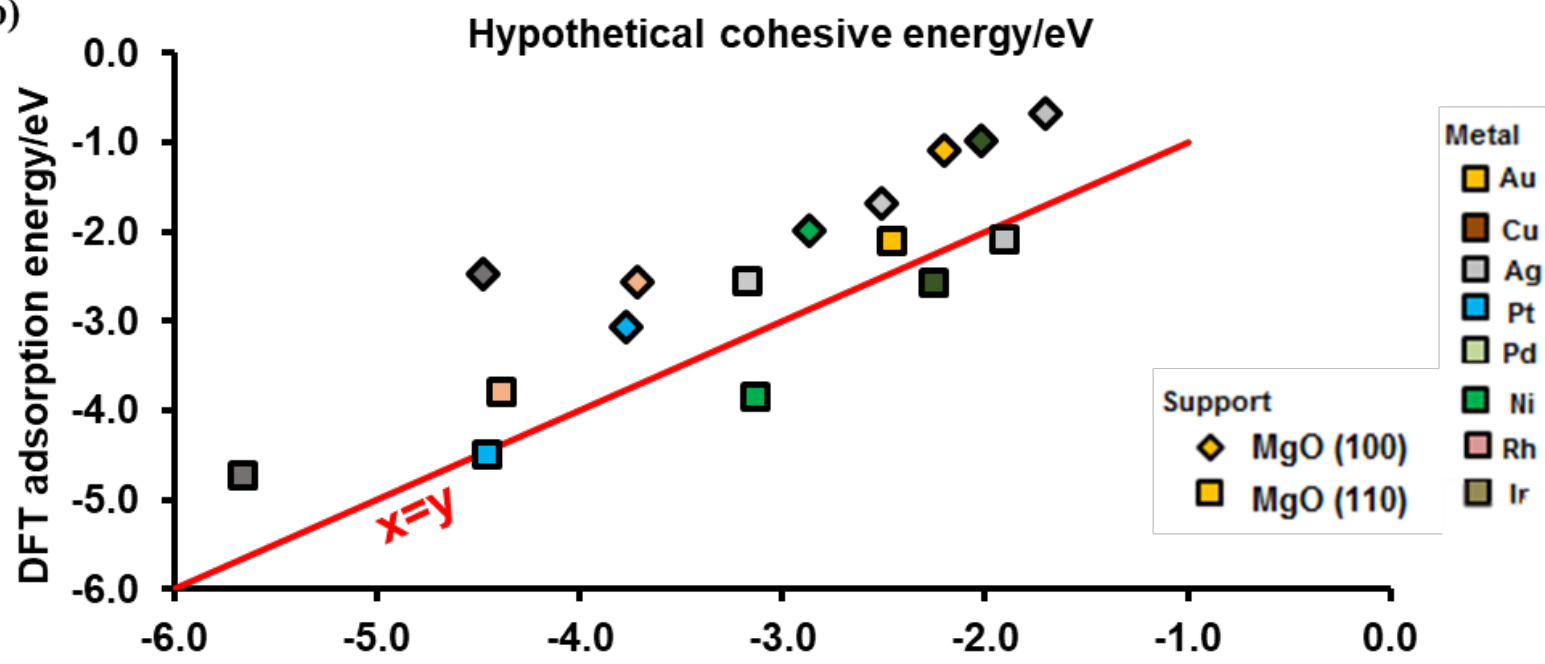

(c)

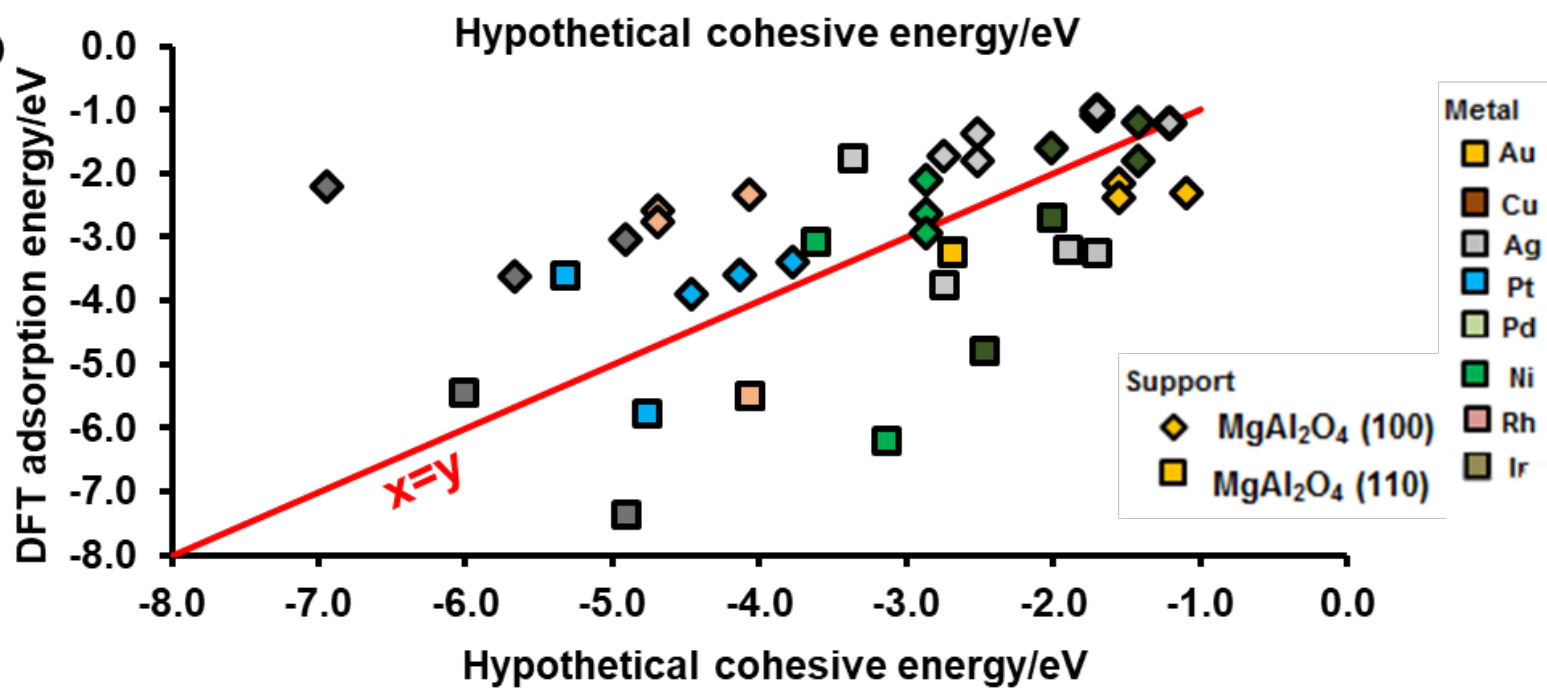

Figure 15 DFT adsorption energy vs hypothetical cohesive energy of supported metal on (a) $\gamma-\mathrm{Al}_{2} \mathrm{O}_{3}$ (b) $\mathrm{MgO}$ and (c) $\mathrm{MgAl}_{2} \mathrm{O}_{4}$. 
In Figure 15 we plot the adsorption energy of the metal atoms on the different supports versus the $E_{\text {hyp }}$ of the metal. In other words, we account for a hypothetical environment where the metal atom is in its own bulk with the same coordination that has on the support. With this formulation we are able to address the metal's atom preference to interact with the support or with its parent metal (in a cluster/nanoparticle). The red line shows the boundary where the supported metal adsorption energy is equal to SRB-calculated metal cohesive energy. The points below the red line indicate the adsorption energy is higher than cohesive energy of given metal atom, and the corresponding SACs formation is therefore suggested to be more favorable. We note that for $\gamma$ $\mathrm{Al}_{2} \mathrm{O}_{3}$ surface, all data points on (100) and (110) are above the red line, which suggests that stabilizing SACs on these facets may be difficult. However, on (111), all the considered metals are likely to yield stable SACs, as they are located below the red line (Figure 15a), showing a facetspecific thermodynamic preference for the formation of SACs. We notice that Pt and Rh SACs have already been synthesized on $\gamma-\mathrm{Al}_{2} \mathrm{O}_{3}{ }^{68-69}$. Similarly, on $\mathrm{MgO}$, the surface facet plays an important role in stabilizing SACs, and four points fall under the red line, which are $\mathrm{Cu} / \mathrm{Ag} / \mathrm{Pt} / \mathrm{Ni}$ on $\mathrm{MgO}$ (110). $\mathrm{Au} / \mathrm{Pt} / \mathrm{Pd} / \mathrm{Rh} / \mathrm{Ir}$ SACs have already been synthesized on $\mathrm{MgO}^{36,61-63,70}$. It should be noticed that in Figure 15b, $\mathrm{Au}, \mathrm{Pd}, \mathrm{Rh}$, and $\mathrm{Ir}$ on $\mathrm{MgO}$ (110) are also close to the red line, validating our predictions. On $\mathrm{MgAl}_{2} \mathrm{O}_{4}$, most of the data points for (110) surface facet sites are under the red line, suggesting that $\mathrm{MgAl}_{2} \mathrm{O}_{4}$ (110) could also be a good support for the formation of SACs (Figure 15c). Indeed, the Ir SAC has already been synthesized on $\mathrm{MgAl}_{2} \mathrm{O}_{4}{ }^{71}$. These results suggest that the balance between SRB based local metal atom cohesive energy and metal adsorption energy could be used as another rough indictor to hypothesize the stability of SACs. 


\subsection{Conclusions}

In this work, we apply DFT and statistical methods to a series of transition metal atoms (Au, $\mathrm{Cu}, \mathrm{Ag}, \mathrm{Pt}, \mathrm{Pd}, \mathrm{Ni}, \mathrm{Rh}$, and Ir) supported on low-index surface facets of $\gamma-\mathrm{Al}_{2} \mathrm{O}_{3}, \mathrm{MgO}$, and $\mathrm{MgAl}_{2} \mathrm{O}_{4}$ on a variety of sites in order to determine descriptors for SAC adsorption. Based on our DFT calculations, we identify two primary descriptors for MSIs: the binding energy of the metaloxygen complex in the gas phase, and the band gap of the oxide support. By combining DFT calculations and a thorough statistical learning approach, we develop a mathematical model that is able to estimate MSIs in SACs. Moreover, we assess the stability of a number of SACs by comparing the DFT adsorption energy with a hypothetical metal atom cohesive energy (tendency of the metal to form clusters than be atomically dispersed on the support) calculated with the square root bond cutting mode ${ }^{59-60}$ of cohesive energy. Finally, this work introduces some guiding principles to hypothesize the synthetic accessibility of a number of SACs based on the balance between adsorption and cohesion of metal nanoparticles on supports. 
Appendix A Example of CP2K Input Files

\section{A.1 Input File (Example $\mathrm{Al}_{2} \mathrm{O}_{3}$ bulk optimization)}

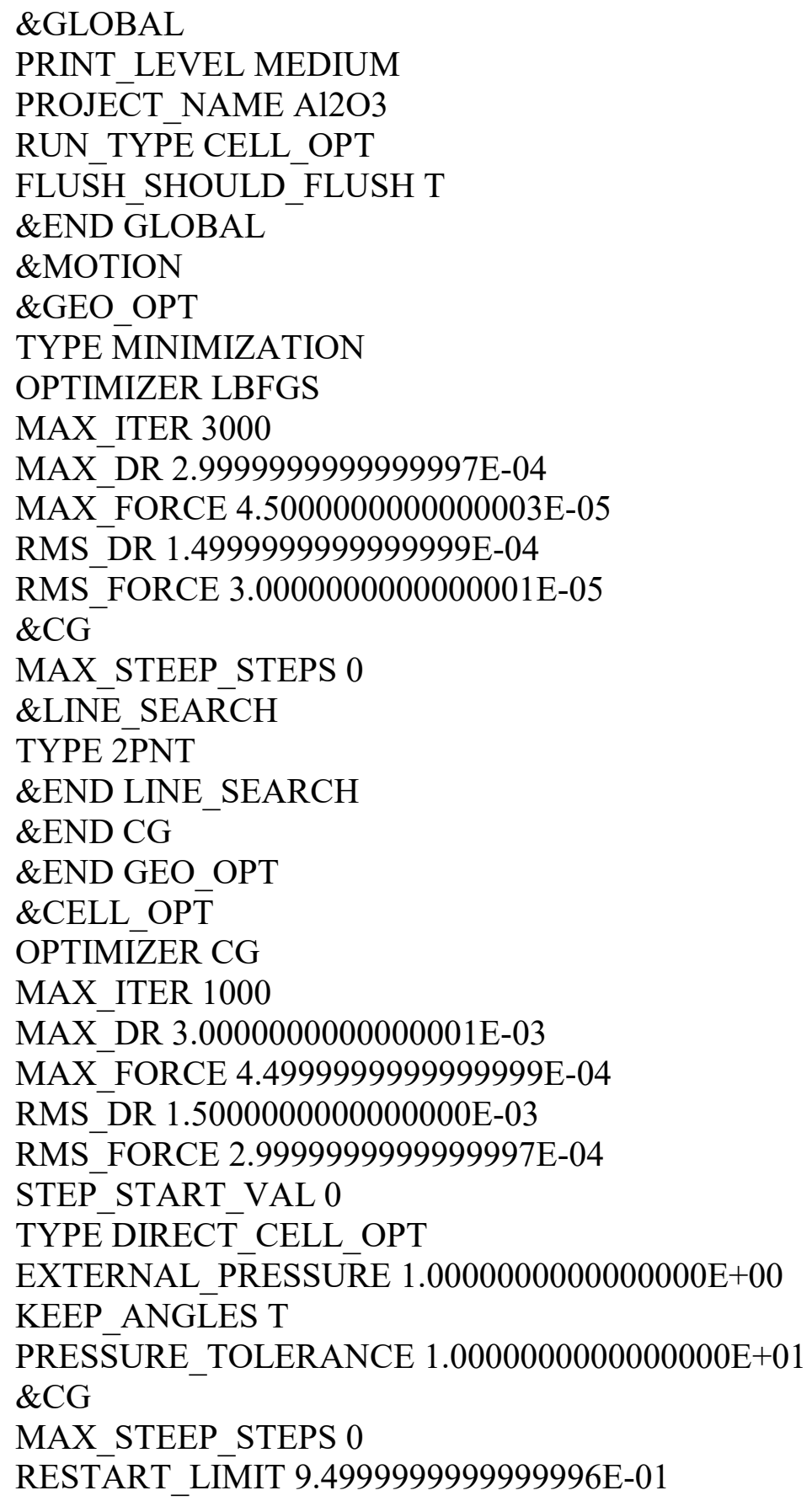




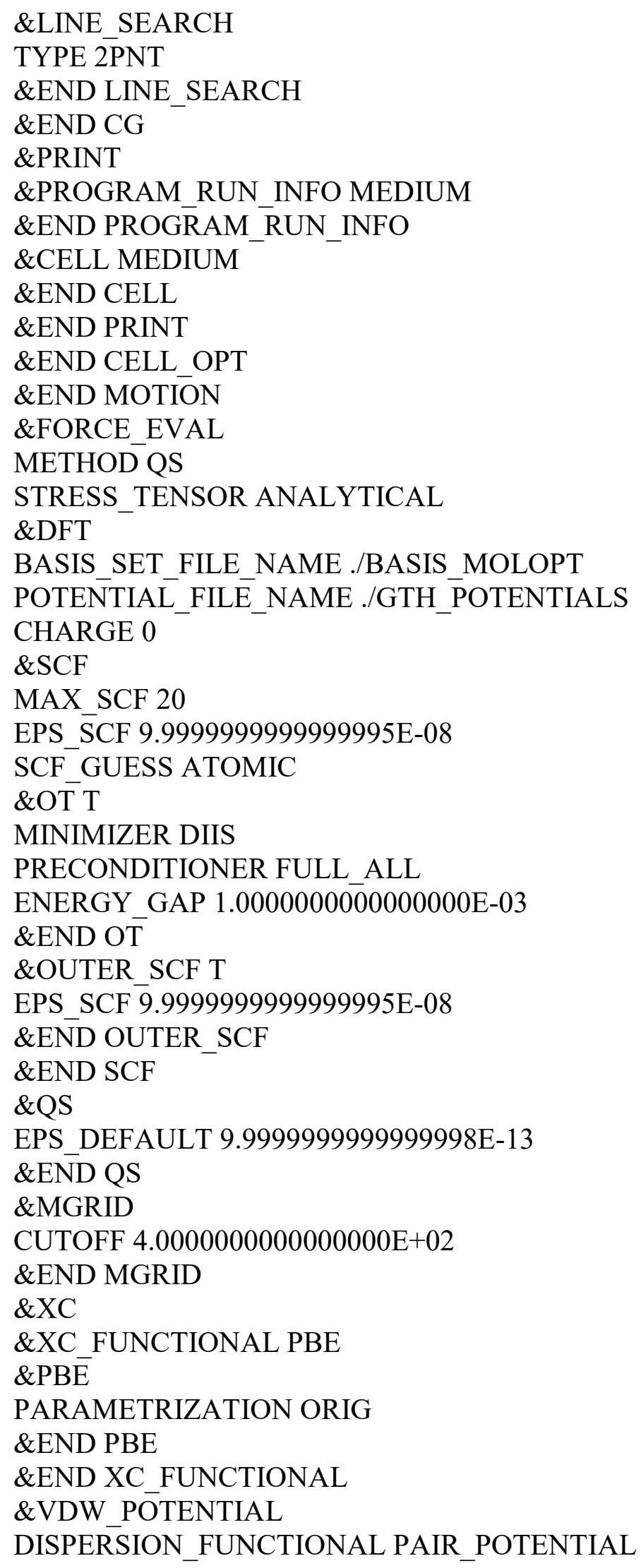




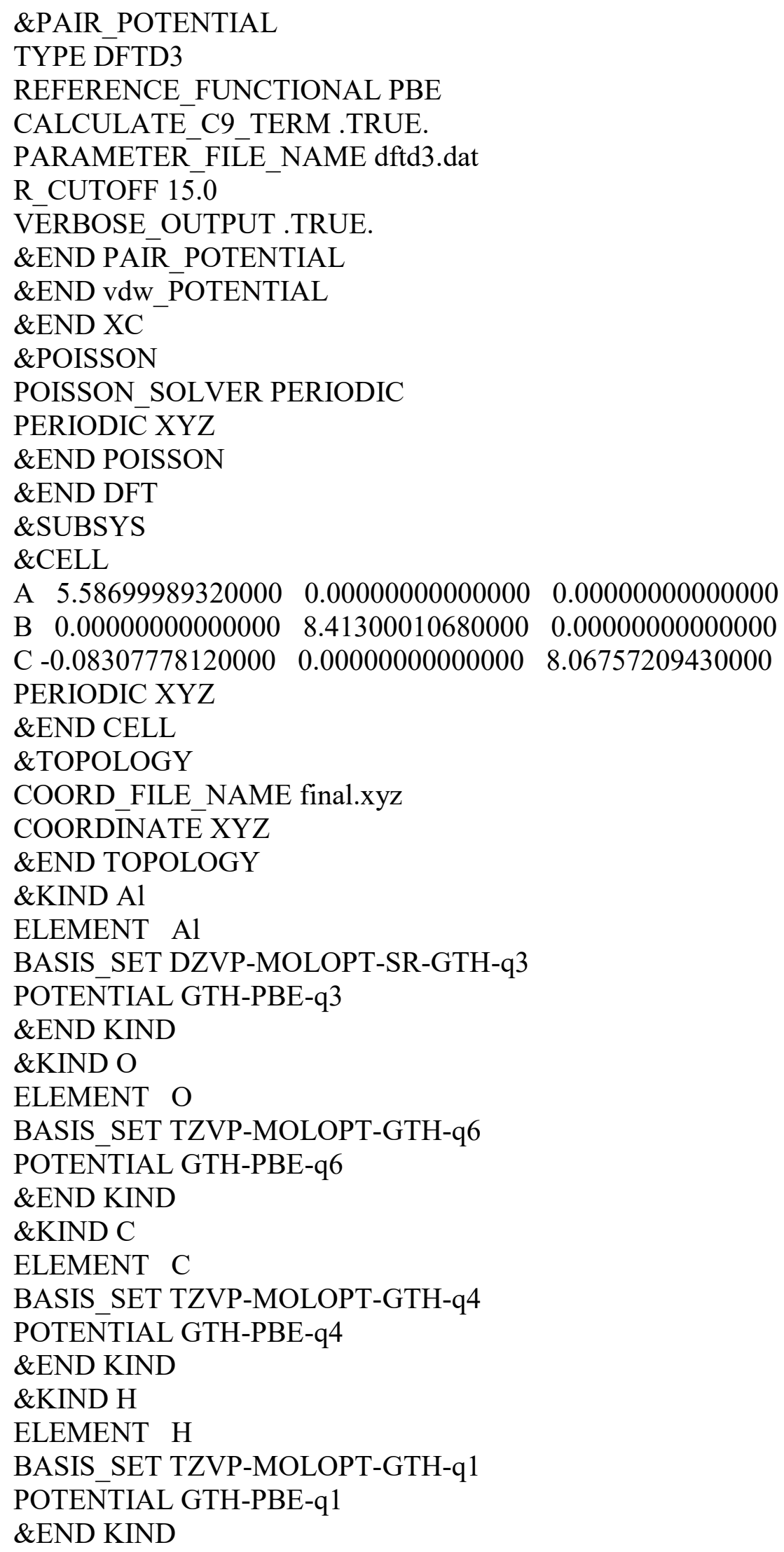




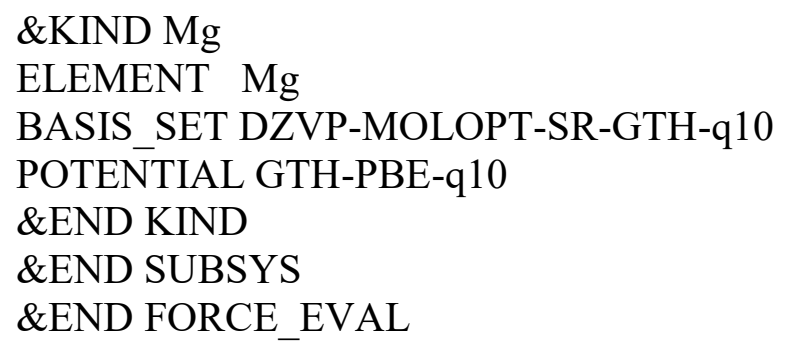

A.2 Input File (Example Au adsorption on $\mathrm{Al}_{2} \mathrm{O}_{3}$ (100) site $\mathrm{A}$ )

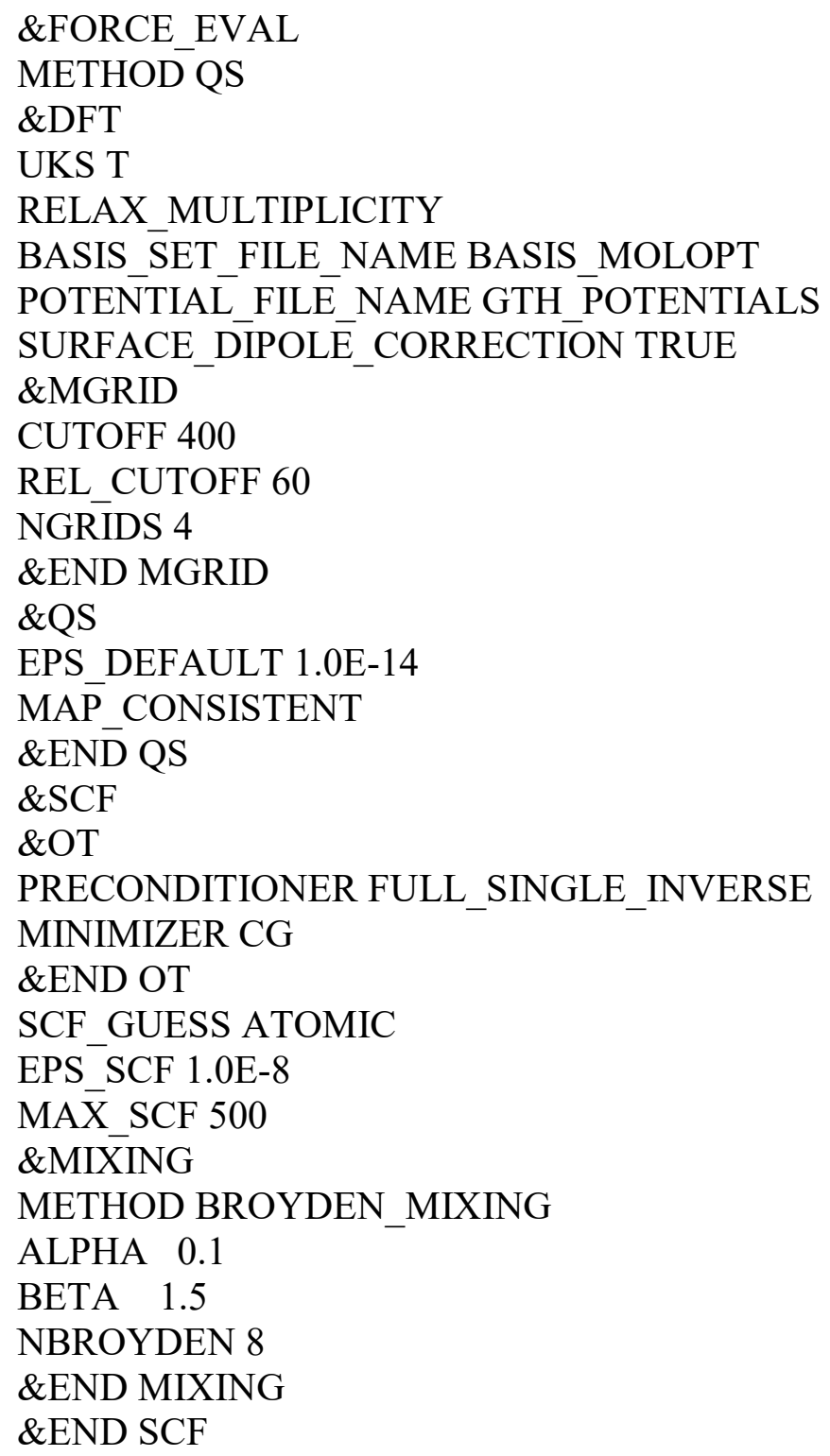




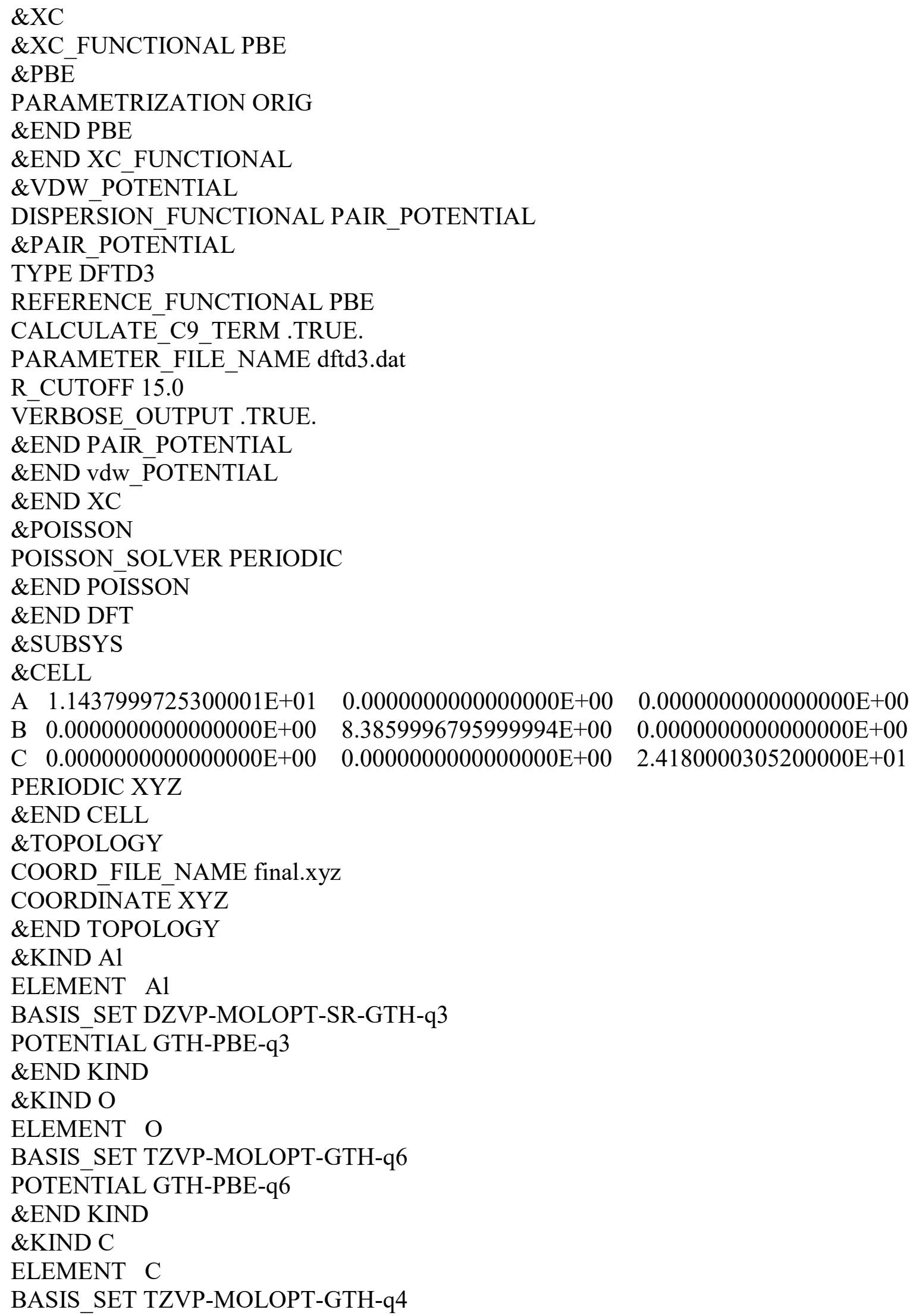




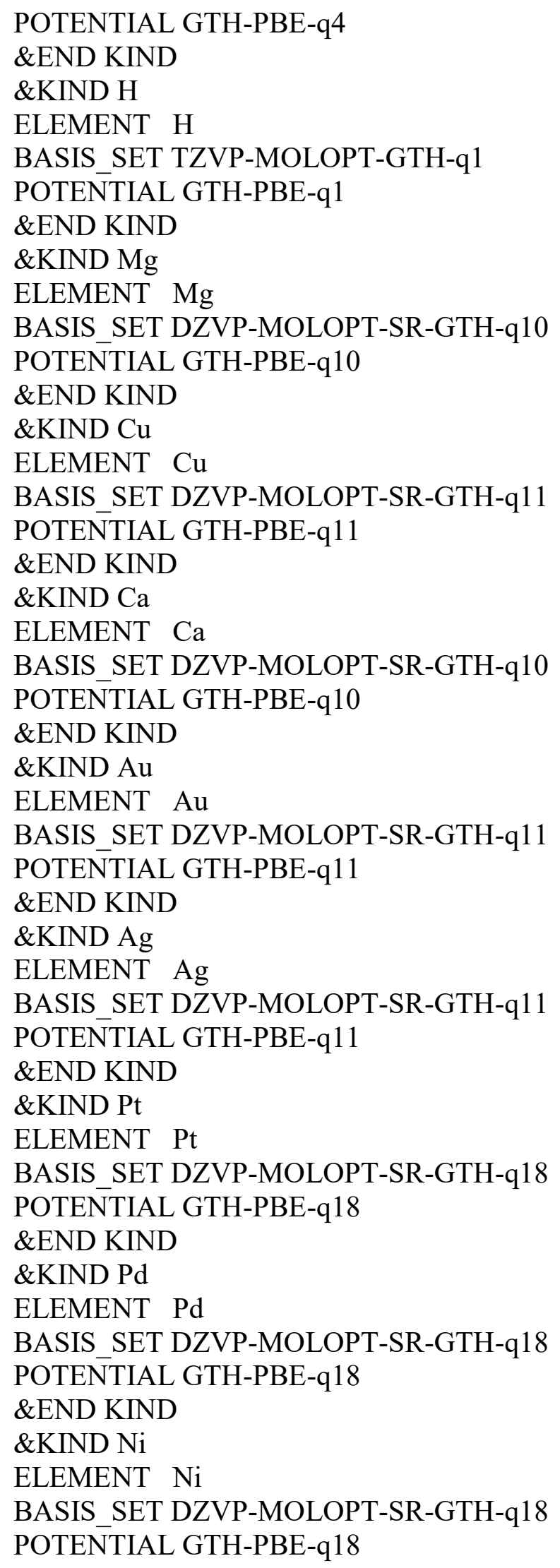




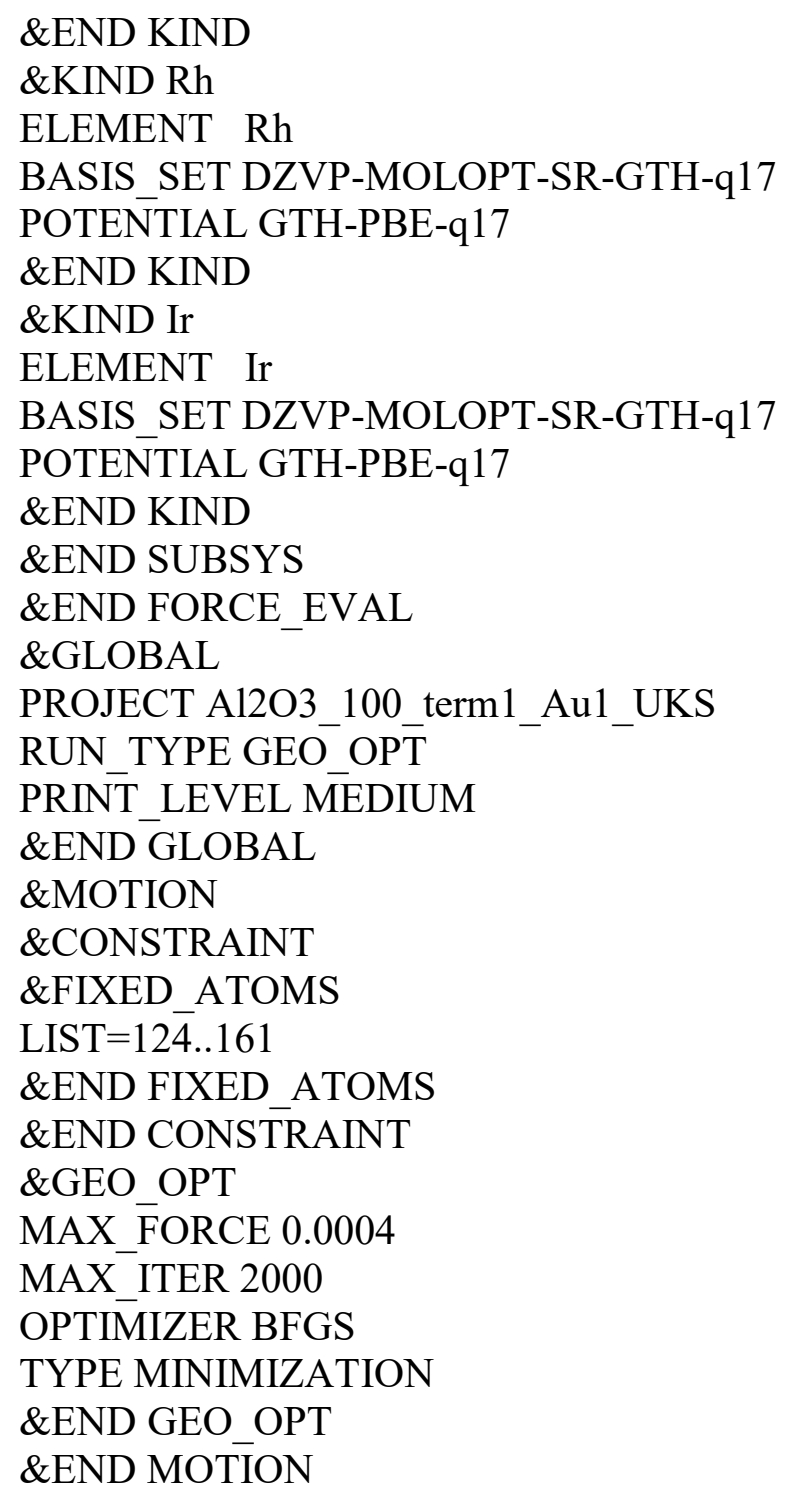

\section{A.3 XYZ File (Example Au adsorption on $\mathrm{Al}_{2} \mathrm{O}_{3}(100)$ site $\mathrm{A}$ )}

$\begin{array}{lccc}161 & & & \\ \mathrm{Au} & 8.9701037411 & 5.9671468252 & 16.2798297944 \\ \mathrm{Al} & 3.9424856282 & 4.8191865202 & 8.0792523196 \\ \mathrm{Al} & 5.3540395319 & 0.6212885556 & 6.1078050331 \\ \mathrm{Al} & 5.6302595689 & 0.3919260636 & 13.8818026428 \\ \mathrm{Al} & 1.0591483147 & 0.6530647778 & 3.1425858944 \\ \mathrm{Al} & 1.0567240955 & 0.6182767858 & 11.0381371353 \\ \mathrm{Al} & 2.5645764100 & 4.8220449286 & 3.1270047187\end{array}$




\begin{tabular}{|c|c|c|c|}
\hline $\mathrm{Al}$ & 2.4835403666 & 4.7984500925 & 11.0007506969 \\
\hline $\mathrm{Al}$ & 1.0498638799 & 4.8129464838 & 8.0751180596 \\
\hline $\mathrm{Al}$ & 2.5126456740 & 0.6226261428 & 6.1049874392 \\
\hline $\mathrm{Al}$ & 2.5717228539 & 0.5972702842 & 13.9713490149 \\
\hline $\mathrm{Al}$ & 5.3091524180 & 4.8241428317 & 5.0994949025 \\
\hline $\mathrm{Al}$ & 4.9849641323 & 4.7674701984 & 13.1736772163 \\
\hline $\mathrm{Al}$ & 3.9930132401 & 0.5946190550 & 9.1109559764 \\
\hline $\mathrm{Al}$ & 3.8978764555 & 7.5490205920 & 4.0356976102 \\
\hline $\mathrm{Al}$ & 3.8892670375 & 7.5202971856 & 11.9789097505 \\
\hline Al & 5.3821271263 & 6.2522299114 & 10.1905212232 \\
\hline $\mathrm{Al}$ & 5.3679971183 & 3.3315880991 & 10.1765710542 \\
\hline $\mathrm{Al}$ & 3.9086239503 & 2.0978588700 & 4.0376012395 \\
\hline $\mathrm{Al}$ & 3.8047139318 & 2.1179173308 & 11.9698207125 \\
\hline $\mathrm{Al}$ & 2.4479857368 & 3.3781969582 & 6.0038860423 \\
\hline $\mathrm{Al}$ & 2.1571111289 & 3.3118237750 & 13.8074554050 \\
\hline $\mathrm{Al}$ & 1.1288083167 & 2.0604483825 & 8.1875447023 \\
\hline $\mathrm{Al}$ & 1.1212462433 & 7.5633355146 & 8.1869022426 \\
\hline $\mathrm{Al}$ & 2.4466546198 & 6.2537410773 & 6.0038573977 \\
\hline $\mathrm{Al}$ & 2.0683712255 & 6.0053643243 & 13.7954971062 \\
\hline $\mathrm{Al}$ & 9.6583263128 & 4.8201598535 & 8.0803017031 \\
\hline $\mathrm{Al}$ & 11.0726769314 & 0.6219865233 & 6.1075314448 \\
\hline $\mathrm{Al}$ & 11.3598504897 & 0.3867954675 & 13.9137225251 \\
\hline $\mathrm{Al}$ & 6.7781847595 & 0.6530572506 & 3.1425448179 \\
\hline $\mathrm{Al}$ & 6.7848968035 & 0.6014142249 & 11.0239101767 \\
\hline $\mathrm{Al}$ & 8.2836027900 & 4.8219128339 & 3.1268368465 \\
\hline $\mathrm{Al}$ & 8.1996393406 & & 11.0078424791 \\
\hline $\mathrm{Al}$ & 6.7687328756 & 4.8110701340 & 8.0765484581 \\
\hline $\mathrm{Al}$ & 8.2315438613 & 0.6220538397 & 6.1057582950 \\
\hline $\mathrm{Al}$ & 8.2862967397 & 0.5924166932 & 13.9689243244 \\
\hline $\mathrm{Al}$ & 11.0280562948 & 4.8241447068 & 5.0994765206 \\
\hline $\mathrm{Al}$ & 10.7422357297 & 4.7553199514 & 13.1390013632 \\
\hline $\mathrm{Al}$ & 9.7129098916 & 0.5937532458 & 9.1108165175 \\
\hline $\mathrm{Al}$ & 9.6167775259 & 7.5490578556 & 4.0356942671 \\
\hline $\mathrm{Al}$ & 9.6045321295 & 7.5143487002 & 11.9839976683 \\
\hline $\mathrm{Al}$ & 11.1058363414 & 6.2613656130 & 10.1854915088 \\
\hline $\mathrm{Al}$ & 11.0822405583 & 3.3322375022 & 10.1681372604 \\
\hline $\mathrm{Al}$ & 9.6274244385 & 2.0978064792 & 4.0375701528 \\
\hline $\mathrm{Al}$ & 9.5266967633 & 2.1129960551 & 11.9755316544 \\
\hline $\mathrm{Al}$ & 8.1670448447 & 3.3778813242 & 6.0038552956 \\
\hline $\mathrm{Al}$ & 7.8303915735 & 3.2779079402 & 13.7906557199 \\
\hline $\mathrm{Al}$ & 6.8466985307 & 2.0601537681 & 8.1873874905 \\
\hline $\mathrm{Al}$ & 6.8385734232 & 7.5573988208 & 8.1865851674 \\
\hline $\mathrm{Al}$ & 8.1657044290 & 6.2528869153 & 6.0033625803 \\
\hline $\mathrm{Al}$ & 7.7768474142 & 6.0082921577 & 13.8330158182 \\
\hline $\mathrm{O}$ & 1.1122339361 & 4.8153804206 & 6.1022452996 \\
\hline $\mathrm{O}$ & 0.8745247902 & 4.6650778169 & 14.0245265567 \\
\hline
\end{tabular}




\begin{tabular}{|c|c|c|c|}
\hline $\mathrm{O}$ & 2.4575808226 & 0.6176229194 & 8.1293881886 \\
\hline $\mathrm{O}$ & 5.3148086347 & 0.6271039452 & 4.2691367833 \\
\hline $\mathrm{O}$ & 5.3270428530 & 0.6164139169 & 12.1106580181 \\
\hline $\mathrm{O}$ & 3.9721626975 & 4.8112750223 & 9.9256827670 \\
\hline $\mathrm{O}$ & 3.8334294469 & 4.8155375491 & 6.2164238493 \\
\hline $\mathrm{O}$ & 3.4163046619 & 4.8125992020 & 14.1752041099 \\
\hline $\mathrm{O}$ & 5.4585591373 & 0.6158125645 & 7.9770455982 \\
\hline $\mathrm{O}$ & 2.5752858527 & 0.6277191863 & 4.1278085519 \\
\hline $\mathrm{O}$ & 2.6010380982 & 0.5554643303 & 12.0297004981 \\
\hline $\mathrm{O}$ & 0.9510502670 & 4.8157933094 & 10.0694767722 \\
\hline $\mathrm{O}$ & 1.1832511624 & 1.9272888059 & 6.2885339377 \\
\hline $\mathrm{O}$ & 1.1201056873 & 1.7183152079 & 14.2729780864 \\
\hline $\mathrm{O}$ & 2.3901677352 & 3.5097390058 & 7.9063486850 \\
\hline $\mathrm{O}$ & 2.3903114987 & 6.1191299628 & 7.9060056955 \\
\hline $\mathrm{O}$ & 1.1830911051 & 7.7012636994 & 6.2872415183 \\
\hline $\mathrm{O}$ & 1.3551275489 & 7.6044437410 & 14.2643655906 \\
\hline $\mathrm{O}$ & 5.2416529383 & 6.2286025548 & 4.0466100763 \\
\hline $\mathrm{O}$ & 5.1653476139 & 6.2005325710 & 12.0731417906 \\
\hline $\mathrm{O}$ & 4.0525498847 & 7.5495172831 & 10.1531765028 \\
\hline $\mathrm{O}$ & 4.0444097512 & 2.0159260043 & 10.1517855455 \\
\hline $\mathrm{O}$ & 5.2455211289 & 3.4179162965 & 4.0497741685 \\
\hline $\mathrm{O}$ & 5.0834091681 & 3.4219851634 & 12.0028290872 \\
\hline $\mathrm{O}$ & 3.8155469073 & 1.9344584579 & 5.9592387691 \\
\hline $\mathrm{O}$ & 3.5784820646 & 2.0921172782 & 13.8713955990 \\
\hline $\mathrm{O}$ & 5.4730540713 & 3.4989643311 & 8.2355533210 \\
\hline $\mathrm{O}$ & 5.4715586305 & 6.1216063524 & 8.2313244988 \\
\hline $\mathrm{O}$ & 3.8155998759 & 7.6980489933 & 5.9584174859 \\
\hline $\mathrm{O}$ & 4.0443477545 & 7.9069234692 & 14.0175604690 \\
\hline $\mathrm{O}$ & 2.6086366801 & 6.2210762894 & 4.2010918784 \\
\hline $\mathrm{O}$ & 2.5336378848 & 6.2200256898 & 12.0870634923 \\
\hline $\mathrm{O}$ & 0.9649384476 & 7.5879111351 & 9.9953512273 \\
\hline $\mathrm{O}$ & 0.9612721939 & 2.0265386175 & 9.9898874597 \\
\hline $\mathrm{O}$ & 2.6082641716 & 3.4154488558 & 4.1990589774 \\
\hline $\mathrm{O}$ & 2.3875707971 & 3.3471347258 & 12.0069747271 \\
\hline $\mathrm{O}$ & 6.8313420590 & 4.8148816322 & 6.1019818179 \\
\hline $\mathrm{O}$ & 6.5899769627 & 4.6587794979 & 14.0222799324 \\
\hline $\mathrm{O}$ & 8.1760297331 & 0.6163158614 & 8.1307842001 \\
\hline $\mathrm{O}$ & 11.0337741904 & 0.6272088063 & 4.2691261595 \\
\hline $\mathrm{O}$ & 11.0520534668 & 0.6153361383 & 12.1492508841 \\
\hline $\mathrm{O}$ & 9.6903327797 & 4.8116946090 & 9.9269927551 \\
\hline $\mathrm{O}$ & 9.5529554281 & 4.8156143704 & 6.2167181023 \\
\hline $\mathrm{O}$ & 9.1521837403 & 4.7487404044 & 14.1056286238 \\
\hline $\mathrm{O}$ & 11.1762532199 & 0.6173397070 & 7.9754838278 \\
\hline $\mathrm{O}$ & 8.2941243159 & 0.6276552470 & 4.1279174817 \\
\hline $\mathrm{O}$ & 8.3261031387 & 0.5540600672 & 12.0223053043 \\
\hline $\mathrm{O}$ & 6.6699171609 & 4.8128814098 & 10.0702984338 \\
\hline
\end{tabular}




\begin{tabular}{|c|c|c|c|}
\hline $\mathrm{O}$ & 6.9020499173 & 1.9267131881 & 6.2887341730 \\
\hline $\mathrm{O}$ & 6.8312371381 & 1.7171311438 & 14.2685771463 \\
\hline $\mathrm{O}$ & 8.1094024580 & 3.5090161672 & 7.9062654818 \\
\hline $\mathrm{O}$ & 8.1098783182 & 6.1173942290 & 7.9052973590 \\
\hline $\mathrm{O}$ & 6.9019911059 & 7.7004885522 & 6.2873106263 \\
\hline $\mathrm{O}$ & 7.0544669570 & 7.6206845804 & 14.1905466364 \\
\hline $\mathrm{O}$ & 10.9606439670 & 6.2286103777 & 4.0465704399 \\
\hline $\mathrm{O}$ & 10.8908427732 & 6.2017651183 & 12.0691950417 \\
\hline $\mathrm{O}$ & 9.7713558157 & 7.5502401180 & 10.1564351537 \\
\hline $\mathrm{O}$ & 9.7647830248 & 2.0132423757 & 10.1533926672 \\
\hline $\mathrm{O}$ & 10.9645829464 & 3.4178652866 & 4.0498370222 \\
\hline $\mathrm{O}$ & 10.8066483422 & 3.4151827613 & 11.9922125989 \\
\hline $\mathrm{O}$ & 9.5342435954 & 1.9343727470 & 5.9591522420 \\
\hline $\mathrm{O}$ & 9.2894909760 & 2.0866740928 & 13.8716145542 \\
\hline $\mathrm{O}$ & 11.1913901926 & 3.5002561621 & 8.2344021711 \\
\hline $\mathrm{O}$ & 11.1918584236 & 6.1245570187 & 8.2323516855 \\
\hline $\mathrm{O}$ & 9.5344354911 & 7.6979084217 & 5.9583856631 \\
\hline $\mathrm{O}$ & 9.7659289872 & 7.9040444533 & 14.0199679122 \\
\hline $\mathrm{O}$ & 8.3277413326 & 6.2209533591 & 4.2009085606 \\
\hline $\mathrm{O}$ & 8.2552319681 & 6.2161373393 & 12.1019222775 \\
\hline $\mathrm{O}$ & 6.6936793793 & 7.5565405992 & 9.9964378166 \\
\hline $\mathrm{O}$ & 6.6809841188 & 2.0219933495 & 9.9898577552 \\
\hline $\mathrm{O}$ & 8.3272411651 & 3.4154214336 & 4.1990550889 \\
\hline $\mathrm{O}$ & 8.1064175839 & 3.3442215937 & 12.0034424120 \\
\hline $\mathrm{Al}$ & 4.0016984924 & 4.8494558360 & 0.1881204024 \\
\hline $\mathrm{Al}$ & 1.1216101616 & 4.8494558360 & 0.1910220024 \\
\hline $\mathrm{Al}$ & 4.0313229574 & 0.6565399149 & 1.1792585907 \\
\hline $\mathrm{Al}$ & 5.4354519867 & 6.3262305222 & 2.2424531074 \\
\hline $\mathrm{Al}$ & 5.4354519867 & 3.3726811415 & 2.2424531074 \\
\hline $\mathrm{Al}$ & 1.1778852918 & 2.0939841284 & 0.2744430035 \\
\hline $\mathrm{Al}$ & 1.1778852918 & 7.6050114624 & 0.2744430035 \\
\hline $\mathrm{Al}$ & 9.7206983550 & 4.8494558360 & 0.1881204024 \\
\hline $\mathrm{Al}$ & 6.8406100242 & 4.8494558360 & 0.1910220024 \\
\hline $\mathrm{Al}$ & 9.7503233005 & 0.6565399149 & 1.1792585907 \\
\hline $\mathrm{Al}$ & 11.1544513690 & 6.3262305222 & 2.2424531074 \\
\hline $\mathrm{Al}$ & 11.1544513690 & 3.3726811415 & 2.2424531074 \\
\hline $\mathrm{Al}$ & 6.8968853946 & 2.0939841284 & 0.2744430035 \\
\hline $\mathrm{Al}$ & 6.8968853946 & 7.6050114624 & 0.2744430035 \\
\hline $\mathrm{O}$ & 2.5098402454 & 0.6565399149 & 0.1958580025 \\
\hline $\mathrm{O}$ & 4.0199995093 & 4.8494558360 & 2.0059728737 \\
\hline $\mathrm{O}$ & 5.4763998999 & 0.6565399149 & 0.0309504004 \\
\hline $\mathrm{O}$ & 1.0554986032 & 4.8494558360 & 2.1604831240 \\
\hline $\mathrm{O}$ & 2.4477319755 & 3.5443427562 & 0.0000000000 \\
\hline $\mathrm{O}$ & 2.4477319755 & 6.1544852236 & 0.0000000000 \\
\hline $\mathrm{O}$ & 4.0872550048 & 7.6360397366 & 2.2351992040 \\
\hline $\mathrm{O}$ & 4.0872550048 & 2.0629560973 & 2.2351992040 \\
\hline
\end{tabular}




$\begin{array}{lccc}\mathrm{O} & 5.5334754042 & 3.5420784944 & 0.3508518044 \\ \mathrm{O} & 5.5334754042 & 6.1567497286 & 0.3508518044 \\ \mathrm{O} & 0.9989948846 & 7.6460189840 & 2.0710170261 \\ \mathrm{O} & 0.9989948846 & 2.0529766067 & 2.0710170261 \\ \mathrm{O} & 8.2288408287 & 0.6565399149 & 0.1958580025 \\ \mathrm{O} & 9.7389993719 & 4.8494558360 & 2.0059728737 \\ \mathrm{O} & 11.1953992822 & 0.6565399149 & 0.0309504004 \\ \mathrm{O} & 6.7744979855 & 4.8494558360 & 2.1604831240 \\ \mathrm{O} & 8.1667318382 & 3.5443427562 & 0.0000000000 \\ \mathrm{O} & 8.1667318382 & 6.1544852236 & 0.0000000000 \\ \mathrm{O} & 9.8062543871 & 7.6360397366 & 2.2351992040 \\ \mathrm{O} & 9.8062543871 & 2.0629560973 & 2.2351992040 \\ \mathrm{O} & 11.2524757358 & 3.5420784944 & 0.3508518044 \\ \mathrm{O} & 11.2524757358 & 6.1567497286 & 0.3508518044 \\ \mathrm{O} & 6.7179946900 & 7.6460189840 & 2.0710170261 \\ \mathrm{O} & 6.7179946900 & 2.0529766067 & 2.0710170261\end{array}$

\section{A.4 Input File (Example HOMO-LUMO gap of gas phase Au)}

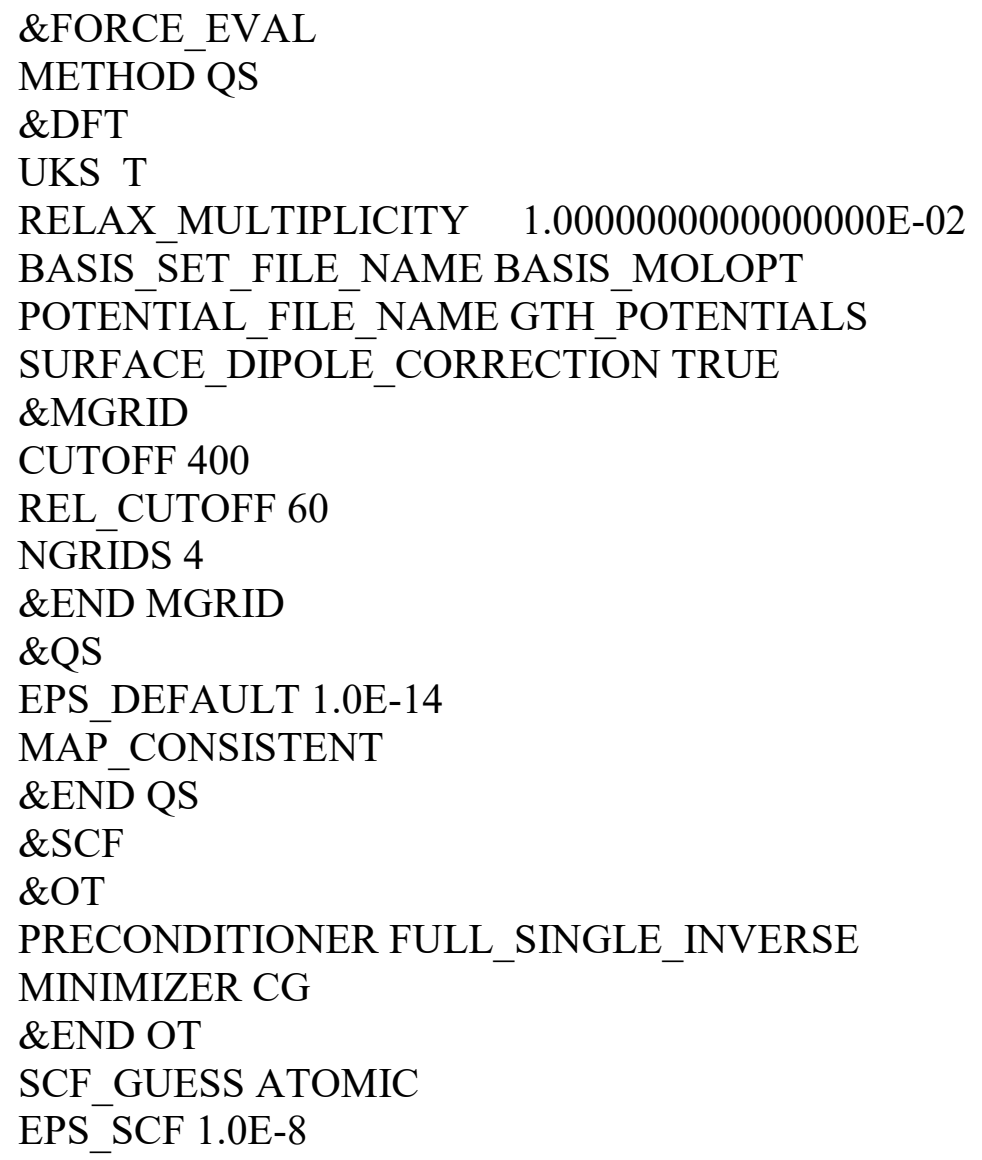




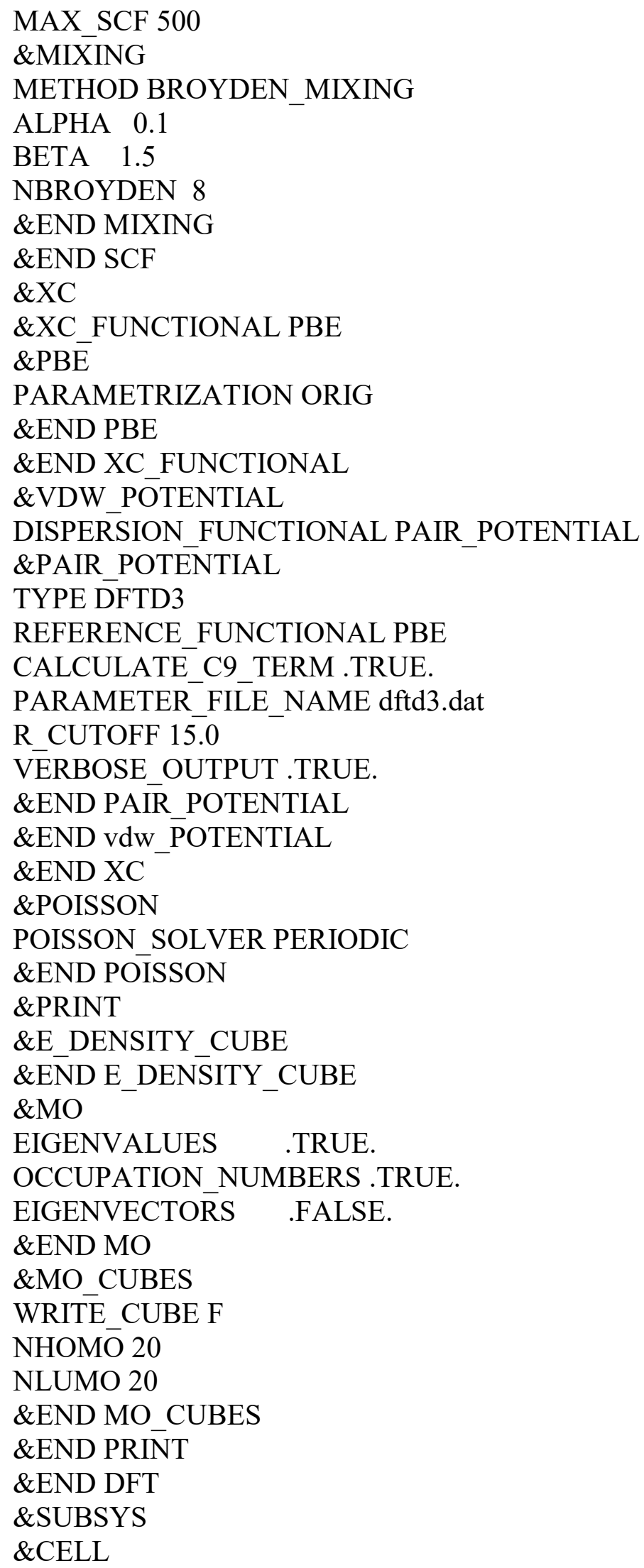




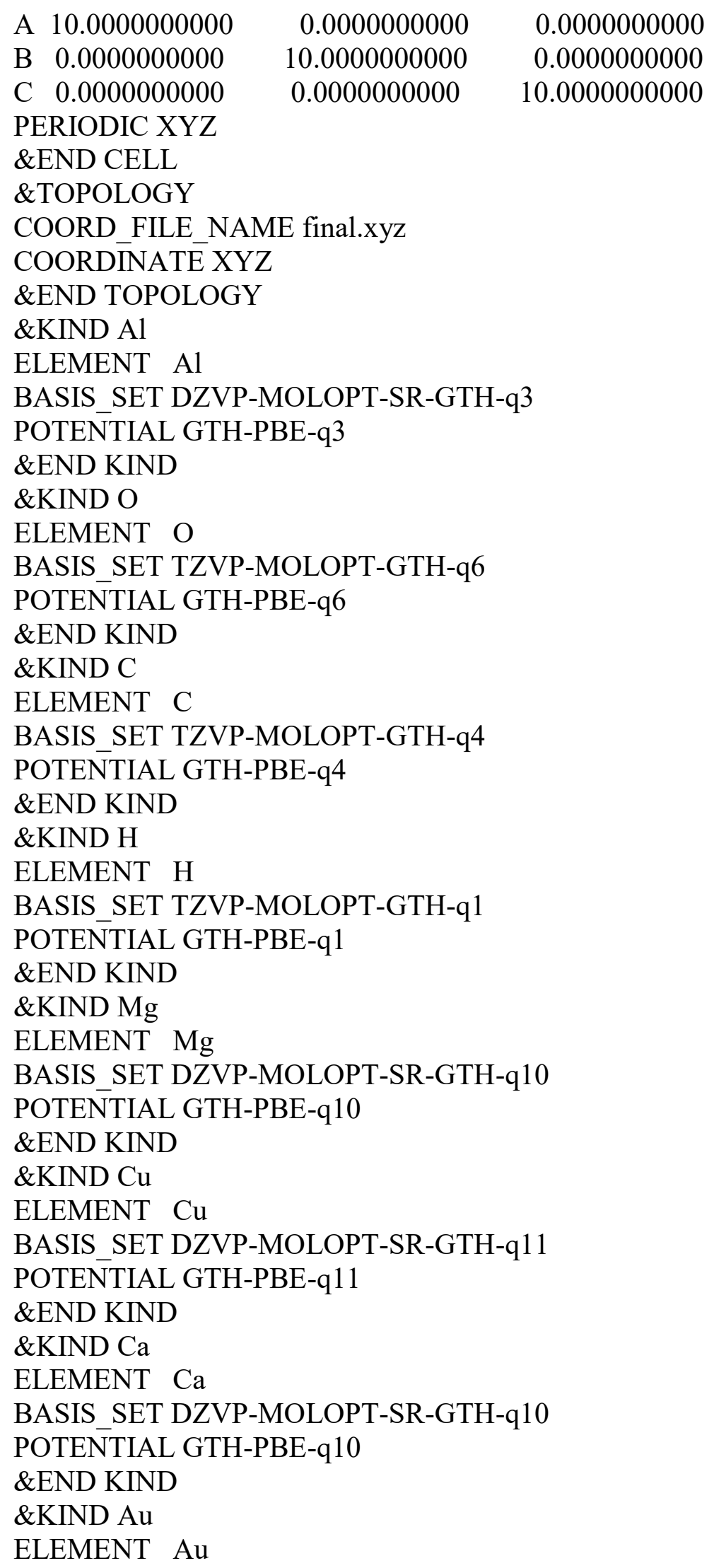




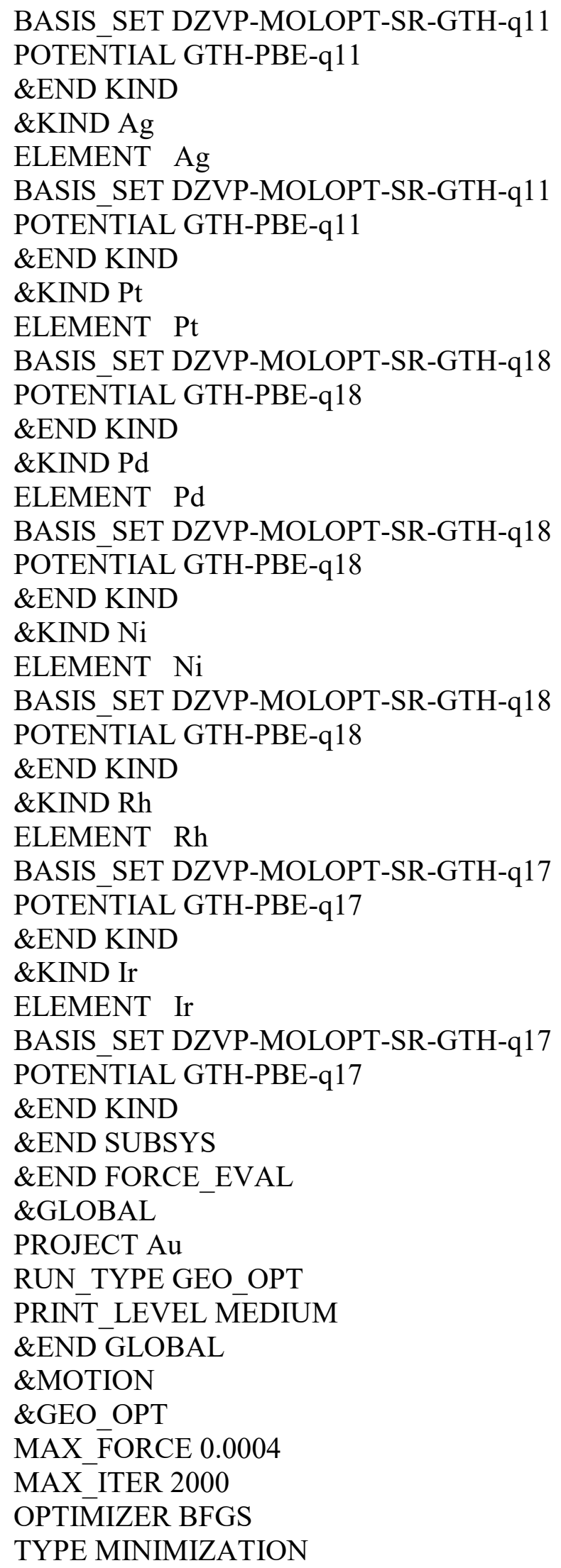


\&END GEO OPT

\&END MOTION 


\section{Appendix B Supporting Figures}

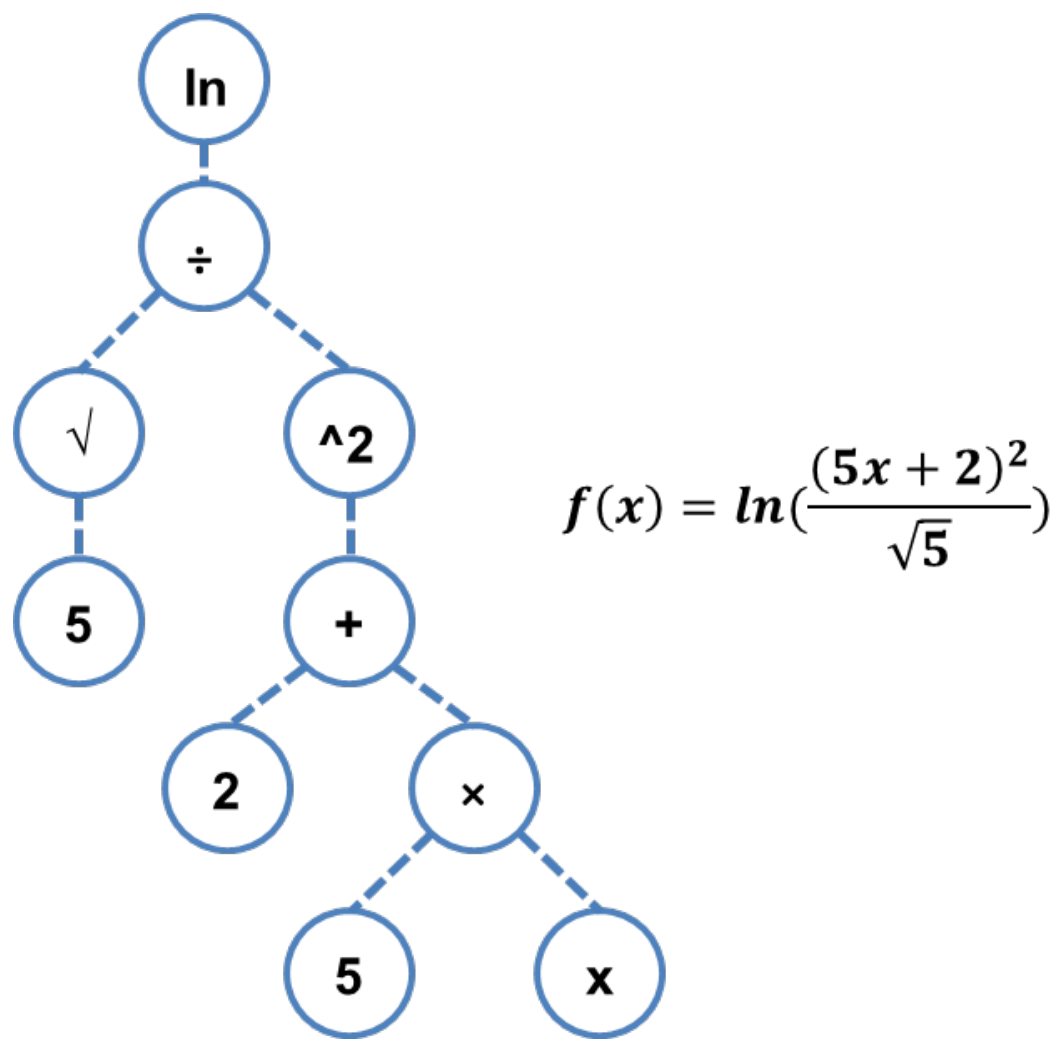

Figure S1 An equation generated randomly by symbolic regression. 


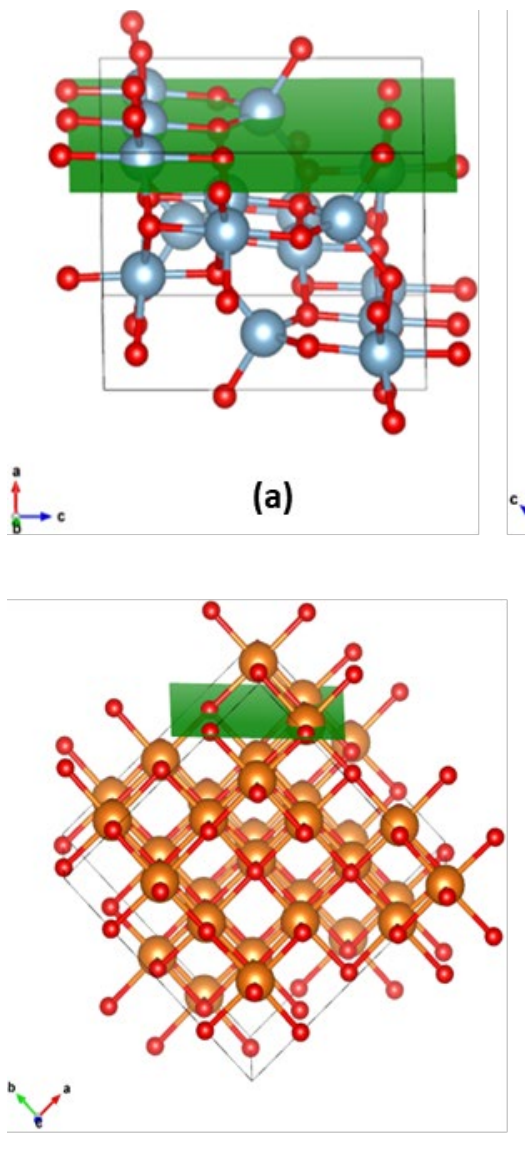

(c)

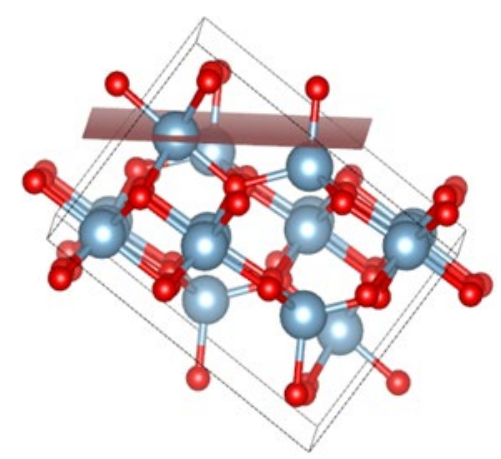

(b)

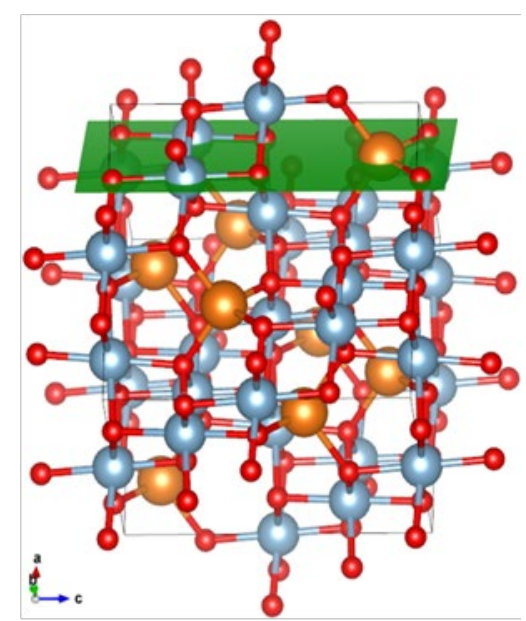

(d)

Figure S2 Structures of surface facets which are not the most stable ones: (a) $\gamma-\mathrm{Al}_{2} \mathrm{O}_{3}$ (110), (b) $\gamma-\mathrm{Al}_{2} \mathrm{O}_{3}(111)$, (c) $\mathrm{MgO}$ (110), and (d) $\mathrm{MgAl}_{2} \mathrm{O}_{4}$ (110). The surface cleaving plane is highlighted in green and brown. Orange atoms represent $\mathrm{Mg}$, grey atoms represent $\mathrm{Al}$, and red atoms represent $\mathrm{O}$. 


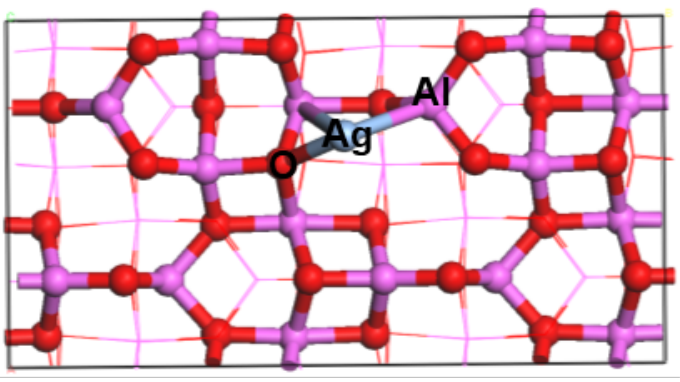

(a)

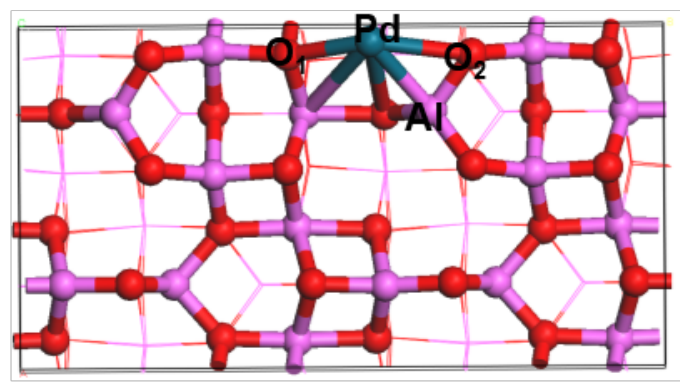

(c)

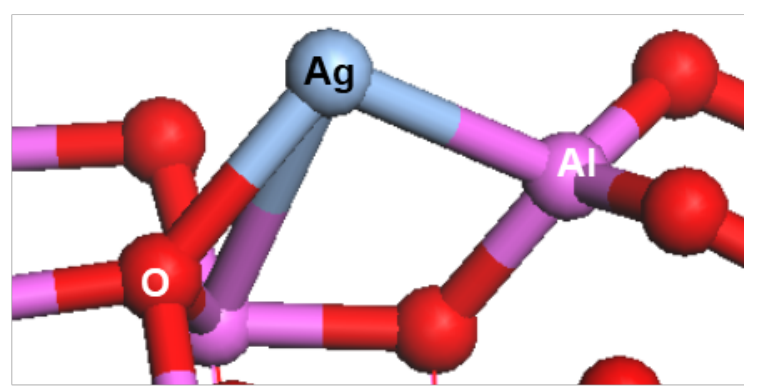

(b)

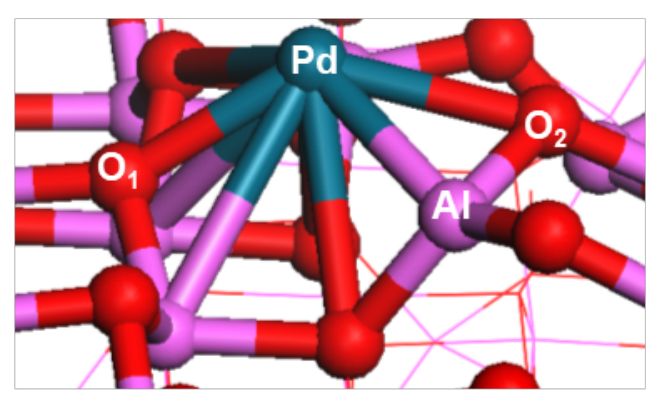

(d)

Figure $\mathrm{S} 3 \mathrm{Ag}$ adsorption on $\gamma-\mathrm{Al}_{2} \mathrm{O}_{3}$ (110) in (a) top view, (b) side view; Pd adsorption on $\gamma-\mathrm{Al}_{2} \mathrm{O}_{3}$ (110) in (a) top view, (b) side view. Grey atoms represent $\mathrm{Ag}$, blue atoms represent $\mathrm{Pd}$, pink atoms represent $\mathrm{Al}$, and red atoms represent $O$. 


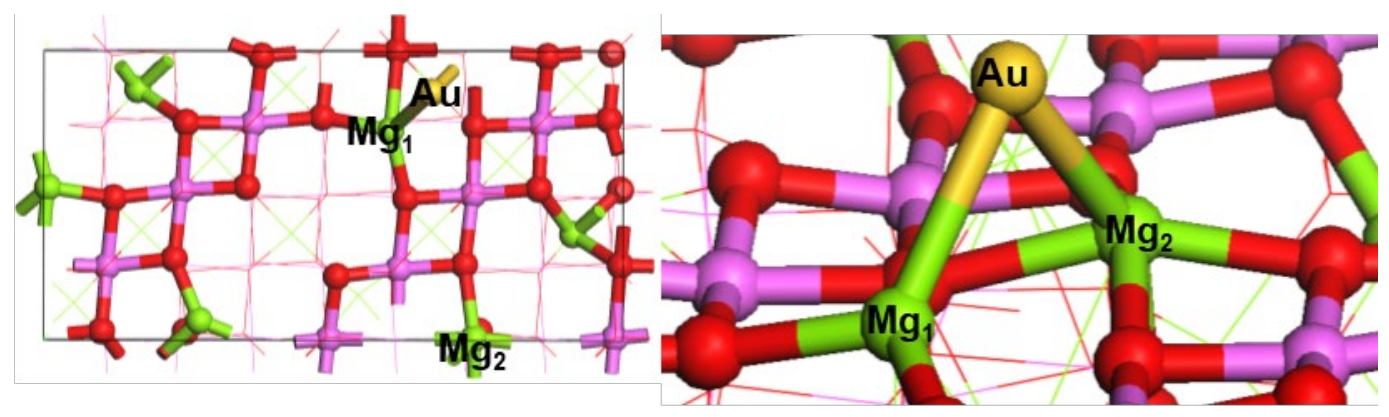

(a)

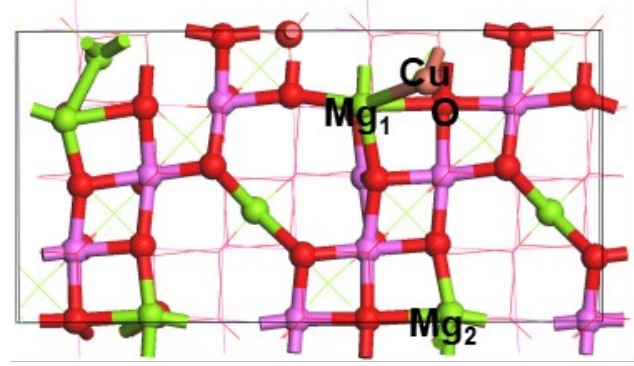

(c) (b)

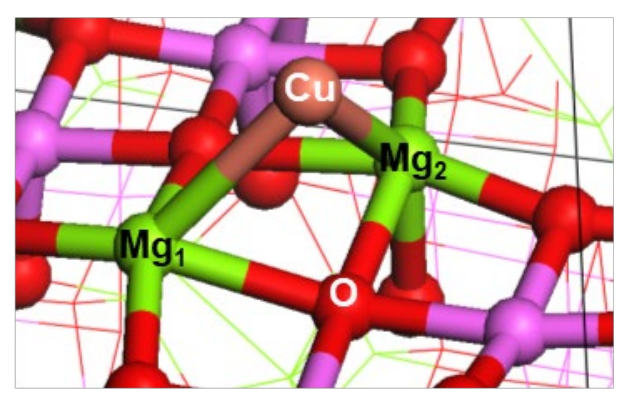

(d)

Figure $\mathrm{S} 4 \mathrm{Au}$ adsorption on $\mathrm{MgAl}_{2} \mathrm{O}_{4}$ (100) in (a) top view, (b) side view; $\mathrm{Cu}$ adsorption on $\mathrm{MgAl}_{2} \mathrm{O}_{4}(100)$ in (c) top view, (d) side view. Yellow atoms represent $\mathrm{Au}$, copper atoms represent $\mathrm{Cu}$, green atoms represent $\mathrm{Mg}$, pink atoms represent $\mathrm{Al}$, and red atoms represent $\mathrm{O}$. 

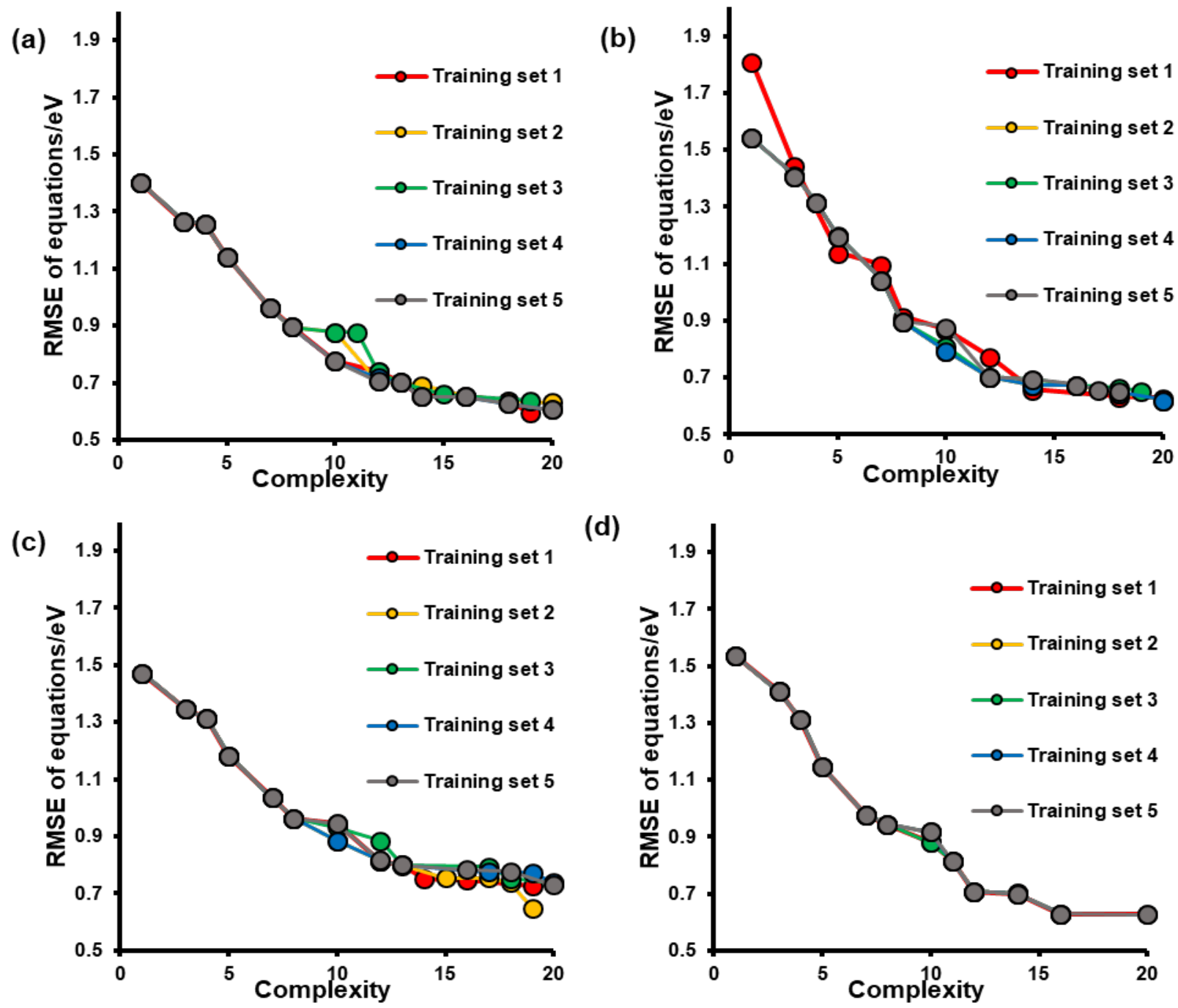

(d)

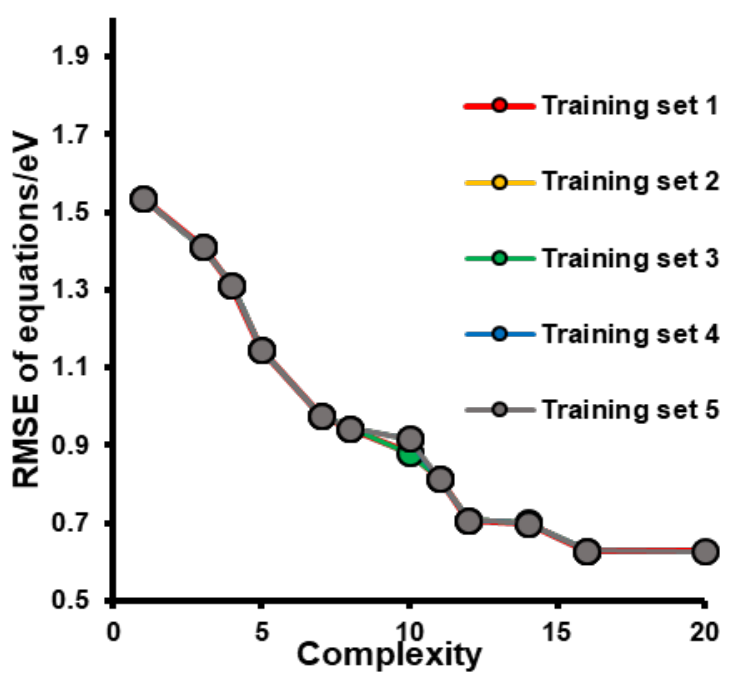

(e)

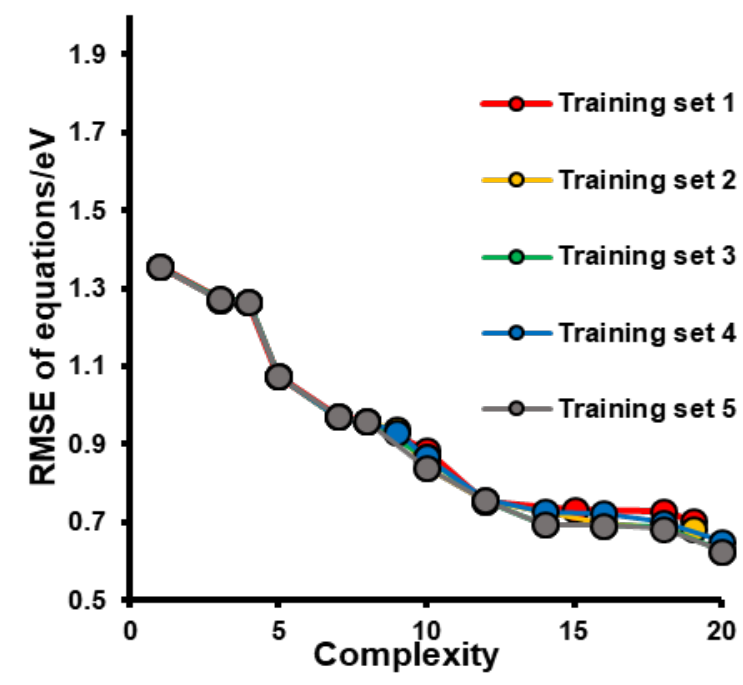

Figure S5 RMSE versus complexity of equations generated in Eureqa by training data of (a) dataset 1, (b) dataset 2, (c) dataset 3, (d) dataset 4, and (e) dataset 5. 


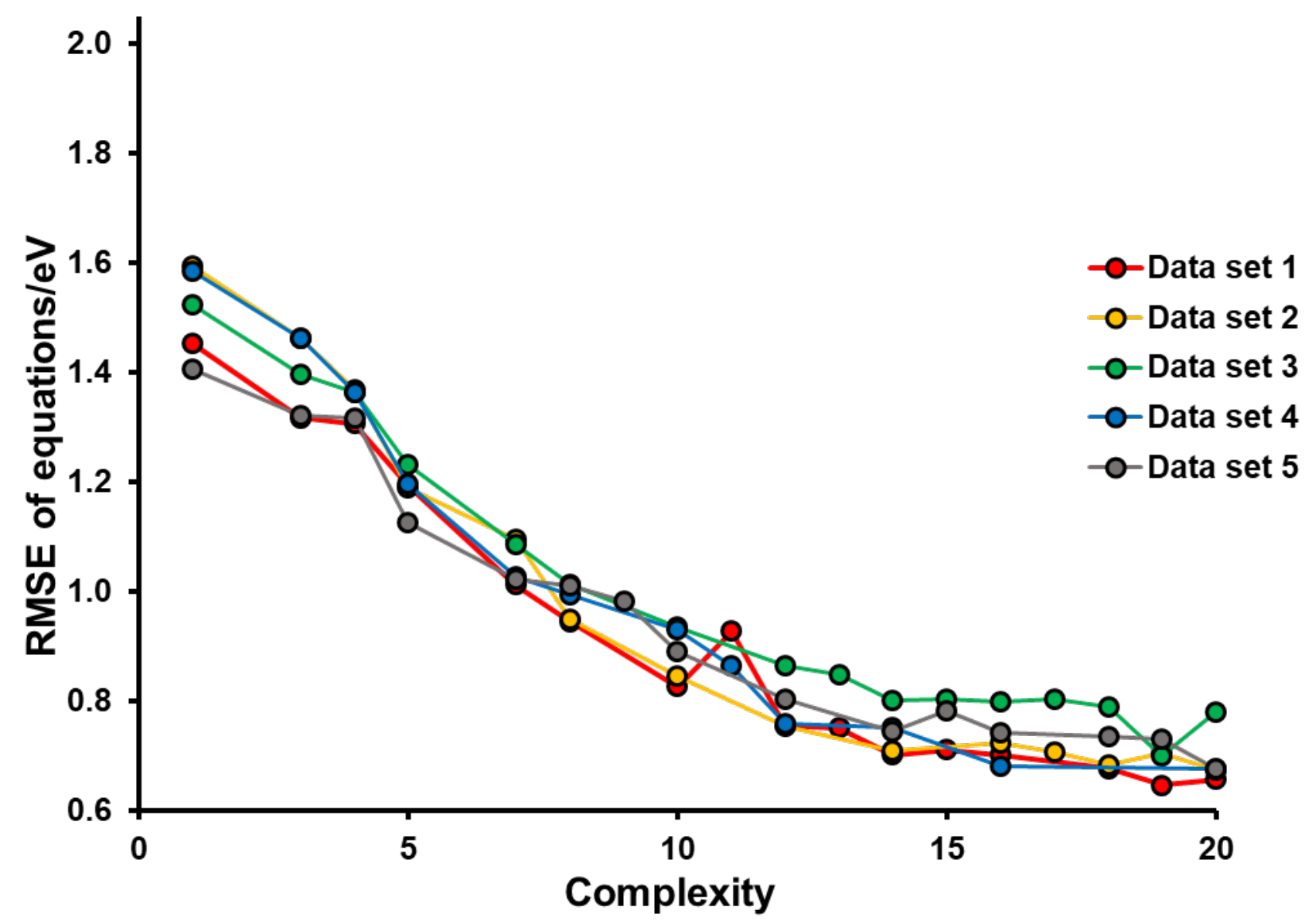

Figure S6 Pareto Front plotted by using the lowest RMSE error in each dataset for a particular complexity. 


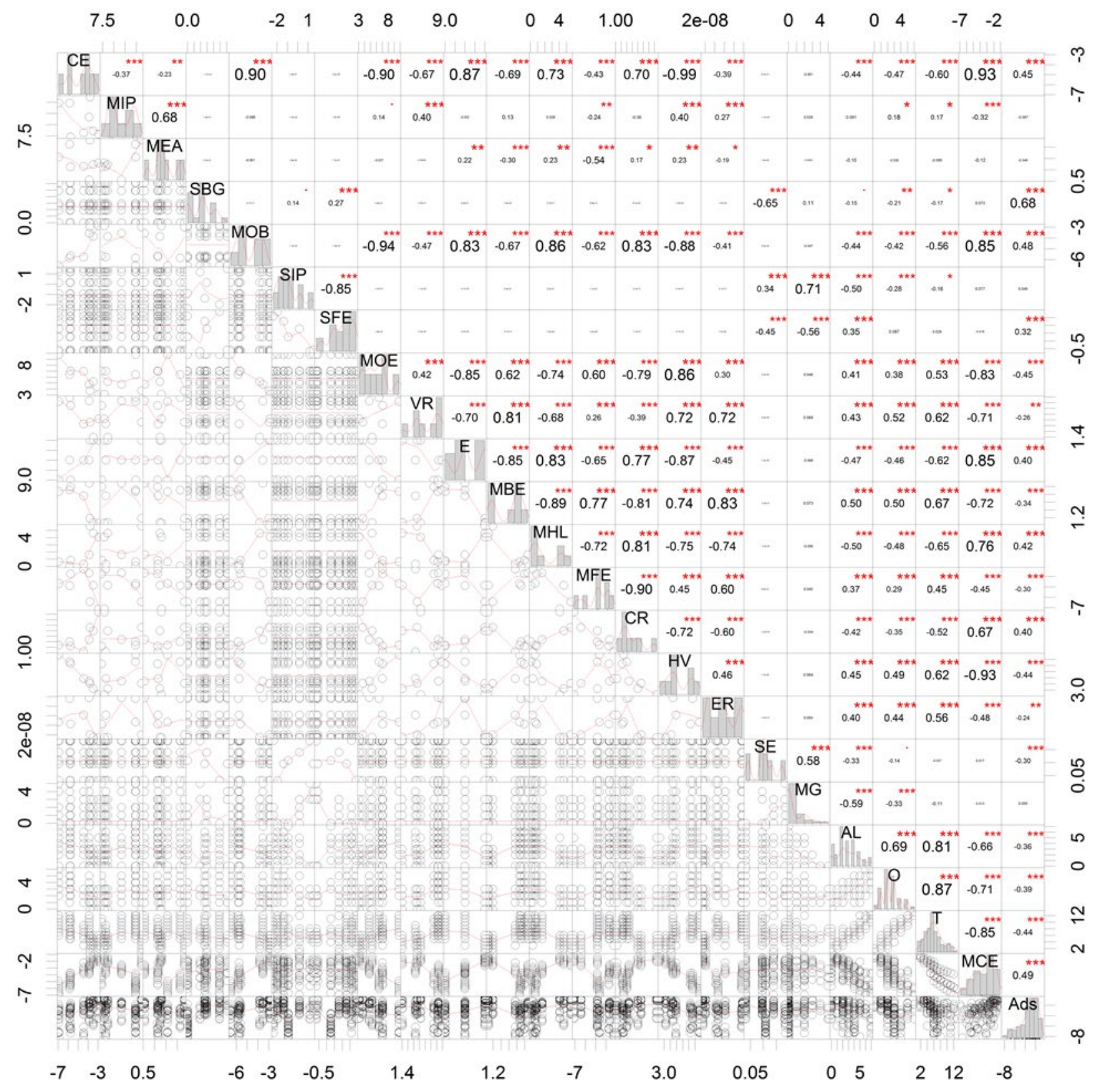

Figure S7 Correlation Matrix of physical properties indicated by Eureqa. Along the diagonal are histograms of the selected descriptors. Correlation coefficients between the different descriptors are plotted in the upper right triangle, with a font chosen to convey their magnitude (e.g. the best correlations are the largest, near-zero correlations are written with a tiny font). Plots of the two descriptors versus one another are in the lower left triangle. As an example, the correlation coefficient between MOB and MOE is $-\mathbf{0 . 9 4}$, and their plot can be found on the leftmost column, three squares up from the bottom. 


\section{Appendix C Supporting Tables}

Table S1 Cell configurations, layers, and lattice constants used in optimizing the surface facets.

\begin{tabular}{|c|c|c|c|c|c|}
\hline \multirow{2}{*}{$\begin{array}{c}\text { Surface } \\
\text { facet }\end{array}$} & \multirow[t]{2}{*}{ Clean cell } & \multirow[t]{2}{*}{ Layers } & \multicolumn{3}{|c|}{ Lattice constant/ $\AA$} \\
\hline & & & $\mathrm{a}$ & $\mathrm{b}$ & $\mathrm{c}$ \\
\hline $\begin{array}{c}\gamma-\mathrm{Al}_{2} \mathrm{O}_{3} \\
(100)\end{array}$ & $\mathrm{Al}_{64} \mathrm{O}_{96}$ & 14 & 11.438 & 8.386 & 24.180 \\
\hline $\begin{array}{c}\gamma-\mathrm{Al}_{2} \mathrm{O}_{3} \\
(110)\end{array}$ & $\mathrm{Al}_{64} \mathrm{O}_{96}$ & 8 & 8.386 & 15.795 & 20.256 \\
\hline $\begin{array}{c}\gamma-\mathrm{Al}_{2} \mathrm{O}_{3} \\
(111)\end{array}$ & $\mathrm{Al}_{64} \mathrm{O}_{96}$ & 12 & 9.798 & 16.772 & 18.638 \\
\hline $\mathrm{MgO}(100)$ & $\mathrm{Mg}_{32} \mathrm{O}_{32}$ & 4 & 8.748 & 8.717 & 21.647 \\
\hline $\mathrm{MgO}(110)$ & $\mathrm{Mg}_{32} \mathrm{O}_{32}$ & 4 & 8.717 & 12.362 & 19.759 \\
\hline $\begin{array}{c}\mathrm{MgAl}_{2} \mathrm{O}_{4} \\
(100)\end{array}$ & $\mathrm{Mg}_{16} \mathrm{Al}_{32} \mathrm{O}_{64}$ & 8 & 16.424 & 8.212 & 17.300 \\
\hline $\begin{array}{c}\mathrm{MgAl}_{2} \mathrm{O}_{4} \\
(110)\end{array}$ & $\mathrm{Mg}_{16} \mathrm{Al}_{32} \mathrm{O}_{64}$ & 8 & 8.212 & 11.614 & 20.323 \\
\hline
\end{tabular}

Table S2 Valence electron configurations of supported metals ${ }^{74}$.

\begin{tabular}{|c|c|}
\hline Metal & Valence configuration \\
\hline $\mathrm{Au}$ & {$[\mathrm{Xe}] 4 \mathrm{f}^{14} 5 \mathrm{~d}^{10} 6 \mathrm{~s}$} \\
\hline $\mathrm{Cu}$ & {$[\mathrm{Ar}] 3 \mathrm{~d}^{10} 4 \mathrm{~s}$} \\
\hline $\mathrm{Ag}$ & {$[\mathrm{Kr}] 4 \mathrm{~d}^{10} 5 \mathrm{~s}$} \\
\hline $\mathrm{Pt}$ & {$[\mathrm{Xe}] 4 \mathrm{f}^{14} 5 \mathrm{~d}^{9} 6 \mathrm{~s}$} \\
\hline $\mathrm{Pd}$ & {$[\mathrm{Kr}] 4 \mathrm{~d}^{10}$} \\
\hline $\mathrm{Ni}$ & {$[\mathrm{Ar}] 3 \mathrm{~d}^{8} 4 \mathrm{~s}^{2}$} \\
\hline $\mathrm{Rh}$ & {$[\mathrm{Kr}] 4 \mathrm{~d}^{8} 5 \mathrm{~s}$} \\
\hline $\mathrm{Ir}$ & {$[\mathrm{Xe}] 4 \mathrm{f}^{14} 5 \mathrm{~d}^{7} 6 \mathrm{~s}^{2}$} \\
\hline
\end{tabular}


Table S3a Physical properties of supported metal from literature.

\begin{tabular}{|c|c|c|c|c|c|}
\hline Metal & $\begin{array}{c}\text { Experimental } \\
\text { bulk cohesive } \\
\text { energy of } \\
\text { supported } \\
\text { metal/eV }\end{array}$ & $\begin{array}{c}\text { Experimental } \\
\text { ionization } \\
\text { potential of } \\
\text { supported } \\
\text { metal/eV }\end{array}$ & $\begin{array}{c}\text { Experimental } \\
\text { electron affinity } \\
\text { of supported } \\
\text { metal/eV }\end{array}$ & $\begin{array}{c}\text { Oxidation } \\
\text { enthalpy of } \\
\text { supported } \\
\text { metal/eV }\end{array}$ & $\begin{array}{c}\text { Van del } \\
\text { Waal radius } \\
\text { of supported } \\
\text { metal/ } \AA^{75-76}\end{array}$ \\
\hline $\mathrm{Au}$ & -3.81 & 9.2255 & 2.30863 & 3.7116 & 1.66 \\
\hline $\mathrm{Cu}$ & -3.49 & 7.7264 & 1.235 & 5.2522 & 1.4 \\
\hline $\mathrm{Ag}$ & -2.95 & 7.5762 & 1.302 & 3.1113 & 1.72 \\
\hline $\mathrm{Pt}$ & -5.84 & 8.9588 & 2.128 & 6.4227 & 2.09 \\
\hline $\mathrm{Pd}$ & -3.89 & 8.3369 & 0.562 & 4.792 & 2.03 \\
\hline $\mathrm{Ni}$ & -4.44 & 7.6398 & 1.156 & 7.003 & 1.63 \\
\hline $\mathrm{Rh}$ & -5.75 & 7.4589 & 1.137 & 7.063 & 1.95 \\
\hline $\mathrm{Ir}$ & -6.94 & 8.967 & 1.5638 & 9.8041 & 2.02 \\
\hline
\end{tabular}


Table S3b Physical properties of supported metal from literature (continued).

\begin{tabular}{|c|c|c|c|c|c|}
\hline Metal & $\begin{array}{c}\text { Electron } \\
\text { configuration } \\
\text { of supported } \\
\text { metal/(e/atom) } \\
74\end{array}$ & $\begin{array}{c}\text { Martynov- } \\
\text { Batsanov } \\
\text { electronegativit } \\
\text { y of supported } \\
\text { metal }^{19}\end{array}$ & $\begin{array}{l}\text { Covalent radius } \\
\text { of triple bond of } \\
\text { supported } \\
\text { metal } / \AA^{77}\end{array}$ & $\begin{array}{c}\text { Heat of } \\
\text { vaporization of } \\
\text { supported } \\
\text { metal } /(\mathrm{eV} / \text { atom })^{78}\end{array}$ & $\begin{array}{c}\text { Electronical } \\
\text { resistivity of } \\
\text { supported metal } \\
(273 \mathrm{~K}) / \Omega^{*} \mathrm{~m}^{74}\end{array}$ \\
\hline $\mathrm{Au}$ & 11 & 1.19 & 1.23 & 3.5568 & $2.05 \mathrm{E}-08$ \\
\hline $\mathrm{Cu}$ & 11 & 1.08 & 1.2 & 3.12416 & $1.54 \mathrm{E}-08$ \\
\hline $\mathrm{Ag}$ & 11 & 1.07 & 1.37 & 2.6416 & $1.47 \mathrm{E}-08$ \\
\hline $\mathrm{Pt}$ & 10 & 1.91 & 1.1 & 5.304 & $9.60 \mathrm{E}-08$ \\
\hline $\mathrm{Pd}$ & 10 & 2.08 & 1.12 & 3.7232 & $9.78 \mathrm{E}-08$ \\
\hline $\mathrm{Ni}$ & 10 & 1.76 & 1.01 & 3.9416 & $6.16 \mathrm{E}-08$ \\
\hline $\mathrm{Rh}$ & 9 & 1.99 & 1.06 & 5.1376 & $4.30 \mathrm{E}-08$ \\
\hline Ir & 9 & 1.87 & 1.07 & 5.8656 & $4.70 \mathrm{E}-08$ \\
\hline
\end{tabular}


Table S3c The metal-oxygen binding energy of supported metal calculated by CP2K program package ${ }^{46}$.

\begin{tabular}{|c|c|c|c|c|c|}
\hline Metal & $\mathrm{E}_{\mathrm{M}} / \mathrm{eV}$ & $\mathrm{E}_{\mathrm{O}} / \mathrm{eV}$ & $\mathrm{E}_{\mathrm{M}+\mathrm{O}} / \mathrm{eV}$ & $\mathrm{E}_{\mathrm{M}-\mathrm{O}} / \mathrm{eV}$ & $\begin{array}{c}\text { Spin-state } \\
\text { of the } \\
\text { metal- } \\
\text { oxygen } \\
\text { complex }\end{array}$ \\
\hline $\mathrm{Au}$ & -901.8916943 & \multirow{8}{*}{-430.9313623} & -1335.787958 & -2.964901042 & 0 \\
\hline $\mathrm{Cu}$ & -1306.121609 & & -1740.886622 & -3.833651054 & 0 \\
\hline $\mathrm{Ag}$ & -1005.078453 & & -1438.869247 & -2.859431633 & 0 \\
\hline $\mathrm{Pt}$ & -3264.330644 & & -3701.097346 & -5.835339304 & 3 \\
\hline $\mathrm{Pd}$ & -3459.111873 & & -3893.593769 & -3.550533389 & 3 \\
\hline $\mathrm{Ni}$ & -4601.989526 & & -5038.670081 & -5.749192419 & 3 \\
\hline $\mathrm{Rh}$ & -2997.570383 & & -3434.134719 & -5.632973714 & 4 \\
\hline Ir & -2862.277935 & & -3299.759153 & -6.549855499 & 4 \\
\hline
\end{tabular}

$\mathrm{E}_{\mathrm{M}}$ is energy of gas phase supported metal atom

Eo is energy of gas phase oxygen atom

$\mathrm{E}_{\mathrm{M}+\mathrm{O}}$ is energy of supported metal atom coordinate with oxygen

$\mathrm{E}_{\mathrm{M}-\mathrm{O}}$ is metal-oxygen binding energy of supported metal atom 
Table S3d Physical properties of supported metal calculated by CP2K program package ${ }^{46}$.

\begin{tabular}{|c|c|c|}
\hline Metal & $\begin{array}{c}\text { HOMO-LUMO gap of supported } \\
\text { metal/eV }\end{array}$ & $\begin{array}{c}\text { Fermi energy of supported } \\
\text { metal/eV }\end{array}$ \\
\hline $\mathrm{Au}$ & 5.599745 & -6.419821 \\
\hline $\mathrm{Cu}$ & 4.621396 & -4.839916 \\
\hline $\mathrm{Ag}$ & 4.084015 & -7.102894 \\
\hline $\mathrm{Pt}$ & 0.065967 & -4.866576 \\
\hline $\mathrm{Pd}$ & 1.620239 & -3.663211 \\
\hline $\mathrm{Ni}$ & 0.315045 & -3.279004 \\
\hline $\mathrm{Rh}$ & 0.853019 & -3.74123 \\
\hline $\mathrm{Ir}$ & 0.636881 & -4.657139 \\
\hline
\end{tabular}


Table S3e Ionization potential of oxide support calculated by CP2K program package ${ }^{46}$.

\begin{tabular}{|c|c|c|c|}
\hline Surface facet & $E\left(\mathrm{Slab}^{+}\right) /$a.u. & $\mathrm{E}(\mathrm{Slab}) /$ a.u. & $\mathrm{IP}_{\mathrm{s}} / \mathrm{eV}$ \\
\hline$\gamma-\mathrm{Al}_{2} \mathrm{O}_{3}(100)$ & -1682.657456 & -1682.585509 & -1.957754172 \\
\hline$\gamma-\mathrm{Al}_{2} \mathrm{O}_{3}(100)$ & -1681.948752 & -1681.898416 & -1.369709954 \\
\hline$\gamma-\mathrm{Al}_{2} \mathrm{O}_{3}(100)$ & -1681.567472 & -1681.533834 & -0.915306751 \\
\hline $\mathrm{MgO}(100)$ & -2542.204887 & -2542.259826 & 1.49493741 \\
\hline $\mathrm{MgO}(110)$ & -2541.336647 & -2541.380045 & 1.180909141 \\
\hline $\mathrm{MgAl}_{2} \mathrm{O}_{4}(100)$ & -2112.106077 & -2112.11214 & 0.164967487 \\
\hline $\mathrm{MgAl}_{2} \mathrm{O}_{4}(110)$ & -2112.283381 & -2112.196836 & -2.354990392 \\
\hline
\end{tabular}

$$
\mathrm{IP}_{\mathrm{s}}=\mathrm{E}\left(\mathrm{Slab}^{+}\right)-\mathrm{E}(\mathrm{Slab})
$$

$\mathrm{IP}_{\mathrm{s}}$ is ionization potential of oxide support, $\mathrm{E}\left(\mathrm{Slab}^{+}\right)$is the energy of surface slab cation, and $\mathrm{E}$ (Slab) is the energy of surface slab. 
Table S3f Physical properties of oxide support calculated by CP2K program package ${ }^{46}$.

\begin{tabular}{|c|c|c|c|}
\hline Surface facet & $\begin{array}{c}\text { Band gap of oxide } \\
\text { support/eV }\end{array}$ & $\begin{array}{c}\text { Fermi energy of } \\
\text { oxide support/eV }\end{array}$ & $\begin{array}{c}\text { Calculated surface } \\
\text { energy of oxide } \\
\text { support/eV/ }\end{array}$ \\
\hline$\gamma-\mathrm{Al}_{2} \mathrm{O}_{3}(100)$ & 2.449223 & 1.884327 & 0.031522388 \\
\hline$\gamma-\mathrm{Al}_{2} \mathrm{O}_{3}(100)$ & 1.312146 & 1.268465 & 0.095494626 \\
\hline$\gamma-\mathrm{Al}_{2} \mathrm{O}_{3}(100)$ & 0 & 0.268132 & 0.108051033 \\
\hline $\mathrm{MgO}(100)$ & 3.049584 & -0.573668 & 0.095568656 \\
\hline $\mathrm{MgO}(110)$ & 0.957561 & -0.665112 & 0.181995043 \\
\hline $\mathrm{MgAl}_{2} \mathrm{O}_{4}(100)$ & 1.468544 & 0.789313 & 0.139333601 \\
\hline $\mathrm{MgAl}_{2} \mathrm{O}_{4}(110)$ & 0.000235 & 1.597015 & 0.184607 \\
\hline
\end{tabular}


Table S4 The information of most preferred sites of supported metals on different surface facets (Unit for distances is $\AA$ ).

$\gamma-\mathrm{Al}_{2} \mathrm{O}_{3}$ (100), supported metal in hollow site between two oxygens

\begin{tabular}{|c|c|c|r|r|}
\hline Metal & M-O ${ }_{1}$ distance & ${\mathrm{M}-\mathrm{O}_{2} \text { distance }}^{\text {Average M-O }}$ & Adsorption energy/eV \\
distance & \\
\hline $\mathrm{Au}$ & 2.644 & 2.286 & 2.465 & -0.971765179 \\
\hline $\mathrm{Cu}$ & 2.068 & 1.959 & 2.0135 & -1.638644248 \\
\hline $\mathrm{Ag}$ & 2.543 & 2.646 & 2.5945 & -0.794451679 \\
\hline $\mathrm{Pt}$ & 2.078 & 2.038 & 2.058 & -4.62211681 \\
\hline $\mathrm{Pd}$ & 1.976 & 2.355 & 2.1655 & -2.585990582 \\
\hline $\mathrm{Ni}$ & 1.977 & 1.907 & 1.942 & -3.553911313 \\
\hline $\mathrm{Rh}$ & 1.991 & 2.346 & 2.1685 & -3.566181225 \\
\hline $\mathrm{Ir}$ & 2.055 & 2.005 & 2.03 & -4.560746808 \\
\hline
\end{tabular}

$\gamma-\mathrm{Al}_{2} \mathrm{O}_{3}$ (110), supported metal in hollow site between $\mathrm{Al}$ and $\mathrm{O}$

\begin{tabular}{|c|r|r|r|r|}
\hline Metal & M-Al distance & M-O distance & $\begin{array}{r}\text { Average M-Al, } \\
\text { M-O distance }\end{array}$ & Adsorption energy/eV \\
\hline $\mathrm{Au}$ & 2.546 & 2.357 & 2.4515 & -1.488570299 \\
\hline $\mathrm{Cu}$ & 2.545 & 1.985 & 2.265 & -1.635164761 \\
\hline $\mathrm{Ag}$ & 2.636 & 2.359 & 2.4975 & -1.180406717 \\
\hline
\end{tabular}

$\gamma-\mathrm{Al}_{2} \mathrm{O}_{3}$ (110), supported metal in hollow site

\begin{tabular}{|c|c|c|c|c|}
\hline Metal & $\mathrm{M}-\mathrm{O}_{1}$ distance & $\mathrm{M}-\mathrm{O}_{2}$ distance & $\begin{array}{c}\text { Average } \mathrm{M}-\mathrm{O} \\
\text { distance }\end{array}$ & Adsorption energy/eV \\
\hline $\mathrm{Pt}$ & 2.041 & 2.032 & 2.0365 & -3.711390283 \\
\hline $\mathrm{Pd}$ & 2.368 & 2.560 & 2.464 & -2.199992913 \\
\hline $\mathrm{Ni}$ & 1.882 & 1.819 & 1.8505 & -3.135086839 \\
\hline $\mathrm{Rh}$ & 2.053 & 1.983 & 2.018 & -2.681001727 \\
\hline $\mathrm{Ir}$ & 2.014 & 1.964 & 1.989 & -3.873928904 \\
\hline
\end{tabular}


Table S4 The information of most preferred sites of supported metals on different surface facets (Unit for distances is $\AA$ ) (continued).

$\gamma-\mathrm{Al}_{2} \mathrm{O}_{3}$ (111), supported metal in hollow site

\begin{tabular}{|c|c|c|c|c|c|}
\hline Metal & $\begin{array}{c}\mathrm{M}-\mathrm{O}_{1} \\
\text { distance }\end{array}$ & $\begin{array}{c}\mathrm{M}-\mathrm{O}_{2} \\
\text { distance }\end{array}$ & $\begin{array}{c}\mathrm{M}-\mathrm{O}_{3} \\
\text { distance }\end{array}$ & $\begin{array}{c}\text { Average M- } \\
\text { O distance }\end{array}$ & $\begin{array}{c}\text { Adsorption } \\
\text { energy/eV }\end{array}$ \\
\hline $\mathrm{Au}$ & 2.202 & 2.182 & 2.522 & 2.302 & -3.753245262 \\
\hline $\mathrm{Cu}$ & 2.01 & 1.973 & 1.873 & 1.952 & -5.962277018 \\
\hline $\mathrm{Ag}$ & 2.287 & 2.31 & 2.394 & 2.330333333 & -4.543309413 \\
\hline $\mathrm{Pt}$ & 2.093 & 1.802 & 2.219 & 1.798 & -6.348793035 \\
\hline $\mathrm{Pd}$ & 2.14 & 2.139 & 2.105 & 2.128 & -5.134024784 \\
\hline $\mathrm{Ni}$ & 1.965 & 1.935 & 1.909 & 1.936333333 & -8.043296895 \\
\hline $\mathrm{Rh}$ & 1.961 & 1.949 & 1.962 & 1.957333333 & -7.362943959 \\
\hline $\mathrm{Ir}$ & 1.945 & 1.928 & 1.936 & 1.936333333 & -8.24674053 \\
\hline
\end{tabular}

$\mathrm{MgO}$ (100), supported metal on top oxygen site

\begin{tabular}{|c|c|c|}
\hline Metal & M-O distance & Adsorption energy/eV \\
\hline $\mathrm{Au}$ & 2.281 & -1.083705048 \\
\hline $\mathrm{Cu}$ & 1.945 & -0.976707065 \\
\hline $\mathrm{Ag}$ & 2.342 & -0.684878487 \\
\hline $\mathrm{Pt}$ & 1.96 & -3.06922768 \\
\hline $\mathrm{Pd}$ & 2.061 & -1.675659784 \\
\hline $\mathrm{Ni}$ & 1.805 & -1.98155824 \\
\hline
\end{tabular}

$\mathrm{MgO}$ (100), supported metal in hollow site

\begin{tabular}{|c|c|c|c|c|}
\hline Metal & $\mathrm{M}-\mathrm{O}_{1}$ distance & $\mathrm{M}-\mathrm{O}_{2}$ distance & $\begin{array}{c}\text { Average M-O } \\
\text { distance }\end{array}$ & $\begin{array}{c}\text { Adsorption } \\
\text { energy/eV }\end{array}$ \\
\hline $\mathrm{Rh}$ & 2.472 & 2.139 & 2.3055 & -2.033494128 \\
\hline $\mathrm{Ir}$ & 2.857 & 1.997 & 2.427 & -2.563721377 \\
\hline
\end{tabular}


Table S4 The information of most preferred sites of supported metals on different surface facets (Unit for distances is $\AA$ ) (continued).

$\mathrm{MgO}$ (110), supported metal in a hollow site between two oxygens

\begin{tabular}{|c|c|c|c|c|}
\hline Metal & $\mathrm{M}-\mathrm{O}_{1}$ distance & $\mathrm{M}-\mathrm{O}_{2}$ distance & $\begin{array}{c}\text { Average M-O } \\
\text { distance }\end{array}$ & $\begin{array}{c}\text { Adsorption } \\
\text { energy/eV }\end{array}$ \\
\hline $\mathrm{Au}$ & 2.412 & 2.445 & 2.4285 & -2.096405264 \\
\hline $\mathrm{Cu}$ & 1.967 & 1.993 & 1.98 & -2.56815116 \\
\hline $\mathrm{Ag}$ & 2.288 & 2.347 & 2.3175 & -2.082625102 \\
\hline $\mathrm{Pd}$ & 2.098 & 2.45 & 2.274 & -2.54276557 \\
\hline $\mathrm{Ni}$ & 1.827 & 1.975 & 1.901 & -3.838469141 \\
\hline $\mathrm{Rh}$ & 2.031 & 2.191 & 2.111 & -3.77759117 \\
\hline $\mathrm{Ir}$ & 1.972 & 2.215 & 2.0935 & -4.725384325 \\
\hline
\end{tabular}

$\mathrm{MgO}$ (110), supported metal on top of oxygen site

\begin{tabular}{|c|c|c|}
\hline Metal & M-O distance & $\begin{array}{c}\text { Adsorption } \\
\text { energy/eV }\end{array}$ \\
\hline $\mathrm{Pt}$ & 1.948 & -4.481155234 \\
\hline
\end{tabular}

$\mathrm{MgAl}_{2} \mathrm{O}_{4}$ (100), supported metal on Mg bridge site

\begin{tabular}{|c|c|c|c|c|}
\hline Metal & $\begin{array}{c}\mathrm{M}-\mathrm{Mg}_{1} \\
\text { distance }\end{array}$ & $\mathrm{M}-\mathrm{Mg}_{2}$ distance & $\begin{array}{c}\text { Average M-Mg } \\
\text { distance }\end{array}$ & $\begin{array}{c}\text { Adsorption } \\
\text { energy/eV }\end{array}$ \\
\hline $\mathrm{Au}$ & 2.773 & 2.851 & 2.812 & -2.379317883 \\
\hline $\mathrm{Cu}$ & 2.771 & 2.856 & 2.8135 & -1.814059648 \\
\hline $\mathrm{Ag}$ & 3.265 & 2.851 & 3.058 & -1.206393017 \\
\hline
\end{tabular}

$\mathrm{MgAl}_{2} \mathrm{O}_{4}$ (100), supported metal in hollow site

\begin{tabular}{|c|c|c|}
\hline Metal & $\begin{array}{c}\text { M-O } \\
\text { distance }\end{array}$ & Adsorption energy/eV \\
\hline $\mathrm{Pt}$ & 1.996 & -3.88688492 \\
\hline $\mathrm{Pd}$ & 2.085 & -1.806300157 \\
\hline $\mathrm{Ni}$ & 1.778 & -2.948917747 \\
\hline
\end{tabular}


Table S4 The information of most preferred sites of supported metals on different surface facets (Unit for distances is $\AA$ ) (continued).

$\mathrm{MgAl}_{2} \mathrm{O}_{4}$ (100), supported metal in the hollow site between two oxygens

\begin{tabular}{|c|c|c|c|c|}
\hline Metal & $\begin{array}{c}\mathrm{M}-\mathrm{O}_{1} \\
\text { distance }\end{array}$ & $\mathrm{M}-\mathrm{O}_{2}$ distance & $\begin{array}{c}\text { Average } \mathrm{M}-\mathrm{O} \\
\text { distance }\end{array}$ & $\begin{array}{c}\text { Adsorption } \\
\text { energy/eV }\end{array}$ \\
\hline $\mathrm{Rh}$ & 2.066 & 2.025 & 2.0455 & -2.755037312 \\
\hline $\mathrm{Ir}$ & 1.939 & 2.028 & 1.9835 & -3.612465149 \\
\hline
\end{tabular}

$\mathrm{MgAl}_{2} \mathrm{O}_{4}$ (110), supported metal in the hollow site between two oxygens

\begin{tabular}{|c|c|c|c|c|}
\hline Metal & $\begin{array}{l}\mathrm{M}-\mathrm{O}_{1} \\
\text { distance }\end{array}$ & $\mathrm{M}-\mathrm{O}_{2}$ distance & $\begin{array}{c}\text { Average M-O } \\
\text { distance }\end{array}$ & $\begin{array}{l}\text { Adsorption } \\
\text { energy/eV }\end{array}$ \\
\hline $\mathrm{Au}$ & 2.05 & 2.047 & 2.0485 & -3.238426545 \\
\hline $\mathrm{Cu}$ & 1.806 & 1.832 & 1.819 & -4.781967961 \\
\hline $\mathrm{Ag}$ & 2.192 & 2.181 & 2.1865 & -3.250601477 \\
\hline $\mathrm{Pt}$ & 1.907 & 1.928 & 1.9175 & -5.769915921 \\
\hline $\mathrm{Pd}$ & 2.065 & 1.815 & 1.94 & -3.735368639 \\
\hline $\mathrm{Ni}$ & 1.766 & 1.759 & 1.7625 & -6.183494928 \\
\hline $\mathrm{Rh}$ & 1.905 & 1.921 & 1.913 & -5.496512462 \\
\hline $\mathrm{Ir}$ & 1.812 & 1.81 & 1.811 & -7.34314605 \\
\hline
\end{tabular}


Table S5 The standard of counting supported metal coordination numbers.

If the distance between adsorbed metal and atom in the surface is smaller than their coordination distance $\left(\mathrm{d}_{\mathrm{CN}}\right)$, then we consider they coordinate with each other.

For metal-metal binding, $\mathrm{d}_{\mathrm{CN}}$ is the sum of their Van del Waal radius.

For metal-oxygen binding, $\mathrm{d}_{\mathrm{CN}}$ is the sum of metal Van der Waal radius and oxygen ionic radius $(1.26 \AA)^{80}$.

The transition metal Van del Waal radius are listed in Supplementary Table 3a.

Van del Waal radius for $\mathrm{Mg}^{75}$ and $\mathrm{Al}^{76}$ are $1.73 \AA$ and $1.84 \AA$.

\begin{tabular}{|c|c|}
\hline Bond & $\mathrm{d}_{\mathrm{CN}} / \AA$ \\
\hline $\mathrm{Au}-\mathrm{Mg}$ & 3.39 \\
\hline $\mathrm{Au}-\mathrm{Al}$ & 3.5 \\
\hline $\mathrm{Au}-\mathrm{O}$ & 2.92 \\
\hline $\mathrm{Cu}-\mathrm{Mg}$ & 3.13 \\
\hline $\mathrm{Cu}-\mathrm{Al}$ & 3.24 \\
\hline $\mathrm{Cu}-\mathrm{O}$ & 2.66 \\
\hline Ag-Mg & 3.45 \\
\hline $\mathrm{Ag}-\mathrm{Al}$ & 3.56 \\
\hline $\mathrm{Ag}-\mathrm{O}$ & 2.98 \\
\hline Pt-Mg & 3.82 \\
\hline Pt-Al & 3.93 \\
\hline Pt-O & 3.35 \\
\hline $\mathrm{Pd}-\mathrm{Mg}$ & 3.75 \\
\hline Pd-Al & 3.86 \\
\hline Pd-O & 3.28 \\
\hline $\mathrm{Ni}-\mathrm{Mg}$ & 3.36 \\
\hline $\mathrm{Ni}-\mathrm{Al}$ & 3.47 \\
\hline $\mathrm{Ni}-\mathrm{O}$ & 2.89 \\
\hline Rh-Mg & 3.68 \\
\hline Rh-Al & 3.79 \\
\hline Rh-O & 3.21 \\
\hline
\end{tabular}


Table S5 The standard of counting supported metal coordination numbers (continued).

\begin{tabular}{|c|c|}
\hline Bond & $\mathrm{d}_{\mathrm{CN}} / \AA$ \\
\hline Ir-Mg & 3.75 \\
\hline Ir-Al & 3.86 \\
\hline Ir-O & 3.28 \\
\hline
\end{tabular}


Table S6 Bootstrapping results for model construction.

Bootstrap sampling uses 10,000 replicates.

Group 1

\begin{tabular}{|c|c|c|}
\hline Complexity & Equation & RMSE (eV) \\
\hline 5 & $F(x)=a * S B G+b$ & 1.381664 \\
\hline 9 & $F(x)=a * S B G+b * M O B+c$ & 1.0391853 \\
\hline 9 & $F(x)=a * S B G+b * M O E+c$ & 1.0854364 \\
\hline 13 & $F(x)=a * S E+b * S B G+c * M O B+d$ & 0.9766593 \\
\hline 13 & $F(x)=a * S F E+b * S I P+c * M O B+d$ & 0.9809163 \\
\hline 17 & $F(x)=a * S E+b * S B G+c * M O B+d * M g+e$ & 0.8355649 \\
\hline 13 & $F(x)=a * S E+b * S B G+c * M O B+d$ & 0.9766593 \\
\hline 17 & $F(x)=a * S E+b * S B G+c * M O B+d * M g+e$ & 0.7798851 \\
\hline 17 & $\begin{array}{c}F(x)=a * S F E+b * S I P+c * M O B+d * S B G \\
+e\end{array}$ & 0.8818448 \\
\hline 21 & $\begin{array}{c}F(x)=a * S E+b * S B G+c * M O B+d * M E A \\
+e * M g+f\end{array}$ & 1.01063069 \\
\hline 27 & $\begin{array}{c}F(x)=a * S E+b * S B G+c * M O B+d * M g * t \\
+e * t+f * M g+g\end{array}$ & 1.04314050 \\
\hline 27 & $\begin{array}{c}F(x)=a * S E+b * S B G+c * M O B+d * S E * t \\
+e * t+f * M g+g\end{array}$ & 1.06581488 \\
\hline
\end{tabular}


Table S6 Bootstrapping results for model construction (continued).

Group 2

\begin{tabular}{|c|c|c|}
\hline Complexity & Equation & RMSE (eV) \\
\hline 10 & $F(x)=\frac{1}{a * S E+b}+c$ & 1.7912391 \\
\hline 10 & $F(x)=\frac{1}{a * S I P+b}+c$ & 1.885260 \\
\hline 14 & $F(x)=a * M O B+\frac{1}{b * S B G+c}+d$ & 1.23097388 \\
\hline 14 & $F(x)=a * M O B+\frac{1}{b * S E+c}+d$ & 1.5425028 \\
\hline 14 & $F(x)=a * M O B+\frac{1}{b * S I P+c}+d$ & 0.9593233 \\
\hline 18 & $F(x)=a * S B G+b * M O B+\frac{1}{c * S E+d}+e$ & 1.0388658 \\
\hline 18 & $F(x)=a * S B G+b * M O B+\frac{1}{c * S I P+d}+e$ & 1.0274604 \\
\hline 14 & $F(x)=a * M O B+\frac{b}{c * S E+d}+e$ & 1.5425106 \\
\hline 14 & $F(x)=a * M O B+\frac{b}{c * S I P+d}+e$ & 0.94622471 \\
\hline 14 & $F(x)=a * M O B+\frac{b}{c * S B G+d}+e$ & 0.8049614 \\
\hline 18 & $F(x)=a * M O B+\frac{b * M g+c}{d * S I P+e}+f$ & 0.9383880 \\
\hline 18 & $F(x)=a * S B G+b * M O B+\frac{c}{d * S E+e}+f$ & 1.03918289 \\
\hline 18 & $F(x)=a * S B G+b * M O B+\frac{c}{d * S I P+e}+f$ & 0.76418773 \\
\hline 22 & $\begin{array}{c}F(x)=a * S F E+b * S I P+c * M O B \\
+\frac{1}{d * S E+e}+f\end{array}$ & 1.0150411 \\
\hline 22 & $\begin{array}{c}F(x)=a * S F E+b * S I P+c * M O B \\
+\frac{1}{d * S I P+e}+f\end{array}$ & 1.0169585 \\
\hline
\end{tabular}


Table S6 Bootstrapping results for model construction (continued).

Group 2

\begin{tabular}{|c|c|c|}
\hline Complexity & Equation & RMSE (eV) \\
\hline 22 & $\begin{array}{c}F(x)=a * S F E+b * S I P+c * M O B+\frac{d}{e * S E+f} \\
+g\end{array}$ & 0.9600233 \\
\hline 22 & $\begin{array}{c}F(x)=a * S F E+b * S I P+c * M O B \\
+\frac{d}{e * S F E+f}+g\end{array}$ & 0.980916726 \\
\hline 26 & $\begin{aligned} F(x)=a * S E & +b * S B G+c * M O B \\
& +\frac{1}{d * S B G+e}+f * M g+g\end{aligned}$ & 1.06159545 \\
\hline 26 & $\begin{aligned} F(x)=a * S E & +b * S B G+c * M O B \\
& +\frac{1}{d * S F E+e}+f * M g+g\end{aligned}$ & 1.02405304 \\
\hline 27 & $\begin{array}{c}F(x)=a * S B G+b * M O B+\frac{1}{c * S B G+d} \\
+\frac{e}{f * S I P+g}+h\end{array}$ & 1.0414007 \\
\hline 32 & $\begin{aligned} F(x)=a * S B G & +b * M O B+c * S E * t \\
& +\frac{1}{d * S E+e}+f * t+g * S E+h\end{aligned}$ & 0.9542535 \\
\hline
\end{tabular}


Table S6 Bootstrapping results for model construction (continued).

Group 3

\begin{tabular}{|c|c|c|}
\hline Complexity & Equation & RMSE (eV) \\
\hline 24 & $F(x)=a * M O B+\frac{1}{b * S I P+c}+\frac{d}{\exp (e * S B G)}+f$ & 0.9167515 \\
\hline 24 & $\begin{array}{c}F(x)=a * S B G+b * M O B+\frac{1}{c * S E+d}+e * S B G^{2} \\
+f\end{array}$ & 0.7786195 \\
\hline 22 & $F(x)=a * M O B+b * S B G+\frac{c * M g+d}{e * S I P+f}+g$ & 0.78136774 \\
\hline 22 & $F(x)=a * S B G+b * M O B+\frac{c * M I P+d}{e * S E+f}+g$ & 1.0372081 \\
\hline 22 & $F(x)=a * S B G+b * M O B+\frac{c * M I P+d}{e * S I P+f}+g$ & 1.0350657 \\
\hline 26 & $\begin{array}{c}F(x)=a * S E+b * S B G+c * M O B+\frac{1}{d * S B G+e} \\
+f * M g+g\end{array}$ & 1.03419145 \\
\hline 26 & $\begin{array}{c}F(x)=a * S F E+b * S I P+c * M O B+\frac{1}{d * S I P+e} \\
+f * S E+g\end{array}$ & 1.3885672 \\
\hline 28 & $\begin{array}{c}F(x)=a * M O B+b * S B G * S E+\frac{1}{c * S I P+d}+e \\
* S B G+f * S E+g\end{array}$ & 0.7930596 \\
\hline 23 & $\begin{array}{c}F(x)=a * M O B+\frac{1}{b * S I P+e}+f * \exp (g * S B G) \\
+h\end{array}$ & 0.9196913 \\
\hline 27 & $\begin{array}{c}F(x)=a * S B G+b * M O B+\frac{c}{d * S B G+e} \\
+\frac{f}{g * S I P+h}+i\end{array}$ & 1.05017888 \\
\hline
\end{tabular}


Table S6 Bootstrapping results for model construction (continued).

Group 4

\begin{tabular}{|c|c|c|}
\hline Complexity & Equation & RMSE (eV) \\
\hline 18 & $F(x)=a * M O B+\frac{b * S I P+c}{d * S B G+e}+f$ & 0.8471124 \\
\hline 18 & $F(x)=a * M O B+\frac{b * S F E+c}{d * S B G+e}+f$ & 0.7669234 \\
\hline 22 & $F(x)=a * M O B+b * S B G+\frac{c * M I P+d}{e * S E+f}+g$ & 0.79288477 \\
\hline 22 & $F(x)=a * M O B+b * S B G+\frac{c * M g+d}{e * S I P+f}+g$ & 0.851006276 \\
& $F(x)=a * S B G+b * M O B+\frac{c * M I P+d}{e * S I P+f}+g$ & \\
\hline 22 & $F$ & \\
\hline
\end{tabular}

Group 5

\begin{tabular}{|c|c|c|}
\hline Complexity & Equation & RMSE (eV) \\
\hline 14 & $F(x)=\frac{a * M O E+b}{c * S B G+d}+e$ & 0.8796041 \\
\hline 23 & $F(x)=\frac{1}{a * S I P+b}+\frac{c * M O B+d}{e * S B G+f}+g$ & 0.8580128 \\
\hline 23 & $F(x)=a * M O B+\frac{b}{c * S I P+d}+\frac{e}{f * S B G+g}+h$ & 0.754600390 \\
\hline
\end{tabular}

Group 6

\begin{tabular}{|c|c|c|}
\hline Complexity & Equation & RMSE (eV) \\
\hline 14 & $F(x)=\frac{a * M O B+b}{c * S B G+d}+e$ & 0.83760501 \\
\hline 16 & $F(x)=\frac{a * S B G+b * M O B+c}{d * S B G+e}+f$ & 0.8376051 \\
\hline 26 & $\begin{array}{c}F(x)=a * S E * A l+\frac{b * M O B+c}{d * S B G+e}+f * A l+g * S E \\
+h\end{array}$ & \\
\hline
\end{tabular}


Table S6 Bootstrapping results for model construction (continued).

Group 7

\begin{tabular}{|r|c|r|}
\hline Complexity & Equation & RMSE (eV) \\
\hline 17 & $F(x)=a * M O B+b * \log (c * S B G+d)+e$ & 0.81590424 \\
\hline 21 & $\begin{array}{c}F(x)=a * M O B+b * \log (c * S B G+d)+e * M g \\
+f\end{array}$ & 0.7304002 \\
\hline 26 & $\begin{array}{c}F(x)=a * M O B+\frac{1}{b * S I P+c}+d \\
* \log (e * S B G+f)+g\end{array}$ & 0.85372357 \\
& $\quad$ & \\
\hline
\end{tabular}

Group 8

\begin{tabular}{|c|c|c|}
\hline Complexity & Equation & RMSE $(\mathrm{eV})$ \\
\hline 28 & $\begin{aligned} F(x)=a * S B G & +b * M O B \\
& +\frac{c}{d * S E * M g+e * M g+f * S E+g} \\
& +h\end{aligned}$ & 0.9770267 \\
\hline 32 & $\begin{aligned} F(x)=a * S B G & +b * M O B \\
& +\frac{1}{c * S E * M g+d * M g+e * S E+f} \\
& +g * E R+h\end{aligned}$ & 1.0367179 \\
\hline 32 & $\begin{aligned} F(x)=a * S B G & +b * M O B+c * S I P \\
& +\frac{1}{d * S E * M g+e * M g+f * S E+g} \\
& +h\end{aligned}$ & 1.0360931 \\
\hline
\end{tabular}


Table S6 Bootstrapping results for model construction (continued).

Group 9

\begin{tabular}{|c|c|c|}
\hline Complexity & Equation & RMSE (eV) \\
\hline 22 & $F(x)=a * M O B+\frac{b * M O B+* S I P+d}{e * S B G+f}+g$ & 0.6904047 \\
\hline 35 & $\begin{array}{l}F(x)=\frac{1}{a * S I P}+b \\
\quad+\frac{b * M O B+c * S E * A l+d * S E+e * A l}{f * S B G+g} \\
\quad+h\end{array}$ & 0.81492294 \\
\hline 28 & $\begin{array}{l}F(x)=a * M O B \\
\qquad \begin{array}{l}+\frac{b * M O B+c * M O B * S I P+d * S I P+e}{f * S B G+g} \\
\quad+h\end{array}\end{array}$ & 0.72221069 \\
\hline
\end{tabular}

Group 10

\begin{tabular}{|c|c|c|}
\hline Complexity & Equation & RMSE (eV) \\
\hline 26 & $F(x)=a * M O B+b * S B G$ & 0.989581711 \\
& $+\frac{c * M g+d * M I P+e}{f * S I P+g}+h$ & \\
\hline 31 & $F(x)=a * M O B+\frac{1}{b * M g+c}+\frac{d * M g+e}{f * S I P+g}+h$ & 0.788503679 \\
& $* S E+i$ & \\
\hline 36 & $F(x)=a * S B G+b * M O B+c * S E * A l$ \\
& $+\frac{d * M g+e}{f * S I P+g}+h * A l+i * S E+j$ & \\
& 2 \\
\hline
\end{tabular}




\section{Bibliography}

1. Wang, A.; Li, J.; Zhang, T., Heterogeneous Single-Atom Catalysis. Nature Reviews Chemistry 2018, 2, 65-81.

2. Liu, J.; Bunes, B. R.; Zang, L.; Wang, C., Supported Single-Atom Catalysts: Synthesis, Characterization, Properties, and Applications. Environmental Chemistry Letters 2018, 16, 477-505.

3. Liu, J., Catalysis by Supported Single Metal Atoms. ACS Catalysis 2017, 7, 34-59.

4. Yang, X.-F.; Wang, A.; Qiao, B.; Li, J.; Liu, J.; Zhang, T., Single-Atom Catalysts: A New Frontier in Heterogeneous Catalysis. Accounts of Chemical Research 2013, 46, 1740-1748.

5. Flytzani-Stephanopoulos, M., Gold Atoms Stabilized on Various Supports Catalyze the Water-Gas Shift Reaction. Accounts of Chemical Research 2014, 47, 783-792.

6. DeRita, L.; Dai, S.; Lopez-Zepeda, K.; Pham, N.; Graham, G. W.; Pan, X.; Christopher, P., Catalyst Architecture for Stable Single Atom Dispersion Enables Site-Specific Spectroscopic and Reactivity Measurements of Co Adsorbed to Pt Atoms, Oxidized Pt Clusters, and Metallic Pt Clusters on Tio2. Journal of the American Chemical Society 2017, $139,14150-14165$.

7. Yan, H.; Cheng, H.; Yi, H.; Lin, Y.; Yao, T.; Wang, C.; Li, J.; Wei, S.; Lu, J., Single-Atom Pd1/Graphene Catalyst Achieved by Atomic Layer Deposition: Remarkable Performance in Selective Hydrogenation of 1,3-Butadiene. Journal of the American Chemical Society 2015, 137, 10484-10487.

8. Jones, J., et al., Thermally Stable Single-Atom Platinum-on-Ceria Catalysts Via Atom Trapping. Science 2016, 353, 150.

9. Zhu, C.; Fu, S.; Shi, Q.; Du, D.; Lin, Y., Single-Atom Electrocatalysts. Angewandte Chemie International Edition 2017, 56, 13944-13960.

10. Campbell, C. T., The Energetics of Supported Metal Nanoparticles: Relationships to Sintering Rates and Catalytic Activity. Accounts of Chemical Research 2013, 46, 17121719.

11. Zhang, B.; Asakura, H.; Zhang, J.; Zhang, J.; De, S.; Yan, N., Stabilizing a Platinum1 Single-Atom Catalyst on Supported Phosphomolybdic Acid without Compromising Hydrogenation Activity. Angewandte Chemie International Edition 2016, 55, 8319-8323. 
12. Campbell, C. T.; Mao, Z., Chemical Potential of Metal Atoms in Supported Nanoparticles: Dependence Upon Particle Size and Support. ACS Catalysis 2017, 7, 8460-8466.

13. Taylor, M. G.; Austin, N.; Gounaris, C. E.; Mpourmpakis, G., Catalyst Design Based on Morphology- and Environment-Dependent Adsorption on Metal Nanoparticles. ACS Catalysis 2015, 5, 6296-6301.

14. Lin, J.; Wang, A.; Qiao, B.; Liu, X.; Yang, X.; Wang, X.; Liang, J.; Li, J.; Liu, J.; Zhang, T., Remarkable Performance of Ir1/Feox Single-Atom Catalyst in Water Gas Shift Reaction. Journal of the American Chemical Society 2013, 135, 15314-15317.

15. Campbell, C. T., Electronic Perturbations. Nature Chemistry 2012, 4, 597.

16. Qiao, B.; Liang, J.-X.; Wang, A.; Xu, C.-Q.; Li, J.; Zhang, T.; Liu, J. J., Ultrastable SingleAtom Gold Catalysts with Strong Covalent Metal-Support Interaction (Cmsi). Nano Research 2015, 8, 2913-2924.

17. Zhang, Z., et al., Thermally Stable Single Atom Pt/M-A12o3 for Selective Hydrogenation and Co Oxidation. Nature Communications 2017, 8, 16100.

18. Liu, J., Advanced Electron Microscopy of Metal-Support Interactions in Supported Metal Catalysts. ChemCatChem 2011, 3, 934-948.

19. O’Connor, N. J.; Jonayat, A. S. M.; Janik, M. J.; Senftle, T. P., Interaction Trends between Single Metal Atoms and Oxide Supports Identified with Density Functional Theory and Statistical Learning. Nature Catalysis 2018, 1, 531-539.

20. Campbell, C. T.; Sellers, J. R. V., Anchored Metal Nanoparticles: Effects of Support and Size on Their Energy, Sintering Resistance and Reactivity. Faraday Discussions 2013, 162, 9-30.

21. Nørskov, J. K.; Bligaard, T.; Rossmeisl, J.; Christensen, C. H., Towards the Computational Design of Solid Catalysts. Nature Chemistry 2009, 1, 37.

22. Noronha, F. B.; Fendley, E. C.; Soares, R. R.; Alvarez, W. E.; Resasco, D. E., Correlation between Catalytic Activity and Support Reducibility in the Co2 Reforming of Methane over Pt/Cexzr1-Xo2 Catalysts. Chemical Engineering Journal 2001, 82, 21-31.

23. Cui, X.; Li, W.; Ryabchuk, P.; Junge, K.; Beller, M., Bridging Homogeneous and Heterogeneous Catalysis by Heterogeneous Single-Metal-Site Catalysts. Nature Catalysis 2018, 1, 385-397.

24. Zhang, H.; Liu, G.; Shi, L.; Ye, J., Single-Atom Catalysts: Emerging Multifunctional Materials in Heterogeneous Catalysis. Advanced Energy Materials 2017, 8, 1701343. 
25. Ghosh, T. K.; Nair, N. N., Rh1/Г-Al2o3 Single-Atom Catalysis of O2 Activation and Co Oxidation: Mechanism, Effects of Hydration, Oxidation State, and Cluster Size. ChemCatChem 2013, 5, 1811-1821.

26. Hu, P.; Huang, Z.; Amghouz, Z.; Makkee, M.; Xu, F.; Kapteijn, F.; Dikhtiarenko, A.; Chen, Y.; Gu, X.; Tang, X., Electronic Metal-Support Interactions in Single-Atom Catalysts. Angewandte Chemie International Edition 2014, 53, 3418-3421.

27. Yang, M.; Allard, L. F.; Flytzani-Stephanopoulos, M., Atomically Dispersed Au-(Oh)X Species Bound on Titania Catalyze the Low-Temperature Water-Gas Shift Reaction. Journal of the American Chemical Society 2013, 135, 3768-3771.

28. Qiao, B.; Wang, A.; Yang, X.; Allard, L. F.; Jiang, Z.; Cui, Y.; Liu, J.; Li, J.; Zhang, T., Single-Atom Catalysis of Co Oxidation Using Pt1/Feox. Nature Chemistry 2011, 3, 634.

29. Wang, L., et al., Atomic-Level Insights in Optimizing Reaction Paths for Hydroformylation Reaction over Rh/Coo Single-Atom Catalyst. Nature Communications 2016, 7, 14036.

30. Cui, X.; Junge, K.; Dai, X.; Kreyenschulte, C.; Pohl, M.-M.; Wohlrab, S.; Shi, F.; Brückner, A.; Beller, M., Synthesis of Single Atom Based Heterogeneous Platinum Catalysts: High Selectivity and Activity for Hydrosilylation Reactions. ACS Central Science 2017, 3, 580-585.

31. Wang, J.; Zhao, X.; Lei, N.; Li, L.; Zhang, L.; Xu, S.; Miao, S.; Pan, X.; Wang, A.; Zhang, T., Hydrogenolysis of Glycerol to 1,3-Propanediol under Low Hydrogen Pressure over Wox-Supported Single/Pseudo-Single Atom Pt Catalyst. ChemSusChem 2016, 9, 784-790.

32. Guo, X., et al., Direct, Nonoxidative Conversion of Methane to Ethylene, Aromatics, and Hydrogen. Science 2014, 344, 616.

33. Duarte, R. B.; Krumeich, F.; van Bokhoven, J. A., Structure, Activity, and Stability of Atomically Dispersed $\mathrm{Rh}$ in Methane Steam Reforming. ACS Catalysis 2014, 4, 12791286.

34. Moses-DeBusk, M.; Yoon, M.; Allard, L. F.; Mullins, D. R.; Wu, Z.; Yang, X.; Veith, G.; Stocks, G. M.; Narula, C. K., Co Oxidation on Supported Single Pt Atoms: Experimental and Ab Initio Density Functional Studies of Co Interaction with Pt Atom on $\Theta-A 1203(010)$ Surface. Journal of the American Chemical Society 2013, 135, 12634-12645.

35. Gu, X.-K.; Qiao, B.; Huang, C.-Q.; Ding, W.-C.; Sun, K.; Zhan, E.; Zhang, T.; Liu, J.; Li, W.-X., Supported Single Pt1/Au1 Atoms for Methanol Steam Reforming. ACS Catalysis 2014, 4, 3886-3890. 
36. Abbet, S.; Sanchez, A.; Heiz, U.; Schneider, W. D.; Ferrari, A. M.; Pacchioni, G.; Rösch, N., Acetylene Cyclotrimerization on Supported Size-Selected Pdn Clusters $(1 \leq \mathrm{N} \leq 30)$ : One Atom Is Enough! Journal of the American Chemical Society 2000, 122, 3453-3457.

37. Sun, S., et al., Single-Atom Catalysis Using Pt/Graphene Achieved through Atomic Layer Deposition. Scientific Reports 2013, 3, 1775.

38. Lang, R., et al., Hydroformylation of Olefins by a Rhodium Single-Atom Catalyst with Activity Comparable to Rhcl(Pph3)3. Angewandte Chemie International Edition 2016, 55, 16054-16058.

39. Schrödinger, E., An Undulatory Theory of the Mechanics of Atoms and Molecules. Physical Review 1926, 28, 1049-1070.

40. Kohn, W., Nobel Lecture: Electronic Structure of Matter---Wave Functions and Density Functionals. Reviews of Modern Physics 1999, 71, 1253-1266.

41. Jones, R. O., Density Functional Theory: Its Origins, Rise to Prominence, and Future. Reviews of Modern Physics 2015, 87, 897-923.

42. Hohenberg, P.; Kohn, W., Inhomogeneous Electron Gas. Physical Review 1964, 136, B864-B871.

43. Kohn, W.; Sham, L. J., Self-Consistent Equations Including Exchange and Correlation Effects. Physical Review 1965, 140, A1133-A1138.

44. Perdew, J. P.; Chevary, J. A.; Vosko, S. H.; Jackson, K. A.; Pederson, M. R.; Singh, D. J.; Fiolhais, C., Atoms, Molecules, Solids, and Surfaces: Applications of the Generalized Gradient Approximation for Exchange and Correlation. Physical Review B 1992, 46, 66716687.

45. Ernzerhof, M.; Scuseria, G. E., Assessment of the Perdew-Burke-Ernzerhof ExchangeCorrelation Functional. The Journal of Chemical Physics 1999, 110, 5029-5036.

46. Hutter, J.; Iannuzzi, M.; Schiffmann, F.; VandeVondele, J., Cp2k: Atomistic Simulations of Condensed Matter Systems. Wiley Interdisciplinary Reviews: Computational Molecular Science 2014, 4, 15-25.

47. Perdew, J. P.; Burke, K.; Ernzerhof, M., Generalized Gradient Approximation Made Simple. Physical Review Letters 1996, 77, 3865-3868.

48. Grimme, S.; Antony, J.; Ehrlich, S.; Krieg, H., A Consistent and Accurate Ab Initio Parametrization of Density Functional Dispersion Correction (Dft-D) for the 94 Elements H-Pu. The Journal of Chemical Physics 2010, 132, 154104. 
49. Bengtsson, L., Dipole Correction for Surface Supercell Calculations. Physical Review B 1999, 59, 12301-12304.

50. VandeVondele, J.; Hutter, J., Gaussian Basis Sets for Accurate Calculations on Molecular Systems in Gas and Condensed Phases. The Journal of Chemical Physics 2007, 127, 114105.

51. Goedecker, S.; Teter, M.; Hutter, J., Separable Dual-Space Gaussian Pseudopotentials. Physical Review B 1996, 54, 1703-1710.

52. Hartwigsen, C.; Goedecker, S.; Hutter, J., Relativistic Separable Dual-Space Gaussian Pseudopotentials from H to Rn. Physical Review B 1998, 58, 3641-3662.

53. Krack, M., Pseudopotentials for $\mathrm{H}$ to Kr Optimized for Gradient-Corrected ExchangeCorrelation Functionals. Theoretical Chemistry Accounts 2005, 114, 145-152.

54. Greenwood, N. N.; Earnshaw, A., Chemistry of the Elements, 2nd ed.; ButterworthHeinemann: Oxford ; Boston, 1997, p xxii, 1341 p.

55. Lu, Q.; Ren, J.; Wang, Z., Using Genetic Programming with Prior Formula Knowledge to Solve Symbolic Regression Problem. Computational intelligence and neuroscience 2016, 2016, 1021378-1021378.

56. O'Reilly, U.-M., Genetic Programming Theory and Practice Ii; Springer: New York, 2005, p xiv, 320 p.

57. Koza, J. R.; Keane, M. A.; Streeter, M. J., What's Ai Done for Me Lately? Genetic Programming's Human-Competitive Results. IEEE Intelligent Systems 2003, 18, 25-31.

58. Schmidt, M.; Lipson, H., Distilling Free-Form Natural Laws from Experimental Data. Science 2009, 324, 81.

59. Tománek, D.; Mukherjee, S.; Bennemann, K. H., Simple Theory for the Electronic and Atomic Structure of Small Clusters. Physical Review B 1983, 28, 665-673.

60. Yan, Z.; Taylor, M. G.; Mascareno, A.; Mpourmpakis, G., Size-, Shape-, and CompositionDependent Model for Metal Nanoparticle Stability Prediction. Nano Letters 2018, 18, 2696-2704.

61. Heiz, U.; Sanchez, A.; Abbet, S.; Schneider, W. D., Catalytic Oxidation of Carbon Monoxide on Monodispersed Platinum Clusters: Each Atom Counts. Journal of the American Chemical Society 1999, 121, 3214-3217.

62. Heiz, U.; Sanchez, A.; Abbet, S.; Schneider, W. D., Tuning the Oxidation of Carbon Monoxide Using Nanoassembled Model Catalysts. Chemical Physics 2000, 262, 189-200. 
63. Hoffman, A. S.; Debefve, L. M.; Zhang, S.; Perez-Aguilar, J. E.; Conley, E. T.; Justl, K. R.; Arslan, I.; Dixon, D. A.; Gates, B. C., Beating Heterogeneity of Single-Site Catalysts: Mgo-Supported Iridium Complexes. ACS Catalysis 2018, 8, 3489-3498.

64. Stair, P. C., The Concept of Lewis Acids and Bases Applied to Surfaces. Journal of the American Chemical Society 1982, 104, 4044-4052.

65. Kostetskyy, P.; Nolan, C. M.; Dixit, M.; Mpourmpakis, G., Understanding Alkane Dehydrogenation through Alcohol Dehydration on $\Gamma$-A12o3. Industrial \& Engineering Chemistry Research 2018, 57, 16657-16663.

66. Díez, V. K.; Apesteguía, C. R.; Di Cosimo, J. I., Acid-Base Properties and Active Site Requirements for Elimination Reactions on Alkali-Promoted Mgo Catalysts. Catalysis Today 2000, 63, 53-62.

67. Evans, O. R.; Bell, A. T.; Tilley, T. D., Oxidative Dehydrogenation of Propane over Vanadia-Based Catalysts Supported on High-Surface-Area Mesoporous Mgal2o4. Journal of Catalysis 2004, 226, 292-300.

68. Lou, Y.; Liu, J., Co Oxidation on Metal Oxide Supported Single Pt Atoms: The Role of the Support. Industrial \& Engineering Chemistry Research 2017, 56, 6916-6925.

69. Van't Blik, H. F. J.; Van Zon, J. B. A. D.; Huizinga, T.; Vis, J. C.; Koningsberger, D. C.; Prins, R., Structure of Rhodium in an Ultradispersed Rhodium/Alumina Catalyst as Studied by Exafs and Other Techniques. Journal of the American Chemical Society 1985, 107, 3139-3147.

70. Sanchez, A.; Abbet, S.; Heiz, U.; Schneider, W. D.; Häkkinen, H.; Barnett, R. N.; Landman, U., When Gold Is Not Noble: Nanoscale Gold Catalysts. The Journal of Physical Chemistry A 1999, 103, 9573-9578.

71. Lu, Y., et al., Identification of the Active Complex for Co Oxidation over Single-Atom Iron-Mgal2o4 Catalysts. Nature Catalysis 2019, 2, 149-156.

72. Pacchioni, G., Electronic Interactions and Charge Transfers of Metal Atoms and Clusters on Oxide Surfaces. Physical Chemistry Chemical Physics 2013, 15, 1737-1757.

73. Kittel, C., Introduction to Solid State Physics, 8th ed.; Wiley: Hoboken, NJ, 2005, p xix, $680 \mathrm{p}$.

74. Haynes, W. M., Crc Handbook of Chemistry and Physics, 92nd Edition; CRC Press: Hoboken, 2011.

75. Hu, S.-Z.; Zhou, Z.-H.; Robertson, B. E., Consistent Approaches to Van Der Waals Radii for the Metallic Elements. In Zeitschrift für Kristallographie International journal for structural, physical, and chemical aspects of crystalline materials, 2009; Vol. 224, p 375. 
76. Mantina, M.; Chamberlin, A. C.; Valero, R.; Cramer, C. J.; Truhlar, D. G., Consistent Van Der Waals Radii for the Whole Main Group. The Journal of Physical Chemistry A 2009, 113, 5806-5812.

77. Pyykkö, P.; Riedel, S.; Patzschke, M., Triple-Bond Covalent Radii. Chemistry - A European Journal 2005, 11, 3511-3520.

78. Zhang, Y.; Evans, J. R. G.; Yang, S., Corrected Values for Boiling Points and Enthalpies of Vaporization of Elements in Handbooks. Journal of Chemical \& Engineering Data 2011, 56, 328-337.

79. Nelder, J. A.; Mead, R., A Simplex Method for Function Minimization. The Computer Journal 1965, 7, 308-313.

80. Shannon, R., Revised Effective Ionic Radii and Systematic Studies of Interatomic Distances in Halides and Chalcogenides. Acta Crystallographica Section A 1976, 32, 751767. 